\title{
Albumin-oxanorbornadiene conjugates formed ex vivo for the extended circulation of hydrophilic cargo
}

Cody J. Higginson, Marsha R. Eno, Susan Khan, Michael D. Cameron, M.G. Finn*

\section{Table of Contents}

\section{Supporting Information}

I. General

II. Synthetic procedures and characterization

III. Reactions with albumins and small molecules

IV. Degradation of model adducts

V. Stability of OND derivatives in rat plasma

VI. Pharmacokinetics of Gd-OND derivatives in rats

VII. Analysis of labeled albumin by mass spectrometry

VIII. Graphical ${ }^{1} \mathrm{H}$ and ${ }^{13} \mathrm{C}$ NMR Spectra for Compounds 


\section{General}

\section{Materials and Methods}

Reagents and solvents were purchased from commercial sources and used as received, unless otherwise stated. When dry solvents were required, solvents were passed through activated alumina columns on an MBraun solvent purification system (MB-SPS), and collected in oven-dried glassware prior to use. Water was purified on a Millipore Milli-Q Advantage A10 system. Dimethyl acetylenedicarboxylate (DMAD) was purified prior to use by passing a $50 \%$ (v/v) solution in DCM through a column of normal phase silica gel (60 mesh), eluting with DCM and condensing under reduced pressure. Unless otherwise stated, the reactions were performed under inert atmosphere in capped reaction vessels. Rat and bovine serum albumins were obtained from commercial sources the thiol content was determined by Ellman's assay in the presence of cystamine dihydrochloride as previously described. Flash chromatography was performed on 60-mesh silica. Analytical TLC was performed on aluminum-backed plates and visualized by exposure to UV light and/or staining with aqueous potassium permanganate (2\% $\mathrm{KMnO}_{4}+5 \% \mathrm{~K}_{2} \mathrm{CO}_{3}$ ) or ninhydrin stain. Preparative TLC was performed on glass-backed silica gel plates of $1 \mathrm{~mm}$ thickness, and visualized with UV light. Dye-containing materials were protected from light by wrapping the reaction and storage vessels in aluminum foil.

\section{Instrumentation}

NMR spectra were obtained on Brüker AMX-400, and DRX-500 instruments in deuterated solvents (Cambridge Isotope Laboratories, Inc.) and referenced to the signals of residual protium in the NMR solvent. Spectra were processed in MestReNova-LITE software (Mestrelab Research). Routine mass spectra were obtained on an Advion Compact Mass Spectrometer (G1946D) ESI-MSD instrument, using direct sample injection followed with 9:1 CH3CN:H2O containing $0.1 \%$ formic acid as mobile phase. High-resolution mass spectrometry was performed on an Agilent $6230 \mathrm{ESI}$-TOF LC/MS instrument (G6230B) operating at $4 \mathrm{GHz}$ with internal reference. LC was performed on an Agilent 1260 HPLC with a mobile phase gradient from $0-90 \%$ acetonitrile/water containing $0.1 \%$ formic acid on a Zorbax Extend-C18 Rapid Resolution HT $(2.1 \times 50 \mathrm{~mm}, 1.8 \mu \mathrm{m})$. Digested samples from pure RSA and rat plasma were 
analyzed on a $Q$ Exactive hybrid quadrupole-Orbitrap mass spectrometer (Thermo Fisher Scientific, Waltham, MA, USA) equipped with an Aeris WIDEPORE $3.6 \mu \mathrm{m} \mathrm{C4,} 150 \times 2.1 \mathrm{~mm}$ (Phenomenex Inc., Torrance, CA). Melting points were measured in a Fisher-Johns melting point apparatus and are corrected. IR spectra were recorded on a Nicolet 6700 FTIR spectrophotometer with Smart Performer single-bounce ATR module in thin films or in solids dispersed on a diamond crystal. Absorbance spectra were recorded on an Evolution 220 UV-Vis spectrophotometer (ThermoFisher). Absorbance and fluorescence spectra were also collected on a VarioskanFlash plate reader (ThermoFisher). Semi-preparative HPLC separations were performed on a Shimadzu instrument equipped with an autoinjector (SIL-10A), diode array detector (SPD-M20A), and reverse phase Zorbax SB-C18 column (9.4 x 250 mm, $5 \mu \mathrm{m}$ ). Analytical HPLC separations were performed with a Varian Microsorb MV 100-5 C18 column $(4.6 \times 150 \mathrm{~mm}, 5 \mu \mathrm{m})$. Inductively coupled plasma atomic emission spectroscopy (ICP-AES) was performed on a Varian Vista AX CCD simultaneous instrument. Still photographs were collected using built-in cameras on iPhone $3 \mathrm{gs}$ and $5 \mathrm{c}$ models. 


\section{Synthetic procedures and characterization}
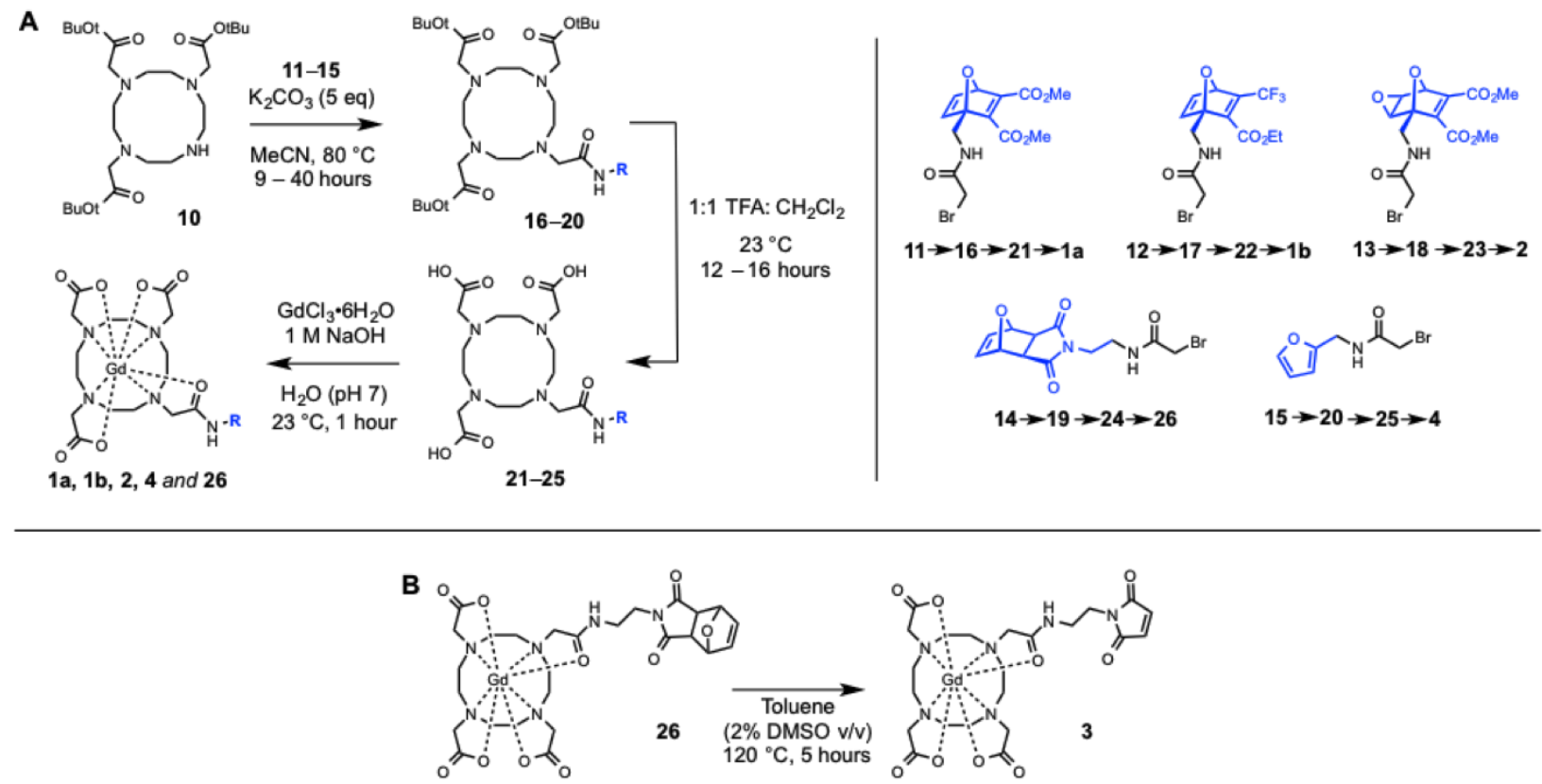

Scheme S1. Synthesis of linkers 1-4. (A) Linkers were prepared in a modular fashion by alkylation of DO3A, followed by deprotection and gadolinium insertion. (B) Maleimide $\mathbf{2 6}$ was protected as the furan Diels-Alder adduct. Thermal deprotection proceeded smoothly in the presence of DMSO cosolvent. See Supporting Information for details and characterization.

2-bromo-N-(furan-2-ylmethyl)acetamide, 15:

Furfurylamine (406 $\mu \mathrm{L}, 4.59 \mathrm{mmols}, 1 \mathrm{eq}$ ) was dissolved in $23 \mathrm{~mL}$ dichloromethane and chilled to $-20{ }^{\circ} \mathrm{C}$.<smiles>NCc1ccco1</smiles>
Triethylamine ( $704 \mu \mathrm{L}, 5.05 \mathrm{mmol}, 1.1 \mathrm{eq}$ ) added while stirring, followed by dropwise addition of bromoacetyl bromide ( $441 \mu \mathrm{L}, 5.05 \mathrm{mmol}, 1.1 \mathrm{eq}$ ) over 5 minutes. The reaction was allowed to reach room temperature after 20 minutes, and stirred at room temperature for 30 minutes more. At this time, $9.2 \mathrm{~mL}$ deionized water was added and stirred for 30 minutes. The layers were separated and the organic layer was washed with $2 \times 10 \mathrm{~mL} 1 \mathrm{~N} \mathrm{HCl}, 1 \times 10 \mathrm{~mL} \mathrm{H} \mathrm{O}_{2}$, and 1 $\times 10 \mathrm{~mL}$ brine, dried over $\mathrm{Na}_{2} \mathrm{SO}_{4}$, filtered and condensed under reduced pressure to produce a tan solid. This was further purified by flash chromatography on silica gel, eluting with a gradient from hexanes to $50 \%$ ethyl acetate in hexanes, to yield $792 \mathrm{mg}$ off-white solid ( $79 \%$ yield). $R_{f}$ $0.63\left(5 \% \mathrm{MeOH} / \mathrm{CH}_{2} \mathrm{Cl}_{2}\right.$ ). ${ }^{1} \mathrm{H} \mathrm{NMR}\left(500 \mathrm{MHz}, \mathrm{CDCl}_{3}\right) \delta 7.36$ (dd, J = $\left.1.8 \mathrm{~Hz}, 0.7 \mathrm{~Hz}, 1 \mathrm{H}\right), 6.87$ (bs, $1 \mathrm{H}), 6.32$ (dd, J = 3.2 Hz, $1.9 \mathrm{~Hz}, 1 \mathrm{H}), 6.25(\mathrm{dd}, \mathrm{J}=3.2 \mathrm{~Hz}, 0.6 \mathrm{~Hz}, 1 \mathrm{H}), 4.45(\mathrm{~d}, \mathrm{~J}=5.6 \mathrm{~Hz}, 2 \mathrm{H})$, $3.88(\mathrm{~s}, 2 \mathrm{H}) .{ }^{13} \mathrm{C} \mathrm{NMR}\left(126 \mathrm{MHz} \mathrm{CDCl}_{3}\right) \delta 165.49,150.49,142.67,110.68,108.06,37.28,29.11$. 


\section{Dimethyl 1-((2-bromoacetamido)methyl)-7-}

oxabicyclo[2.2.1]hepta-2,5-diene-2,3-dicarboxylate,

11: Furan 15 (125.7 mg, 0.576 mmols, 1 eq) was combined with dimethyl acetylenedicarboxylate $(92$ $\mu \mathrm{L}, 0.75 \mathrm{mmols}, 1.3 \mathrm{eq}$ ) in $50 \mu \mathrm{L}$ toluene in a sealed vial and heated while stirring at $50-60{ }^{\circ} \mathrm{C}$ for 12 hours. The

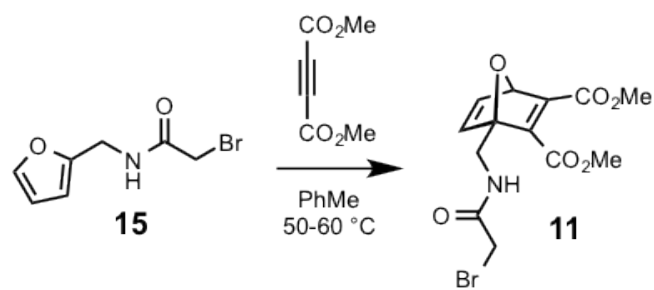
resulting residue was purified by flash chromatography on silica gel, eluting with a gradient from hexanes through $70 \%$ ethyl acetate/hexanes to provide $178 \mathrm{mg}$ of an off-white solid (86\% yield). $\mathrm{R}_{\mathrm{f}} 0.28$ (50\% EtOAc/Hexane). ${ }^{1} \mathrm{H}$ NMR (500 MHz, CDCl $) \delta 7.23$ (dd, J = $\left.5.3 \mathrm{~Hz}, 1.9 \mathrm{~Hz}, 1 \mathrm{H}\right)$, $6.99(\mathrm{~d}, \mathrm{~J}=5.3,1 \mathrm{H}), 6.87(\mathrm{bs}, 1 \mathrm{H}), 5.64(\mathrm{~d}, \mathrm{~J}=2.0 \mathrm{~Hz}, 1 \mathrm{H}), 4.11(\mathrm{~m}, 2 \mathrm{H}), 3.86(\mathrm{~s}, 2 \mathrm{H}), 3.82(\mathrm{~s}, 3 \mathrm{H})$, $3.78(\mathrm{~s}, 3 \mathrm{H}) .{ }^{13} \mathrm{C}$ NMR $\left(126 \mathrm{MHz} \mathrm{CDCl}_{3}\right) \delta 165.90,163.99,162.85,153.66,152.95,145.66$, $142.90,96.57,84.04,52.83,52.63,38.72,28.96$.

\section{Ethyl 1-((2-bromoacetamido)methyl)-3-} (trifluoromethyl)-7-oxabicyclo[2.2.1] hepta-2,5-diene-2-

carboxylate, 12: Furan 15 (113.5 mg, $0.52 \mathrm{mmol}, 1 \mathrm{eq})$ was combined with ethyl 4,4,4-trifluoro-2-butynoate (97 $\mu \mathrm{L}, 0.676 \mathrm{mmols}, 1.3 \mathrm{eq})$ in $100 \mu \mathrm{L}$ benzene in a sealed

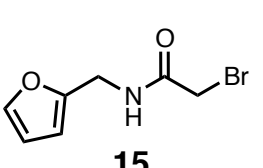

15

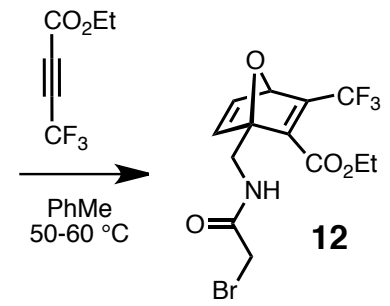

vial and heated while stirring at $50-60{ }^{\circ} \mathrm{C}$ for 12 hours.

The resulting residue was triturated in hexanes to produce $189.9 \mathrm{mg}$ of an off-white powder (95\% yield). $\mathrm{R}_{\mathrm{f}} 0.51$ (50\% EtOAc/Hexane). ${ }^{1} \mathrm{H}$ NMR (500 MHz, $\left.\mathrm{CDCl}_{3}\right) \delta 7.21$ (dd, J = $5.3 \mathrm{~Hz}, 1.9$ $\mathrm{Hz}, 1 \mathrm{H}), 7.05(\mathrm{~d}, \mathrm{~J}=5.3,1 \mathrm{H}), 6.87(\mathrm{bs}, 1 \mathrm{H}), 5.64(\mathrm{~d}, \mathrm{~J}=1.9 \mathrm{~Hz}, 1 \mathrm{H}), 4.26(\mathrm{~m}, 2 \mathrm{H}), 4.15(\mathrm{q}, \mathrm{J}=5.8$ $\mathrm{Hz}, 2 \mathrm{H}), 3.87(\mathrm{~s}, 2 \mathrm{H}), 1.31(\mathrm{t}, \mathrm{J}=7.0 \mathrm{~Hz}, 3 \mathrm{H}) .{ }^{13} \mathrm{C} \mathrm{NMR}\left(126 \mathrm{MHz}, \mathrm{CDCl}_{3}\right) \delta \quad 165.92,162.43$, $152.32(q, J=37 \mathrm{~Hz}), 150.68(q, J=5 \mathrm{~Hz}), 144.94,143.55,121.5(q, J=270 \mathrm{~Hz}), 96.68,82.95(q, J$ $=2 \mathrm{~Hz}), 62.39,38.67,28.97,14.02 .{ }^{19} \mathrm{~F} \mathrm{NMR}\left(470 \mathrm{MHz} \mathrm{CDCl}_{3}\right) \delta-62.84(\mathrm{~s}=1 \mathrm{~F}$, minor regioisomer), -63.82 ( $\int=11 \mathrm{~F}$, major regioisomer).

Dimethyl 1-((2-bromoacetamido)methyl)-3,8dioxatricyclo[3.2.1.0 $0^{2,4}$ oct-6-ene-6,7-dicarboxylate, 13: OND 11 (128 mg, 0.355 mmols, 1 eq) was dissolved in dichloromethane $(0.77 \mathrm{~mL})$ and $m$-chloroperoxybenzoic acid (131.5 mg, 0.533 mmols, $1.5 \mathrm{eq}$ ) was added and stirred at room temperature for 4 hours. The reaction
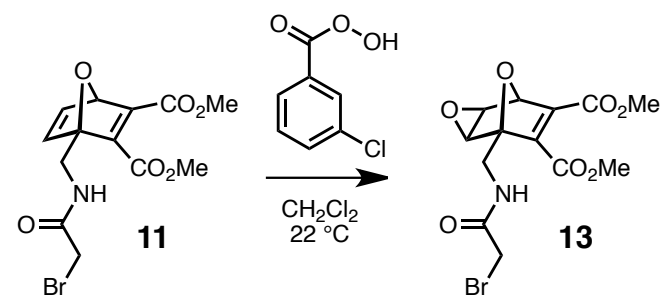
mixture was diluted with $5 \mathrm{~mL} \mathrm{DCM}$ and washed with $4 \times 5 \mathrm{~mL}$ 4:1 $1 \mathrm{M} \mathrm{Na}_{2} \mathrm{CO}_{3}$ : sat'd $\mathrm{NaHCO}_{3}$. The combined washes were back-extracted once with $5 \mathrm{~mL} \mathrm{DCM}$ and the combined organic extracts were dried over $\mathrm{MgSO}_{4}$, filtered, and condensed under reduced pressure. The residue was purified by flash chromatography on silica gel, eluting with a gradient from $20 \%$ ethyl acetate/hexanes through $60 \%$ ethyl acetate/hexanes to provide $108 \mathrm{mg}$ of a white solid (81\% yield). $R_{f} 0.50$ (50\% EtOAc/Hexane). ${ }^{1} \mathrm{H}$ NMR (500 MHz, $\left.\mathrm{CDCl}_{3}\right) \delta 6.87$ (triplet, J = 5.2, $1 \mathrm{H}$ ), 5.10 
(s, 1H), $4.06(d d, J=14.8,6.2,1 H), 3.97(d d, J=14.8,5.5,1 H), 3.85(d, J=2,2 H), 3.83(s, 3 H)$, $3.79(\mathrm{~s}, 3 \mathrm{H}), 3.78(\mathrm{~d}, \mathrm{~J}=3.6,1 \mathrm{H}), 3.70(\mathrm{~d}, \mathrm{~J}=3.6,1 \mathrm{H}) .{ }^{13} \mathrm{C} \mathrm{NMR}\left(50 \mathrm{MHz}^{\mathrm{C}} \mathrm{CDCl}_{3}\right) \delta 166.12$, $162.99,161.99,149.01,147.50,90.82$, 78.58, 57.28, 56.45, 53.10, 52.88, 37.97, 28.77.

tert-butyl (2-(1,3-dioxo-1,3,3a,4,7,7a-hexahydro-2H4,7-epoxyisoindol-2-yl)ethyl) carbamate, S1: The Diels-Alder adduct of furan and maleic anhydride was prepared as previous described. This material $(879.2$

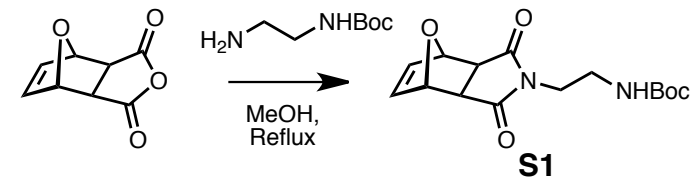
$\mathrm{mg}, 5.29 \mathrm{mmols}, 1 \mathrm{eq}$ ) was combined with mono-Boc-ethylenediamine (848 mg, $5.29 \mathrm{mmols}, 1$ eq) in $7 \mathrm{~mL}$ methanol. This mixture was stirred at room temperature for 30 minutes, and then heated in a $60{ }^{\circ} \mathrm{C}$ oil bath for 12 hours. The reaction mixture was then cooled to room temperature, and the flask was scratched and chilled at $4{ }^{\circ} \mathrm{C}$ to induce precipitation. The resulting precipitate was collected as $514 \mathrm{mg}$ of an off-white solid ( $32 \%$ yield). $R_{f} 0.77$ (10\% $\mathrm{MeOH} / \mathrm{DCM}$, product stains blue-green in ninhydrin). ${ }^{1} \mathrm{H} \mathrm{NMR}\left(200 \mathrm{MHz}, \mathrm{CDCl}_{3}\right) \delta 6.50(\mathrm{~s}, 2 \mathrm{H})$, $5.25(\mathrm{~s}, 2 \mathrm{H}), 4.78(\mathrm{bs}, 1 \mathrm{H}), 3.61(\mathrm{app} \mathrm{t}, \mathrm{J}=2.2,2 \mathrm{H}), 3.29$ (app d, J = 2, 2H), $2.84(\mathrm{~s}, 2 \mathrm{H}), 1.40$ (s, $9 \mathrm{H}) .{ }^{13} \mathrm{C} N M R\left(50 \mathrm{MHz}, \mathrm{CDCl}_{3}\right) \delta 166.16,162.92,161.91,148.96,147.37,90.78,78.44,57.19$, $56.39,53.02,52.80,37.84,28.71$.

(2-(1,3-dioxo-1,3,3a,4,7,7a-hexahydro-2H-4,7epoxyisoindol-2-yl)ethyl) ammonium chloride, S2: Carbamate-protected S1 (500 mg, 1.62 mmols, 1 eq) was dissolved at $0.32 \mathrm{M}$ in $2.4 \mathrm{M}$

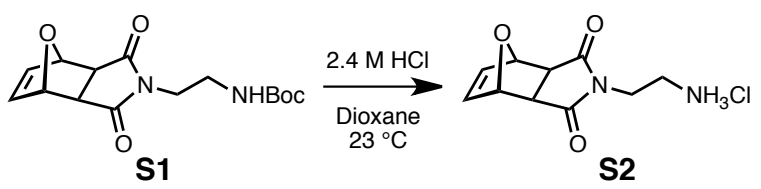
hydrochloric acid in dioxanes $(5 \mathrm{~mL})$ at room temperature. This mixture was stirred at room temperature for 3 hours, at which time the reaction contained a precipitate. This was collected by vacuum filtration to product $400 \mathrm{mg}$ of white solid (>99\% yield). Residual dioxane was present upon ${ }^{1} \mathrm{H}-\mathrm{NMR}$ analysis. $\mathrm{R}_{\mathrm{f}} 0.00(10 \% \mathrm{MeOH} / \mathrm{DCM}$, product stains blue-green in ninhydrin). ${ }^{1} \mathrm{H}$ NMR (500 MHz, $\left.\mathrm{D}_{2} \mathrm{O}\right) \delta 6.64(\mathrm{~s}, 2 \mathrm{H}), 5.36(\mathrm{~s}, 2 \mathrm{H}), 3.85(\mathrm{t}, \mathrm{J}=5.8 \mathrm{~Hz}, 2 \mathrm{H}), 3.77$ (residual dioxane, $2.8 \mathrm{~mol} \%), 3.24(\mathrm{t}, \mathrm{J}=5.8 \mathrm{~Hz}, 2 \mathrm{H}), 3.20(\mathrm{~s}, 2 \mathrm{H}) .{ }^{13} \mathrm{C} \mathrm{NMR}\left(126 \mathrm{MHz}^{\mathrm{C}} \mathrm{CDCl}_{3}\right) \delta$ $178.74,136.22,136.22,80.78,80.78,66.38,47.38,47.38,37.35,36.02$.

\section{2-bromo-N-(2-(1,3-dioxo-1,3,3a,4,7,7a-} hexahydro-2H-4,7-epoxyisoindol-2-yl)

ethyl)acetamide, 14: Hydrochloride salt S2 (80 $\mathrm{mg}, 0.327$ mmols, $1 \mathrm{eq})$ was dissolved in

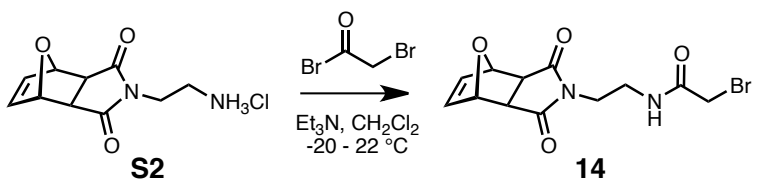
dichloromethane $(4 \mathrm{~mL})$ at $-10{ }^{\circ} \mathrm{C}$, and triethylamine $(100 \mu \mathrm{L}, 0.720 \mathrm{mmols}, 2.2 \mathrm{eq})$ was added. Bromoacetyl bromide ( $31.4 \mu \mathrm{L}, 0.360 \mathrm{mmols}, 1.1 \mathrm{eq})$ was added dropwise over 5 minutes and the reaction was allowed to gradually reach room temperature over 1 hour. The reaction mixture was washed with $2 \times 5 \mathrm{~mL} 0.1 \mathrm{~N} \mathrm{HCl}$, and the aqueous layer was back-extracted with $2 \mathrm{x}$ $5 \mathrm{~mL} \mathrm{DCM}$. Combined organic layers were washed once with brine and then dried over $\mathrm{Na}_{2} \mathrm{SO}_{4}$, 
filtered and condensed under reduced pressure. The organic crude was purified by flash chromatography, eluting with gradient from hexanes to $90 \%$ ethyl acetate/hexanes. A pale yellow residue that formed plate-like crystals under vacuum was collected $(77.5 \mathrm{mg}, 72 \%$ yield). $\mathrm{R}_{\mathrm{f}} 0.55$ (5\% MeOH/DCM, product stains blue-green in ninhydrin). ${ }^{1} \mathrm{H} N M R\left(500 \mathrm{MHz}, \mathrm{D}_{2} \mathrm{O}\right) \delta$ $6.80(\mathrm{bs}, 1 \mathrm{H}), 6.49(\mathrm{~s}, 2 \mathrm{H}), 5.25(\mathrm{~s}, 2 \mathrm{H}), 3.78(\mathrm{~s}, 2 \mathrm{H}), 3.66(\mathrm{t}, \mathrm{J}=5.4 \mathrm{~Hz}, 2 \mathrm{H}), 3.46(\mathrm{app} \mathrm{q}, \mathrm{J}=5.6$ $\mathrm{Hz}, 2 \mathrm{H}), 2.85(\mathrm{~s}, 2 \mathrm{H}) .{ }^{13} \mathrm{C}$ NMR $\left(126 \mathrm{MHz}, \mathrm{CDCl}_{3}\right) \delta 176.61,176.59,166.26,136.76,136.60,81.37$, $81.21,81.18,81.03,47.71,47.54,38.68,38.66,38.59,38.48,38.15,37.93,29.05$.

tri-tert-butyl-DO3A-mono-(2-(1,3-dioxo1,3,3a,4,7,7a-hexahydro-2H-4,7epoxyisoindol-2-yl)ethyl)acetamide, 19: Tristert-butyl acetate modified cyclen derivative 10 was prepared as previously described. ${ }^{36}$
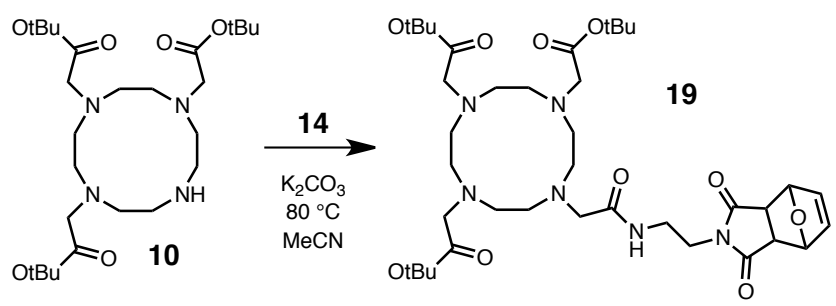

This compound ( $78 \mathrm{mg}, 0.131 \mathrm{mmols}, 1 \mathrm{eq}$ ) was dissolved in dry acetonitrile $(2.3 \mathrm{~mL})$ at $22{ }^{\circ} \mathrm{C}$, and $\mathrm{K}_{2} \mathrm{CO}_{3}(91 \mathrm{mg}, 0.655 \mathrm{mmols}, 5$ eq) was added. Compound 14 (50 mg, 0.152 mmols, $1.2 \mathrm{eq}$ ) was added and the reaction was heated at $50{ }^{\circ} \mathrm{C}$ under inert atmosphere for 9 hours. The reaction mixture was condensed and purified by flash chromatography, eluting with gradient from DCM to $10 \%$ methanol/DCM. A glassy, offwhite, foaming solid was collected ( $88 \mathrm{mg}, 88 \%$ yield). $\mathrm{R}_{\mathrm{f}} 0.13$ (5\% MeOH/DCM). ${ }^{1} \mathrm{H}$ NMR collected at room temperature contains some peaks that are very broad and poorly defined due to conformers and restricted rotation of functional groups around the cyclen macrocycle. This is comparable to other DO3A derivatives reported in the literature. ${ }^{12}{ }^{1} \mathrm{H}$ NMR $(500 \mathrm{MHz}$, $\left.\mathrm{CDCl}_{3}\right) \delta 9.28(\mathrm{bs}, 1 \mathrm{H}), 6.40(\mathrm{~s}, 2 \mathrm{H}), 5.15(\mathrm{~s}, 2 \mathrm{H}), 3.28(\mathrm{~s}, 2 \mathrm{H}), 3.42-3.92(\mathrm{bs}, 4 \mathrm{H}), 3.05-3.04$ (bs, $4 \mathrm{H}), 1.7-3.05$ (broad m, 20H), $1.42(\mathrm{~s}, 9 \mathrm{H}), 1.40(\mathrm{~s}, 18 \mathrm{H}) .{ }^{13} \mathrm{C} \mathrm{NMR}\left(126 \mathrm{MHz}, \mathrm{CDCl}_{3}\right) \delta 177.43$, $172.57,172.50,136.42,81.99,81.80,80.72,56.22,55.92,52.60,48.57,38.27,37.13,28.18$, 28.06. ESI-MS: $\left[\mathrm{C}_{38} \mathrm{H}_{62} \mathrm{~N}_{6} \mathrm{O}_{10}+\mathrm{H}\right]^{+} 763.4$, also observed [M-tBu+H] ${ }^{+} 707.8$.

DO3A-mono-(2-(1,3-dioxo-1,3,3a,4,7,7ahexahydro-2H-4,7-epoxyisoindol-2-

yl)ethyl) acetamide, 24: Protected cyclen derivative 19 (88.5 $\mathrm{mg}, 0.116$ mmols, 1 eq) was dissolved in a 1:1 mixture of
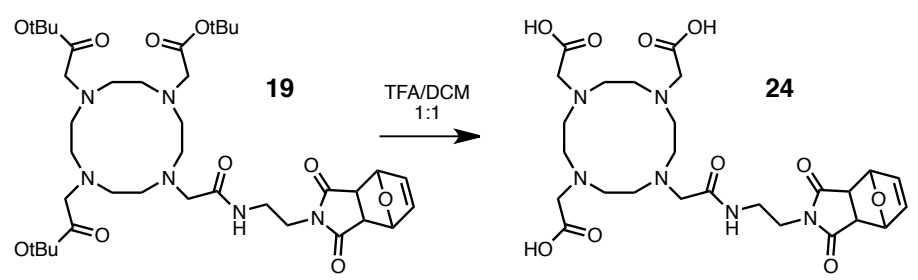
trifluoroacetic acid and dichloromethane $(3.87 \mathrm{~mL}$ ) at room temperature and stirred under argon for 16 hours. The reaction was then condensed under reduced pressure and azeotroped with benzene, methanol, and chloroform (in that order) before placing on high vacuum to yield

${ }^{1}$ Raghunand, N.; Guntle, G. P.; Gokhale, V.; Nichol, G. S.; Mash, E. A.; Jagadish, B. J. Med. Chem. 2010, 53, 6747.

2 Pazos, E.; Golicnik, M.; Mascarenas, J. L.; Eugenio Vazquez, M. Chemical Communications 2012, 48, 9534. 
$97.9 \mathrm{mg}$ of an off-white foaming solid ( $>100 \%$ yield by mass, corresponding to a salt with an average of 2 TFA molecules per molecule). ${ }^{1} \mathrm{H} \mathrm{NMR}\left(500 \mathrm{MHz}, \mathrm{CDCl}_{3}\right) \delta 6.80$ (bs, $\left.1 \mathrm{H}\right), 6.49$ (s, $2 \mathrm{H}), 5.25(\mathrm{~s}, 2 \mathrm{H}), 3.78(\mathrm{~s}, 2 \mathrm{H}), 3.66(\mathrm{t}, \mathrm{J}=5.4 \mathrm{~Hz}, 2 \mathrm{H}), 3.46(\mathrm{app} \mathrm{q}, \mathrm{J}=5.6 \mathrm{~Hz}, 2 \mathrm{H}), 2.85(\mathrm{~s}, 2 \mathrm{H}) .{ }^{13} \mathrm{C}$ $\operatorname{NMR}\left(126 \mathrm{MHz}_{\mathrm{CDCl}}\right) \delta 176.61,176.59,166.26,136.76,136.60,81.37,81.21,81.18,81.03$, $47.71,47.54,38.68,38.66,38.59,38.48,38.15,37.93,29.05$. ESI-MS: $\left[\mathrm{C}_{26} \mathrm{H}_{38} \mathrm{~N}_{6} \mathrm{O}_{10}+\mathrm{H}\right]^{+} 595.3$.

\section{tri-tert-butyl-D03A-Dimethyl acetamido)methyl)-7-oxabicyclo}

[2.2.1]hepta-2,5-diene-2,3-dicarboxylate, 16:

Tris-tert-butyl acetate modified cyclen 10

(276 mg, 0.462 mmols, $1 \mathrm{eq}$ ) was dissolved in
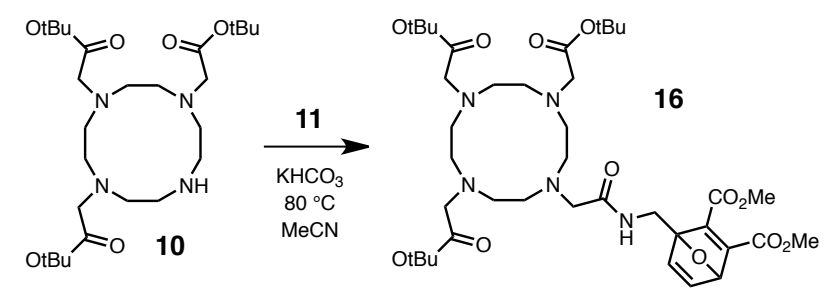
dry acetonitrile $\left(10 \mathrm{~mL}\right.$ ) at $22{ }^{\circ} \mathrm{C}$, and $\mathrm{KHCO}_{3}(194 \mathrm{mg}, 2.31 \mathrm{mmols}, 5 \mathrm{eq})$ was added. Compound 11 (200 mg, $0.555 \mathrm{mmols}, 1.2 \mathrm{eq}$ ) was added and the reaction was heated at $80^{\circ} \mathrm{C}$ under inert atmosphere for 40 hours. The reaction mixture was condensed and purified by flash chromatography, eluting with gradient from DCM to $10 \%$ methanol/DCM. A glassy, offwhite, foaming solid was collected ( $265 \mathrm{mg}, 72 \%$ yield). $\mathrm{R}_{\mathrm{f}} 0.13$ (5\% MeOH/DCM). ${ }^{1} \mathrm{H}$ NMR collected at room temperature contains some peaks that are very broad and poorly defined due to conformers and restricted rotation of functional groups around the cyclen macrocycle. This is comparable to other DO3A derivatives reported in the literature. ${ }^{1}{ }^{1} \mathrm{H} \mathrm{NMR}\left(500 \mathrm{MHz} \mathrm{CDCl}_{3}\right) \delta$ 7.98 (bs, 1H), 7.19 (bs, 1H), 6.94 (dd, J = 5.1 Hz, J = 1.3 Hz, 1H), 5.36 (d, J = $1.8 \mathrm{~Hz}, 1 \mathrm{H}), 3.90(\mathrm{~m}$, $2 \mathrm{H}), 3.65(\mathrm{~s}, 3 \mathrm{H}), 3.60(\mathrm{~s}, 3 \mathrm{H}), 3.45-1.64$ (broad $\mathrm{m}, 24 \mathrm{H}), 1.27$ (overlapping singlets, $27 \mathrm{H}) .{ }^{13} \mathrm{C}$ NMR $\left(126 \mathrm{MHz}, \mathrm{CDCl}_{3}\right) \delta 172.34,171.89,170.39,169.49,163.94,162.71,153.96,152.81$, $144.23,96.68,83.06,81.58,81.49,81.45,81.25,57.77,56.42,55.50,55.36,55.32,55.26,52.23$, 52.12, 52.05, 50.97, 48.82, 47.25, 37.15, 27.83, 27.71. ESI-MS: $\left[\mathrm{C}_{39} \mathrm{H}_{63} \mathrm{~N}_{5} \mathrm{O}_{12}+\mathrm{H}\right]^{+} 794.4$, also observed $[\mathrm{M}-\mathrm{tBu}+\mathrm{H}]^{+} 738.4$.

\section{tri-tert-butyl-D03A-ethyl 1-((2-acetamido) methyl)-3-(trifluoromethyl)-7-oxabicyclo} [2.2.1]hepta-2,5-diene-2-carboxylate, 17: Tris-tert-butyl acetate modified cyclen 10 (150 mg, 0.25 mmols, 1 eq) was dissolved in
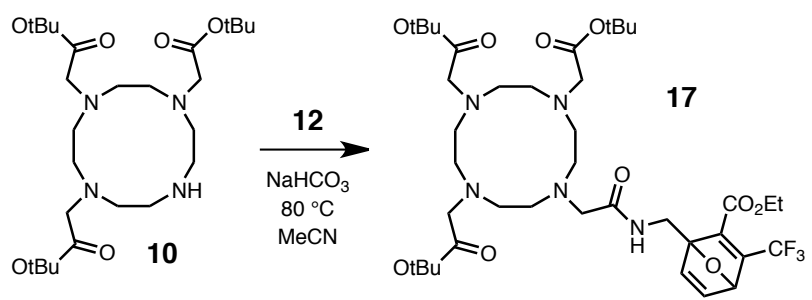
dry acetonitrile $(4.7 \mathrm{~mL})$ at $22^{\circ} \mathrm{C}$, and $\mathrm{NaHCO}_{3}$

(105 mg, 1.25 mmols, 5 eq) was added. OND 12 (125 mg, 0.325 mmols, $1.3 \mathrm{eq}$ ) was added and the reaction was heated at $80{ }^{\circ} \mathrm{C}$ under inert atmosphere for 40 hours. The reaction mixture was condensed and purified by flash chromatography, eluting with gradient from ethyl acetate to $10 \%$ methanol/ethyl acetate. A glassy, off-white, foaming solid was collected (175 $\mathrm{mg}, 85 \%$ yield). $\mathrm{R}_{\mathrm{f}} 0.12$ (5\% MeOH/DCM). ${ }^{1} \mathrm{H} \mathrm{NMR}\left(500 \mathrm{MHz}, \mathrm{CDCl}_{3}\right) \delta 8.33$ (bs, $1 \mathrm{H}$ ), 7.43 (bs, 1H), 7.02 (d, $\mathrm{J}=4.3 \mathrm{~Hz}, 1 \mathrm{H}), 5.43(\mathrm{~s}, 1 \mathrm{H}), 4.20(\mathrm{~m}, 3 \mathrm{H}), 3.98(\mathrm{bs}, 1 \mathrm{H}), 3.60-1.80(\mathrm{~m}, 26 \mathrm{H}), 1.38(\mathrm{~m}, 29 \mathrm{H}), 1.24$ $(t, J=7.2 \mathrm{~Hz}, 3 \mathrm{H}) .{ }^{13} \mathrm{C} \mathrm{NMR}\left(126 \mathrm{MHz}, \mathrm{CDCl}_{3}\right) \delta 172.58,172.22,151.9\left(\mathrm{q}^{\mathrm{C}-\mathrm{F} J}=37 \mathrm{~Hz}\right), 151.48$, 
145.39, 143.66, $121.71\left(\mathrm{q},{ }^{\mathrm{C}-\mathrm{F}} \mathrm{J}=267 \mathrm{~Hz}\right), 97.19,82.31,81.94,81.87,81.81,61.89,56.73,55.81$, 52.45 (broad), 48.56 (broad), 37.23, 37.22, 29.77, 28.14, 28.03, 27.99, 13.98. ${ }^{19} \mathrm{~F}$ NMR (470 $\left.\mathrm{MHz}, \mathrm{CDCl}_{3}\right) \delta-62.71$ ( $\int=1 \mathrm{~F}$, minor regioisomer), -63.83 ( $\int=14 \mathrm{~F}$, major regioisomer). ESI-MS: $\left[\mathrm{C}_{39} \mathrm{H}_{62} \mathrm{~F}_{3} \mathrm{~N}_{5} \mathrm{O}_{10}+\mathrm{H}\right]^{+} 818.5$, also observed $[\mathrm{M}-\mathrm{tBu}+\mathrm{H}]^{+}$762.4.

D03A-Dimethyl 1-((2-acetamido)methyl)7-oxa-bicyclo[2.2.1] hepta-2,5-diene-2,3dicarboxylate, 21: Protected cyclen derivative 16 (264.5 $\mathrm{mg}, 0.333$ mmols, 1 eq) was dissolved in a 1:1 mixture of

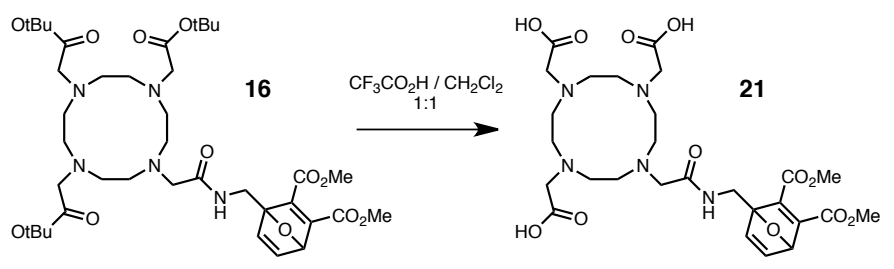
trifluoroacetic acid and dichloromethane $(11 \mathrm{~mL})$ at room temperature and stirred under argon for 16 hours. The reaction was then condensed under reduced pressure and azeotroped with benzene, methanol, and chloroform. The resulting residue was dissolved in minimal methanol and diethyl ether was added to produce $202 \mathrm{mg}$ of a tan precipitate, which was dried under vacuum (71\% yield, assuming 2 TFA molecules per desired product). ${ }^{1} \mathrm{H} N M R\left(500 \mathrm{MHz}, \mathrm{D}_{2} \mathrm{O}\right) \delta$ $7.35(\mathrm{dd}, \mathrm{J}=5.3 \mathrm{~Hz}, \mathrm{~J}=2.0 \mathrm{~Hz}, 1 \mathrm{H}), 7.16(\mathrm{~d}, \mathrm{~J}=5.3,1 \mathrm{H}), 5.79(\mathrm{~d}, \mathrm{~J}=2.0 \mathrm{~Hz}, 1 \mathrm{H}), 3.95(\mathrm{~m}, 2 \mathrm{H})$, $3.86(\mathrm{~s}, 3 \mathrm{H}), 3.82(\mathrm{~s}, 3 \mathrm{H}), 3.64(\mathrm{~m}, 2 \mathrm{H}), 3.35$ (broad multiplet, $24 \mathrm{H}) .{ }^{13} \mathrm{C} N M R\left(126 \mathrm{MHz}, \mathrm{D}_{2} \mathrm{O}\right) \delta$ $174.29,170.86,170.82,169.55,165.00,163.90,154.08,152.74,145.08,142.26,96.63,83.48$, $55.75,54.38,52.97,52.77,51.51,48.84,47.58,42.11,37.21$. ESI-MS: $\left[\mathrm{C}_{27} \mathrm{H}_{39} \mathrm{~N}_{5} \mathrm{O}_{12}+\mathrm{H}\right]^{+} 626.3$.

D03A-ethyl 1-((2-acetamido) methyl)-3(trifluoromethyl)-7-oxabicyclo [2.2.1]hepta-2,5-diene-2-carboxylate, 22: Protected cyclen derivative 17 (174.8 mg, 0.214 mmols, 1 eq) was dissolved in a $1: 1$
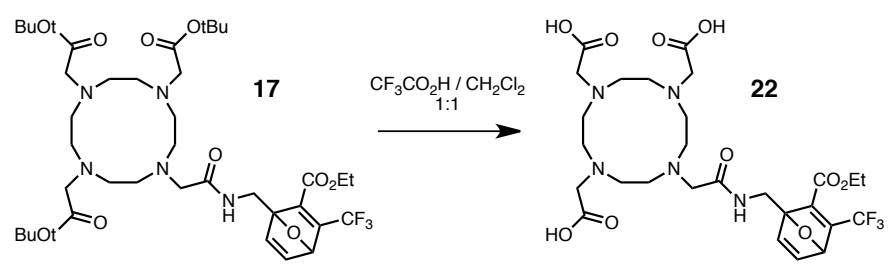
mixture of trifluoroacetic acid (TFA) and dichloromethane $(6.7 \mathrm{~mL})$ at room temperature and stirred under argon for 16 hours. The reaction was then condensed under reduced pressure and azeotroped with benzene, methanol, and chloroform. The resulting residue was dissolved in minimal methanol and diethyl ether was added to produce $109 \mathrm{mg}$ of a tan precipitate, which was dried under vacuum, dissolved in $2 \mathrm{~mL}$ of water and lyophilized (62\% yield, salt with 1.45 TFA molecules, determined by $\left.{ }^{19} \mathrm{~F}-\mathrm{NMR}\right) .{ }^{1} \mathrm{H}$ NMR (500 MHz, $\left.\mathrm{D}_{2} \mathrm{O}\right) \delta 7.32$ (dd, J = 5.0, $1.3 \mathrm{~Hz}$, $1 \mathrm{H}), 7.21(\mathrm{~d}, \mathrm{~J}=5.3 \mathrm{~Hz}, 1 \mathrm{H}), 5.81(\mathrm{~d}, \mathrm{~J}=1.3 \mathrm{~Hz}, 1 \mathrm{H}), 4.33-4.22(\mathrm{~m}, 3 \mathrm{H}), 3.96(\mathrm{~d}, \mathrm{~J}=15 \mathrm{~Hz}, 2 \mathrm{H})$, 3.88-3.00 (broad multiplet, 24H), $1.28(\mathrm{t}, \mathrm{J}=7.1 \mathrm{~Hz}, 3 \mathrm{H}) .{ }^{13} \mathrm{C} \mathrm{NMR}\left(126 \mathrm{MHz}, \mathrm{D}_{2} \mathrm{O}\right) \delta 170.19$ (broad), 163.45, $162.58\left(q,{ }^{C-F} \mathrm{~J}=35 \mathrm{~Hz}\right.$, trifluoroacetate salt), $151.69\left(q^{\mathrm{C}-\mathrm{F}} \mathrm{J}=37 \mathrm{~Hz}\right), 150.59$, $150.55,144.70,142.78,121.00\left(q,{ }^{C-F} \mathrm{~J}=267 \mathrm{~Hz}\right), 116.41\left(\mathrm{q},{ }^{\mathrm{C}-\mathrm{F}} \mathrm{J}=290 \mathrm{~Hz}\right.$, trifluoroacetate salt), 96.85, 96.19, 95.17, 90.23, 82.29, 71.78, 62.97, 55.19 (broad), 54.32, 53.31 (broad), 50.19 (broad), 48.75 (broad), 36.98, 12.89. $\left.{ }^{19} \mathrm{~F} \mathrm{NMR} \mathrm{(470} \mathrm{MHz,} \mathrm{CDCl}_{3}\right) \delta-62.97$ ( $\int=1 \mathrm{~F}$, minor regioisomer), -64.29 ( $\int=35 \mathrm{~F}$, major regioisomer $),-76.74$ ( $\int=50 \mathrm{~F}$, trifluoroacetate salt). ESI-MS: $\left[\mathrm{C}_{27} \mathrm{H}_{38} \mathrm{~F}_{3} \mathrm{~N}_{5} \mathrm{O}_{10}+\mathrm{H}\right]^{+} 650.3$. 


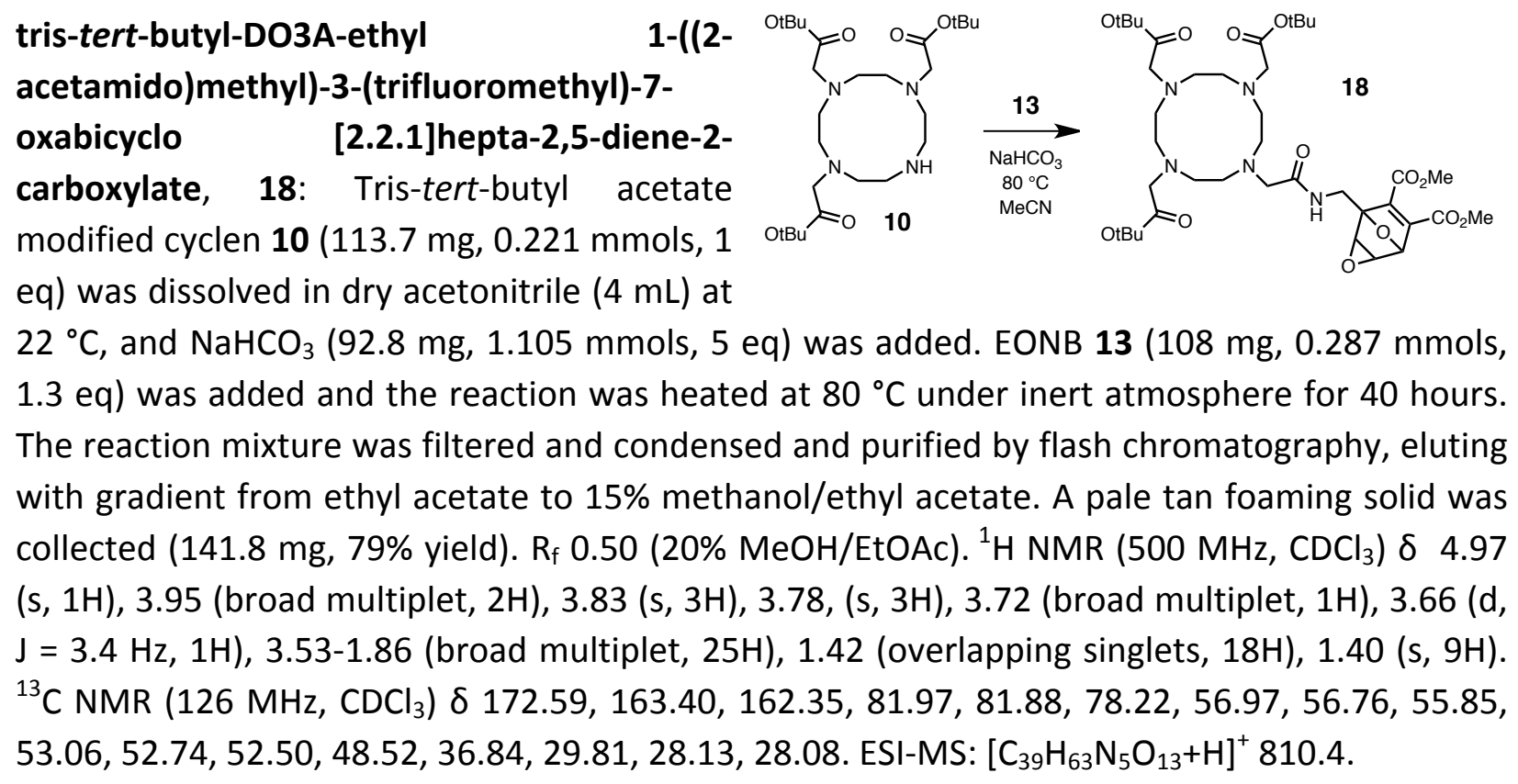

D03A-dimethyl 1-((2-acetamido)methyl)3,8-dioxa-tricyclo[3.2.1.0 $0^{2,4}$ ]oct-6-ene-6,7dicarboxylate, 23: Protected cyclen derivative 18 (94 mg, 0.116 mmols, 1 eq) was dissolved in a 1:1 mixture of

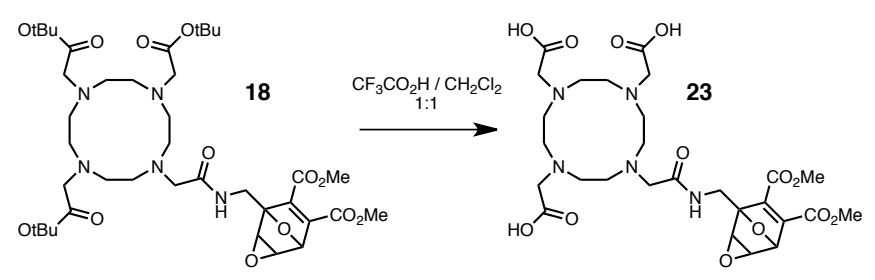
trifluoroacetic acid and dichloromethane $(3.5 \mathrm{~mL})$ at room temperature and stirred under argon for 16 hours. The reaction was then condensed under reduced pressure and azeotroped with benzene, methanol, and chloroform. The resulting residue was dissolved in minimal methanol and diethyl ether was added to produce $73.3 \mathrm{mg}$ of an off-white precipitate, which was dried under vacuum, dissolved in $2 \mathrm{~mL}$ water and lyophilized (71\% yield, salt with an average of 2.24 TFA molecules per desired product, determined by ${ }^{1} \mathrm{H}$ - and ${ }^{19} \mathrm{~F}-\mathrm{NMR}$ in the presence of $\alpha, \alpha, \alpha$ trifluorotoluene). ${ }^{1} \mathrm{H} N M R\left(500 \mathrm{MHz}, \mathrm{D}_{2} \mathrm{O}\right) \delta 5.27(\mathrm{~s}, 1 \mathrm{H}), 4.08(\mathrm{~d}, \mathrm{~J}=3.7,1 \mathrm{H}), 4.03(\mathrm{~d}, \mathrm{~J}=3.6 \mathrm{~Hz}$, $1 \mathrm{H}), 3.87(\mathrm{~s}, 3 \mathrm{H}), 3.83(\mathrm{~s}, 3 \mathrm{H}), 3.76(\mathrm{~m}, 2 \mathrm{H}), 3.62-2.94$ (broad multiplet, $24 \mathrm{H}) .{ }^{13} \mathrm{C}$ NMR $(126$ $\left.\mathrm{MHz}, \mathrm{D}_{2} \mathrm{O}\right) \delta 170.33$ (broad), 163.94, 163.08, 162.80, 162.52, 162.24, 148.30, 148.14, 116.15, 90.63, 78.17, 57.49, 56.61, 54.86 (broad), 54.33, 53.15, 52.94, 49.16 (broad), 36.42. ESI-MS: $\left[\mathrm{C}_{27} \mathrm{H}_{39} \mathrm{~N}_{5} \mathrm{O}_{13}+\mathrm{H}\right]^{+} 642.3$.

[Gd•DO3A]-Dimethyl 1-((2-acetamido) methyl)-7-oxabicyclo[2.2.1]hepta-2,5diene-2,3-dicarboxylate, 1a: Triscarboxylic acid 21 (62.4 mg, 0.064 mmols, 1 eq) was dissolved in deionized water
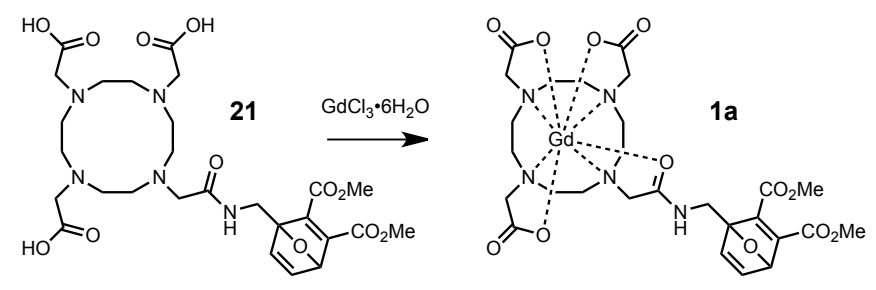
(0.98 $\mathrm{mL})$, and $\mathrm{GdCl}_{3} \cdot 6 \mathrm{H}_{2} \mathrm{O}(28.5 \mathrm{mg}, 0.077 \mathrm{mmols}, 1.2 \mathrm{eq})$ was added. The $\mathrm{pH}$ of the solution was adjusted and maintained during the reaction to $6.8-7.0$ by dropwise addition of $1 \mathrm{~N} \mathrm{NaOH}$. After 30 minutes, no starting material was observed by mass spectrometry, and the reaction mixture was condensed in vacuum. The crude product was purified in batches by semipreparative HPLC, eluting for 5 minutes with water containing $0.1 \%$ TFA, followed by a gradient over 15 minutes to $50 \% \mathrm{MeCN} / \mathrm{H}_{2} \mathrm{O}$ with $0.1 \%$ TFA to yield a total of $22 \mathrm{mg}$ white fluffy solid, after lyophilization (44\% yield over 2 steps). HPLC: R.T. $14.7 \mathrm{~min}$. HRMS $\left[\mathrm{C}_{27} \mathrm{H}_{35} \mathrm{GdN}_{5} \mathrm{O}_{12}+\mathrm{H}\right]^{+}$: Calc. 781.1674, Obs 781.1670. See Figures S1 and S2 for HPLC chromatogram and HRMS spectrum, respectively.

[Gd•DO3A]-ethyl 1-((2-acetamido) methyl)-3-(trifluoromethyl)-7-oxabicyclo

[2.2.1] hepta-2,5-diene-2-carboxylate, 1b:

Tris-carboxylic acid OND 22 (70 mg, 0.071 mmols, 1 eq) was dissolved in deionized

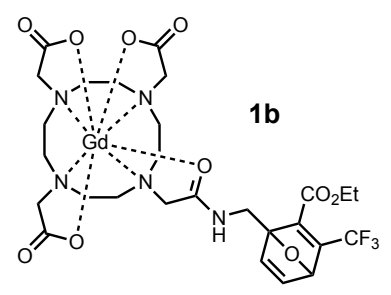
water $(0.78 \mathrm{~mL})$ and $\mathrm{GdCl}_{3} \bullet 6 \mathrm{H}_{2} \mathrm{O}(41 \mathrm{mg}, 0.11 \mathrm{mmols}, 1.2 \mathrm{eq})$ was added. The $\mathrm{pH}$ of the solution was adjusted to 6.8-7 and maintained during the reaction by dropwise addition of $1 \mathrm{~N} \mathrm{NaOH}$. After 30 minutes of stirring, the reaction mixture was condensed in vacuum to produce a brown crude residue. The crude product was purified in 5 batches by semi-preparative HPLC, eluting for 5 minutes with water containing 0.1\% TFA, followed by a gradient over 15 minutes to $50 \%$ $\mathrm{MeCN} / \mathrm{H}_{2} \mathrm{O}$ with $0.1 \%$ TFA to produce $40 \mathrm{mg}$ of a white fluffy solid after lyophilization (70\% yield) HPLC: R.T. 17.7 min. HRMS $\left[\mathrm{C}_{27} \mathrm{H}_{35} \mathrm{~F}_{3} \mathrm{GdN}_{5} \mathrm{O}_{10}+\mathrm{H}\right]^{+}$: Calc. 805.1650, Obs 805.1643. See Figures S1 and S2 for HPLC chromatogram and HRMS spectrum, respectively.

\section{[Gd•DO3A]-dimethyl 1-((2-acetamido)} methyl)-3,8-dioxatricyclo[3.2.1.0 $0^{2,4}$ ]oct-6ene-6,7-dicarboxylate, 2: Tris-carboxylic acid EONB 23 (227.8 mg, 0.232 mmols) was dissolved in deionized water $(3.6 \mathrm{~mL})$

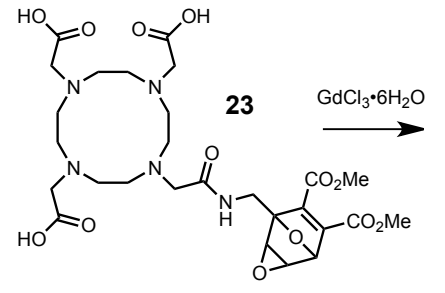
and $\mathrm{GdCl}_{3} \bullet 6 \mathrm{H}_{2} \mathrm{O}$ (95 mg, 0.255 mmols, $1.1 \mathrm{eq}$ ) was added. The $\mathrm{pH}$ of the solution was adjusted to 6.8-7 and maintained during the reaction by dropwise addition of $1 \mathrm{~N} \mathrm{NaOH}$. After 30 minutes of stirring, the reaction mixture was condensed in vacuum. A portion of the crude product was purified in $3 \times 10 \mathrm{mg}$ batches by semi-preparative HPLC, eluting for 5 minutes with water containing $0.1 \%$ TFA, followed by a gradient over 15 minutes to $50 \% \mathrm{MeCN} / \mathrm{H}_{2} \mathrm{O}$ with $0.1 \%$ TFA to yield $12.4 \mathrm{mg}$ of a fluffy pale yellow solid after lyophilization (40\% yield over 2 steps). HPLC: R.T. 14.2 min. HRMS $\left[\mathrm{C}_{27} \mathrm{H}_{36} \mathrm{GdN}_{5} \mathrm{O}_{13}+\mathrm{H}\right]^{+}$: Calc. 797.1623, Obs 797.1595. See Figures $\mathrm{S} 1$ and $\mathrm{S} 2$ for HPLC chromatogram and HRMS spectrum, respectively. 
[Gd•DO3A]-mono-(2-(1,3-dioxo-

$1,3,3 a, 4,7,7 a-h e x a h y d r o-2 H-4,7-$ epoxyisoindol-2-yl)ethyl)acetamide, $\quad 26$ :

Tris-carboxylic acid 24 (227.8 $\mathrm{mg}, \sim 0.232$ mmols) was dissolved in deionized water

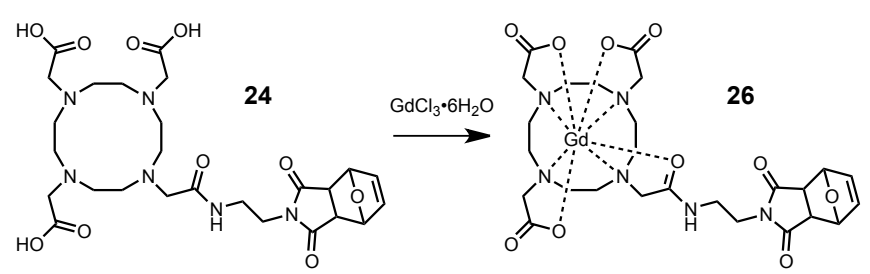
(3.6 mL) and $\mathrm{GdCl}_{3} \cdot 6 \mathrm{H}_{2} \mathrm{O}$ (95 mg, 0.255 mmols, $1.1 \mathrm{eq}$ ) was added. The $\mathrm{pH}$ of the solution was adjusted to 6.8-7 and maintained during the reaction by dropwise addition of $1 \mathrm{~N} \mathrm{NaOH}$. After 30 minutes of stirring, the reaction mixture was condensed in vacuum. The crude product was carried on to the next step without further purification or characterization. ESI-MS: $\left[\mathrm{C}_{26} \mathrm{H}_{35} \mathrm{GdN}_{6} \mathrm{O}_{10}+\mathrm{H}\right]^{+} 750.2$.

\section{[Gd•DO3A]-mono-(2-(N-maleimidyl)ethyl)}

acetamide, 3: Gd-bearing maskedmaleimide 26 (75 mg crude, 0.1 mmols, 1 eq) was suspended in dry toluene $(8 \mathrm{~mL})$ and $200 \mu \mathrm{L}$ HPLC grade DMSO was added.

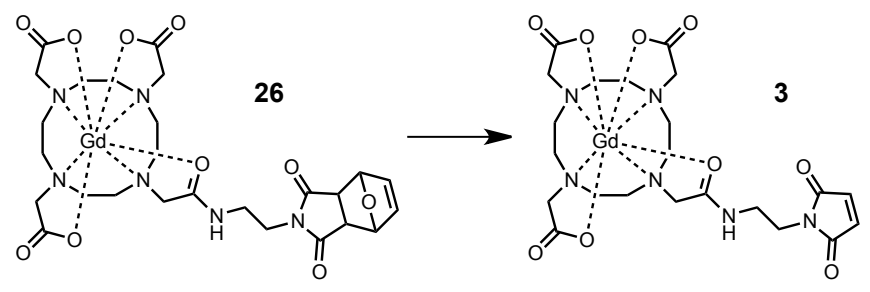
This mixture was heated under a reflux condenser topped with a $\mathrm{CaCl}_{2}$ drying tube at $110-120$ ${ }^{\circ} \mathrm{C}$ for 5 hours. Note: exclusion of DMSO in this reaction results in a very sluggish deprotection, with starting material still detectable my mass spectrometry after 48 hours of heating. A portion of the crude product was purified in $4 \times 20 \mathrm{mg}$ batches by semi-preparative HPLC, eluting for 5 minutes with water containing $0.1 \%$ TFA, followed by a gradient over 15 minutes to $50 \% \mathrm{MeCN} / \mathrm{H}_{2} \mathrm{O}$ with $0.1 \%$ TFA to yield $26 \mathrm{mg}$ of a fluffy white solid after lyophilization (38\% yield over two steps). HPLC: R.T. $11.9 \mathrm{~min}$, compound absorbs strongly at $300 \mathrm{~nm}$, consistent with maleimide structure. $\mathrm{HRMS}\left[\mathrm{C}_{22} \mathrm{H}_{31} \mathrm{GdN}_{6} \mathrm{O}_{9}+\mathrm{H}\right]^{+}$: Calc. 682.1466, Obs 682.1463. See Figures S1 and S2 for HPLC chromatogram and HRMS spectrum, respectively.

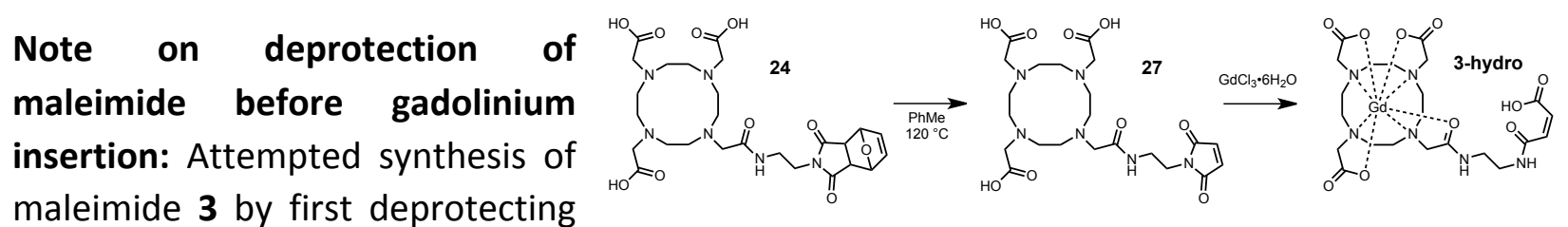
the maleimide moiety by retro-Diels-Alder proved challenging. The resulting DO3A-malemide 27 was capable of chelating gadolinium, using similar ligand exchange conditions as described above, but the resulting product was the hydrolyzed maleimide, or maleamate, as determined by mass spectrometry. The hydrolysis of the pendant maleimide is likely accelerated by the presence of $\mathrm{GdCl}_{3}$ Lewis acid in the reaction mixture. Deprotected linker 27 could be reprotected by Diels-Alder reaction in the presence of an excess of furan. The route shown above was abandoned and deprotection of the maleimide was performed as the final step to produce 3 , avoiding hydrolysis. 
tris-tert-butyl-DO3A-mono-N-(furan-2-

ylmethyl)acetamide, 20: Tris-tert-butyl acetate modified cyclen 10 (149 mg, 0.25 mmols, 1 eq) was dissolved in dry acetonitrile $(4.7 \mathrm{~mL})$ at 22 ${ }^{\circ} \mathrm{C}$, and $\mathrm{NaHCO}_{3}(105 \mathrm{mg}, 1.25$ mmols, 5 eq) was added. Furan 15 (76.3 mg, 0.35 mmols, 1.4 eq)

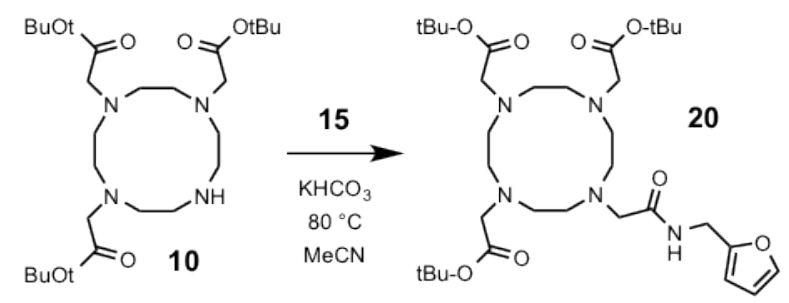
was added and the reaction was heated at $80{ }^{\circ} \mathrm{C}$ under inert atmosphere for 40 hours. The reaction mixture was filtered and condensed. The residue was purified by column chromatography on silica gel, eluting with a gradient from ethyl acetate through $10 \%$ methanol in ethyl acetate to produce $150 \mathrm{mg}$ of a colorless foaming solid (92\% yield) $R_{f} 0.55$ (10\% $\mathrm{MeOH} / \mathrm{DCM}) .{ }^{1} \mathrm{H}$ NMR $\left(500 \mathrm{MHz}, \mathrm{CDCl}_{3}\right) \delta 8.50(\mathrm{t}, \mathrm{J}=5.7,1 \mathrm{H}), 7.08(\mathrm{~m}, 2 \mathrm{H}), 7.02(\mathrm{~d}, \mathrm{~J}=4.3 \mathrm{~Hz}$, $1 \mathrm{H}), 4.22(\mathrm{~s}, 2 \mathrm{H}), 3.53-1.72$ (broad $\mathrm{m}, 23 \mathrm{H}), 1.27$ (overlapping singlets, $27 \mathrm{H}) .{ }^{13} \mathrm{C} \mathrm{NMR}(126 \mathrm{MHz}$, $\left.\mathrm{CDCl}_{3}\right) \delta 172.31,171.68,152.74,140.71,110.07,106.37,81.59,81.53,76.97,56.13,55.52$, $55.44,52.21,48.29,35.86,27.77,27.74$. ESI-MS: $\left[\mathrm{C}_{33} \mathrm{H}_{57} \mathrm{~N}_{5} \mathrm{O}_{8}+\mathrm{H}\right]^{+} 652.4$.

\section{DO3A-mono-N-(furan-2-ylmethyl)}

acetamide, 25: Protected cyclen furan derivative 20 (150 $\mathrm{mg}, 0.23$ mmols, $1 \mathrm{eq}$ ) was dissolved in a 1:1 mixture of trifluoroacetic acid and dichloromethane (9.4 $\mathrm{mL})$ at room temperature in the
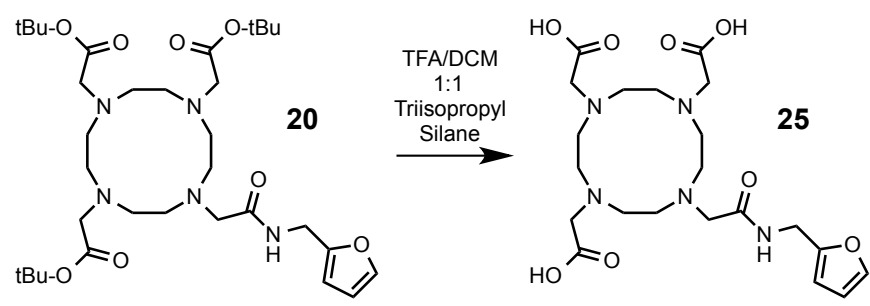
presence of triisopropyl silane ( $304 \mu \mathrm{L}, 1.48 \mathrm{mmols}, 5 \mathrm{eq})$ and stirred under argon for 16 hours. Note: exclusion of triisopropyl silane in this deprotection resulted in degradation of the furan product, producing dark-colored reaction mixtures. The reaction was then condensed under a stream of nitrogen and azeotroped with benzene, methanol, and chloroform in vacuum. The resulting residue was dissolved in minimal methanol and diethyl ether was added to produce $144 \mathrm{mg}$ of an off-white/grey precipitate, which was dried under vacuum, dissolved in $2 \mathrm{~mL}$ water and lyophilized (66\% yield, salt with an average of 2.2 molecules TFA per furan, determined by ${ }^{1} \mathrm{H}$ - and ${ }^{19} \mathrm{~F}$-NMR in the presence of 2,2,2-trifluoroethanol internal standard). ${ }^{1} \mathrm{H}$ NMR $\left(500 \mathrm{MHz}, \mathrm{D}_{2} \mathrm{O}\right) \delta 7.43(\mathrm{~d}, \mathrm{~J}=1.2,1 \mathrm{H}), 6.39(\mathrm{dd}, \mathrm{J}=3.1,2.0,1 \mathrm{H}), 6.30(\mathrm{~d}, \mathrm{~J}=3.1 \mathrm{~Hz}, 1 \mathrm{H})$, 4.35 (s, 2H), 3.76 (bs, 8H), 3.28 (bs, 16H). ${ }^{13} \mathrm{C}$ NMR (126 MHz, D $\left.{ }_{2} \mathrm{O}\right) \delta 171.39,162.68,162.40$, $150.67,142.53,116.17$ (q, ${ }^{C-F} \mathrm{~J}=290$, trifluoroacetate salt), 110.48, 107.39, 54.83, 54.28, 49.47, 35.92. ESI-MS: $\left[\mathrm{C}_{21} \mathrm{H}_{33} \mathrm{~N}_{5} \mathrm{O}_{8}+\mathrm{H}\right]^{+} 484.2$.

[Gd•DO3A]-mono-N-(furan-2-ylmethyl)

acetamide, 4: Tris-carboxylic acid furan 25 (144 mg, 0.233 mmols) was dissolved in deionized water $\left(3.75 \mathrm{~mL}\right.$ ) and $\mathrm{GdCl}_{3} \bullet 6 \mathrm{H}_{2} \mathrm{O}$ (104 mg, 0.28 mmols, $1.2 \mathrm{eq}$ ) was added. The $\mathrm{pH}$ of the solution was adjusted to $6.8-7$ and

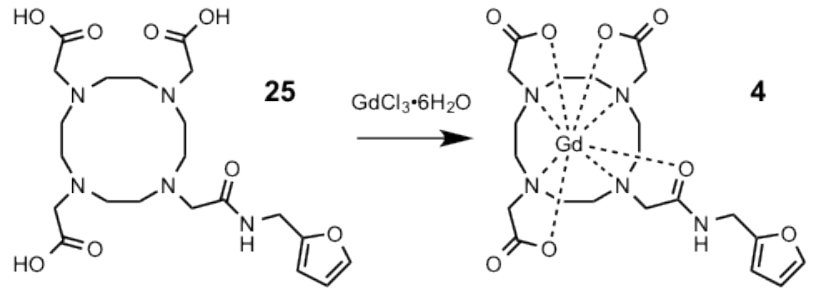


maintained during the reaction by dropwise addition of $1 \mathrm{~N} \mathrm{NaOH}$. After 30 minutes of stirring, the reaction mixture was condensed in vacuum to produce a brown residue. A $17 \mathrm{mg}$ portion of the crude product was purified in 2 batches by semi-preparative HPLC, eluting for 5 minutes with water containing $0.1 \%$ TFA, followed by a gradient over 15 minutes to $50 \% \mathrm{MeCN} / \mathrm{H}_{2} \mathrm{O}$ with $0.1 \%$ TFA to yield $7.4 \mathrm{mg}$ of a fluffy pale yellow solid after lyophilization (43\% yield over 2 steps). HPLC: R.T. 12.0 min. HRMS $\left[\mathrm{C}_{21} \mathrm{H}_{30} \mathrm{GdN}_{5} \mathrm{O}_{8}+\mathrm{H}\right]^{+}$: Calc. 639.1408, Obs 639.1407. See Figures S1 and S2 for HPLC chromatrogram and HRMS spectrum, respectively.

A

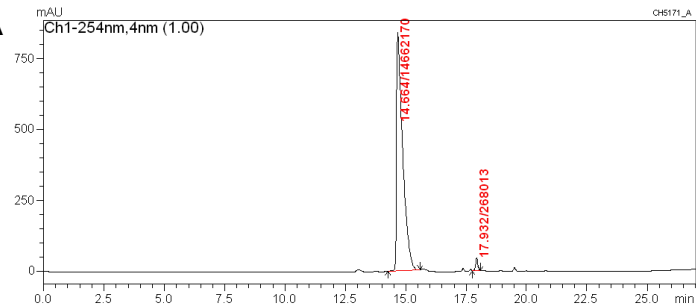

C

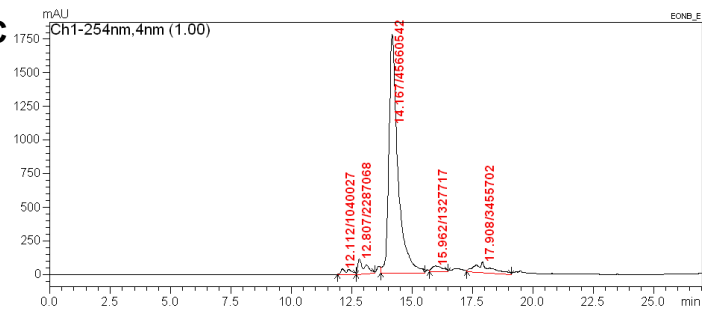

E

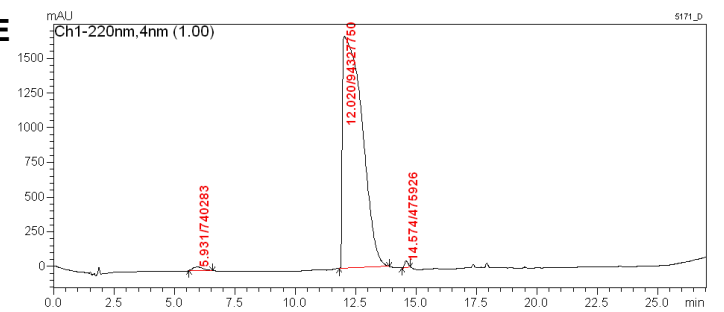

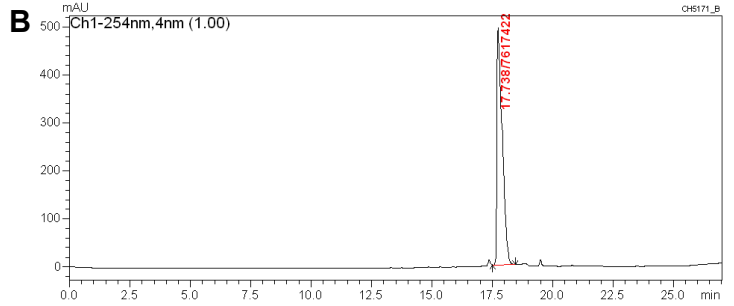

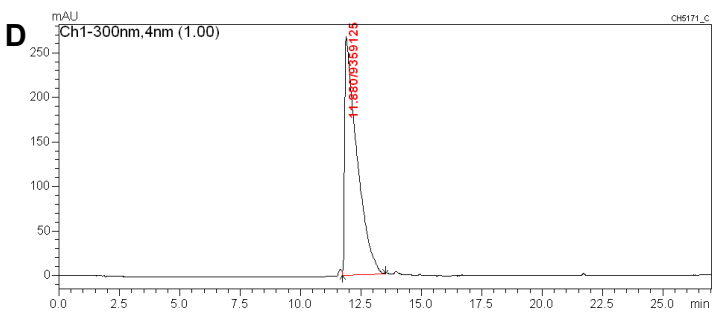

Figure S1. Analytical HPLC traces of a $250 \mu \mathrm{g}$ injection of Gd-OND derivatives, $0-50 \%$ $\mathrm{MeCN} / \mathrm{H}_{2} \mathrm{O}+0.1 \%$ TFA over 15 minutes $(\mathrm{A})=$ 1a, $(B)=1 b,(C)=2,(D)=3,(E)=4$. Note, compound 2 contains small impurity peaks. 

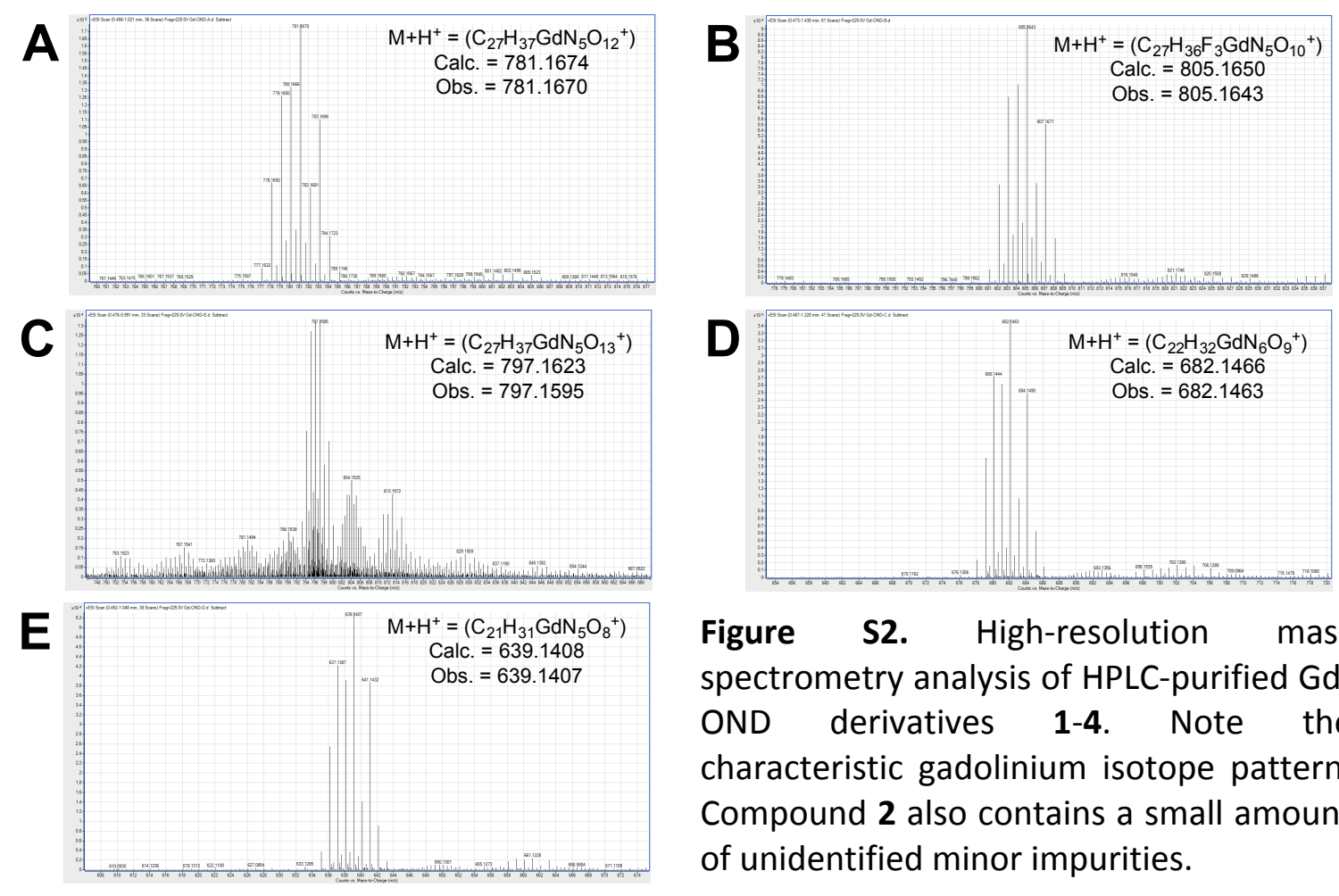

Figure S2. High-resolution mass spectrometry analysis of HPLC-purified GdOND derivatives 1-4. Note the characteristic gadolinium isotope pattern. Compound 2 also contains a small amount of unidentified minor impurities.

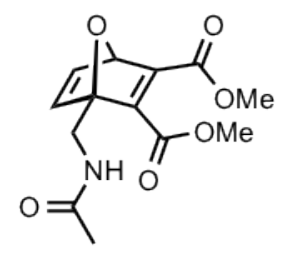

5

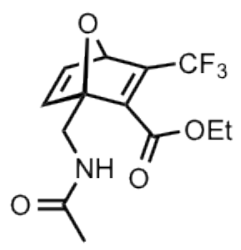

6

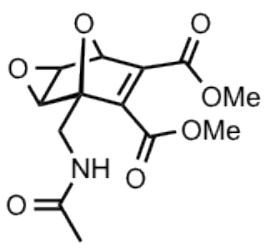

7<smiles>CCN1C(=O)C=CC1=O</smiles>

8<smiles>CC(=O)NCc1ccco1</smiles>

9

Compounds 5, 7, and 9 were prepared as described in references 10-12 of the main text. Nethylmaleimide 8 was purchased. OND 6 was prepared by Diels-Alder reaction of 9 and ethyl 4,4,4-trifluoro-2-butynoate, as described in references $10-11$ of the main text.

Dimethyl 1-(acetamidomethyl)-3,8-dioxatricyclo[3.2.1.0 $0^{2,4}$ ]oct-6-ene-6,7-dicarboxylate, EONB, 7. A vial was charged with previously described3-dimethyl 1(acetamidomethyl)-7-oxabicyclo[2.2.1] hepta-2,5-diene-

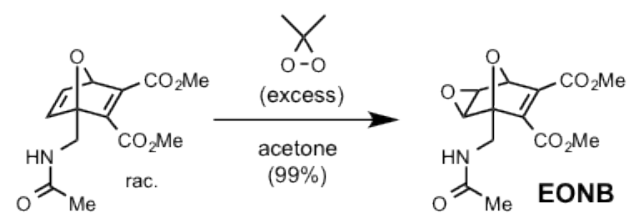
2,3-dicarboxylate (21.5 mg, 0.076 mmols, 1 equiv), and dissolved in $1.5 \mathrm{~mL} \sim 0.07 \mathrm{M}$ solution of DMDO ( 1.1 equiv) in acetone at room temperature. The resulting solution was stirred at room temperature for 4 hours, and then condensed under

3 Kislukhin, A.; Higginson, C.; Hong, V.; Finn, M J. Am. Chem. Soc. 2012, 134, 6491-6497. 
reduced pressure to yield a white solid $\left(22.7 \mathrm{mg}\right.$, quantitative). $R_{f} 0.28$ (EtOAc). ${ }^{1} \mathrm{H}$ NMR (500 $\left.\mathrm{MHz}, \mathrm{CDCl}_{3}\right) \delta 5.87(\mathrm{~s}, 1 \mathrm{H}), 5.09(\mathrm{~s}, 1 \mathrm{H}), 4.06(\mathrm{dd}, \mathrm{J}=14.9,6.3 \mathrm{~Hz}, 1 \mathrm{H}), 3.92(\mathrm{dd}, \mathrm{J}=14.9,5.3 \mathrm{~Hz}$, $1 \mathrm{H}), 3.84(\mathrm{~s}, 3 \mathrm{H}), 3.80(\mathrm{~s}, 3 \mathrm{H}), 3.78(\mathrm{~d}, \mathrm{~J}=3.6 \mathrm{~Hz}, 1 \mathrm{H}), 3.72(\mathrm{~d}, \mathrm{~J}=3.6 \mathrm{~Hz}, 1 \mathrm{H}), 1.98(\mathrm{~s}, 3 \mathrm{H}) .{ }^{13} \mathrm{C}$ $\operatorname{NMR}\left(126 \mathrm{MHz} \mathrm{CDCl}_{3}\right) \delta 170.42,163.13,162.02,149.95,146.89,91.35,78.52,77.48,77.23$, 76.98, 57.30, 56.55, 53.11, 52.89, 37.31, 23.17. FT-IR $\left(\mathrm{cm}^{-1}\right): 3375,2956,1717,1660,1537$, 1435, 1239, 1132, 877. LC-HRMS: $\left[\mathrm{C}_{13} \mathrm{H}_{15} \mathrm{NO}_{7}+\mathrm{H}^{+}\right]$calc: 298.0921 , obs: 298.0927. rt: $3.803 \mathrm{~min}$ $\left(0-90 \% \mathrm{MeCN} / \mathrm{H}_{2} \mathrm{O}\right)$.

\section{Reactions with albumins and small molecules}

III.a. Labeling of isolated rat serum albumin (RSA) in vitro with Gd-modified compounds

Rat serum albumin containing $\sim 0.7$ free thiols per protein was prepared by reduction of a $5 \mathrm{mg} / \mathrm{mL}$ solution in $\mathrm{pH} 7.0$ phosphate buffer with $1 \mathrm{mM}$ DTT for 1 hour. DTT was removed by size-exclusion spin filtration on a 10kDa MWCO Amicon spin filter, followed by 5 rounds of diafiltration. Finally, the sample was concentrated to $\sim 21 \mathrm{mg} / \mathrm{mL}$, as determined by Bradford assay. The thiol content was determined by Ellman's assay. Most samples treated in this manner contained roughly one free thiol per protein. The final thiol content was "diluted" by addition of an appropriate amount of low thiol-content RSA solution at $21 \mathrm{mg} / \mathrm{mL}$.

These RSA solutions were treated with either $3.51 \mathrm{mM}$ or $143 \mu \mathrm{M}$ of 1-4 to simulate the expected concentration of linker in $1 \mathrm{~mL}$ of blood drawn into a syringe, and immediately after injection into a rat with an average mass of $400 \mathrm{~g} .{ }^{39}$ OND stock solutions were prepared in milliQ water immediately prior to use. For simulated pre-injection conditions, samples were incubated at room temperature for 15 minutes prior to chromatography on a PD-10 disposable desalting column equilibrated with milliQ water. For simulated post-injection conditions, plasma samples and OND stock solutions were pre-warmed to $37{ }^{\circ} \mathrm{C}$, and reactions were quenched by size exclusion chromatography after 10 minutes. Roughly $12 \mathrm{~mL}$ of eluate were collected in $0.5 \mathrm{~mL}$ fractions (actual collected volume determined by mass of eluate collected).

The absorbance of each fraction at $280 \mathrm{~nm}$ was measured on a nanodrop 1000 instrument to determine protein concentration. Each fraction was then analyzed by ICP-AES after dilution to 1 $\mathrm{mL}$ volume (final $\mathrm{HNO}_{3}$ concentraion of $2 \% \mathrm{v} / \mathrm{v}$ ) and addition of $10 \mathrm{ppm} \mathrm{Y}$ internal standard. Protein concentration and gadolinium concentration were plotted against elution volume (Figure S3 and Figures 3-4 in main text). 
Figure

Chromatograms

reactions of RSA (20 $\mathrm{mg} / \mathrm{mL}$ ) with Gd-OND derivatives $\mathbf{1 a}, \mathbf{1 b}$, and $\mathbf{4}$ (3.51 mM) after 15 minutes at $23{ }^{\circ} \mathrm{C}$. [RSA] was estimated from $\mathrm{Abs}_{280}$ values and [Gd] was determined by ICPAES of collected fractions. Note that a small $\mathrm{Abs}_{280}$ peak at $\sim 3-4 \mathrm{~mL}$ is contributed by linkers 1a and $\mathbf{1 b}$ at the concentrations used in this experiment.

S3.

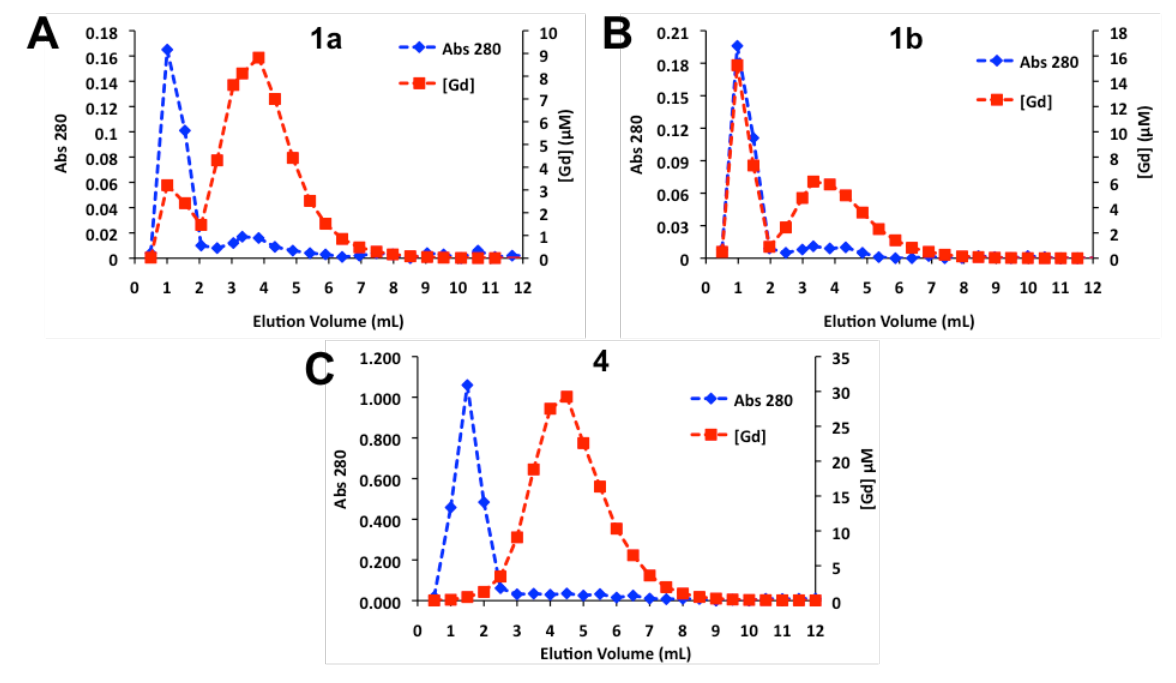

\section{III.b. Release of Gd cargo from RSA labeled in vitro}

RSA samples treated with $\mathbf{1 a}, \mathbf{1} \mathbf{b}$, and $\mathbf{3}$ were incubated at $37{ }^{\circ} \mathrm{C}$ in a sealed tube in the dark. Periodically, $100 \mu \mathrm{L}$ aliquots were removed and purified by size-exclusion chromatography as described above and the entire $2 \mathrm{~mL}$ protein fraction was pooled and analyzed for [Gd] by ICP-AES.

IV.c. Labeling of thiol-depleted bovine and rat serum albumins, $N$-acetyl cysteine, and aminocaproate with fluorogenic OND linkers

Thiol-free RSA and BSA were prepared by alkyation with $\mathrm{N}$-ethylmaleimide, followed by purification by size exclusion. Mercaptalbumin samples were generated by brief reduction with DTT, followed by size exclusion. Thiol content was determined by Ellman's assay, and protein concentration was determined by Bradford assay (Coomassie stain). Reactions were carried out in 96-well plates with three previously described fluorogenic OND electrophiles S3-S5 (Figure S4).

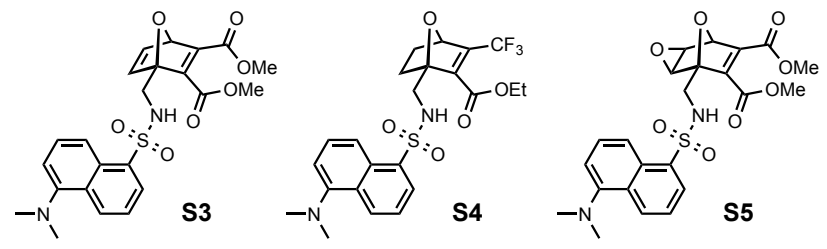

Figure S4. Fluorogenic electrophiles. Diester S3, trifluoromethylated linker S4, and epoxyoxanorbornene (EONB) S5. 
Aqueous solutions of RSA at $69 \mu \mathrm{M}, \mathrm{BSA}$ at $68 \mu \mathrm{M}$, or other nucleophiles in phospate buffer (pH 7.0-7.4) at room temperature were added to $4 \mathrm{mM}$ stocks of fluorogenic ONDs in DMSO to a final [OND] of $100 \mu \mathrm{M}$. The fluorescence of the reaction mixture was monitored with excitation at $332 \mathrm{~nm}$ and emission at $550 \mathrm{~nm}$ every 30 seconds for 3-4 hours. Reactions with aminocaproic acid contained $47.5 \mathrm{mM}$ of the amine to allow monitoring of this slow conjugate addition on experimentally practical time-scales. The fluorescence intensity at each time point was corrected to a reaction mixture containing no nucleophile, and the values were normalized to the fluorescence observed at full conversion of the OND. Adducts of aminocaproate were assumed to have fluorescence properties similar to the thiol adducts when calculating fractional conversion. The increase in fluorescence over time was graphed (Figure S5 for protein labeling and Figure S6 for $\mathrm{N}$-acetylcysteine and aminocaproic reactions) and the data was fit to the second order rate equation using the method of least squares to obtain $k_{\text {obs }}$ values shown in Figure S5 and Table S1.
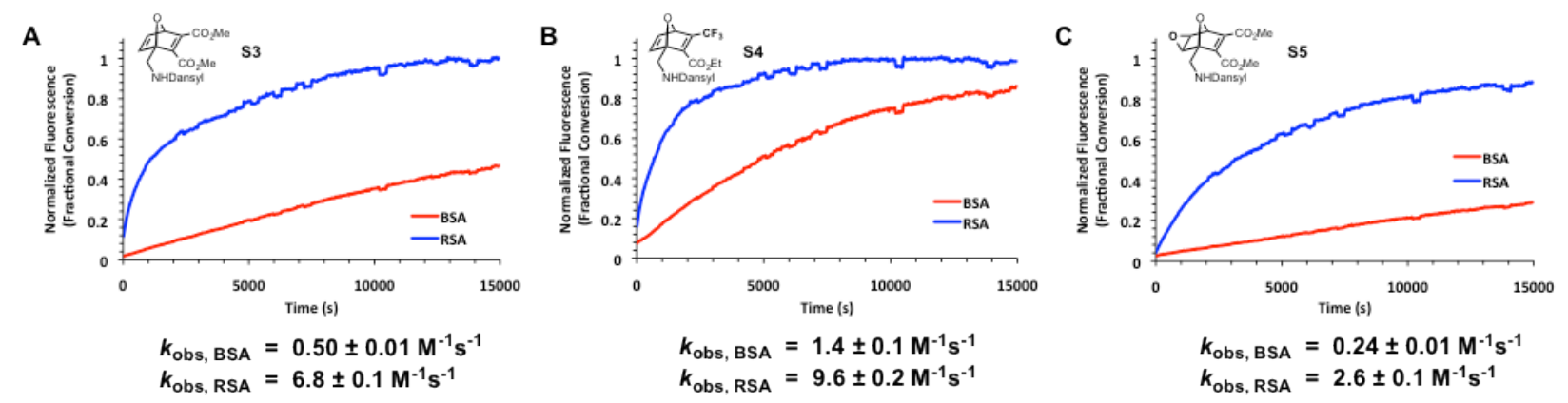

Figure S5. Reaction of fluorogenic ONDs S3-S5 $(100 \mu \mathrm{M})$ with BSA and RSA (65 $\mu \mathrm{M}$, previously capped with $\mathrm{N}$-ethylmaleimide) in $\mathrm{pH} 7.0$ phosphate buffer at $22{ }^{\circ} \mathrm{C}$.
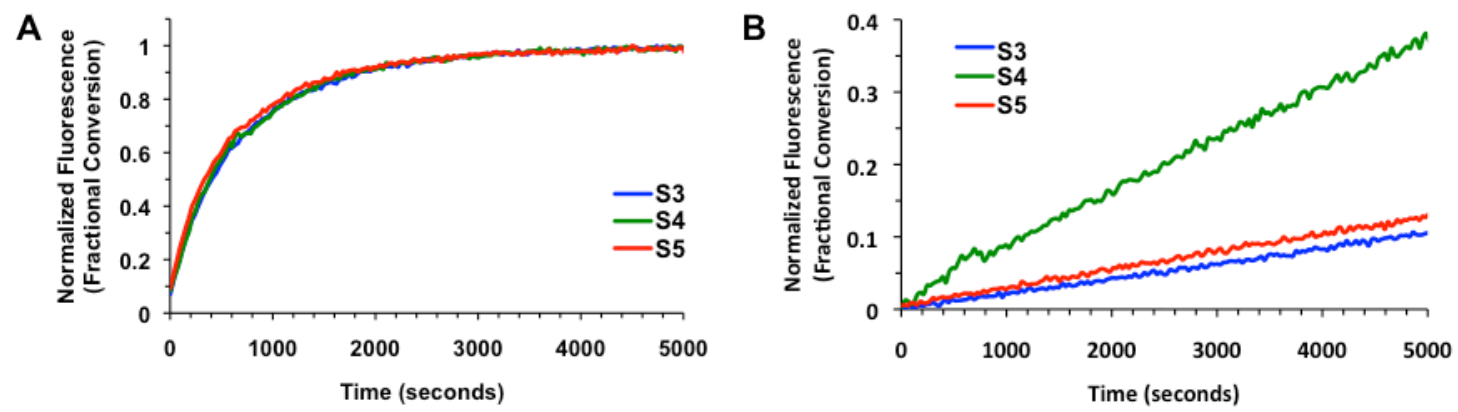

Figure S6. Comparison of reactivity of ONDs S3-S5 $(50 \mu \mathrm{M})$ with N-acetylcysteine $(95 \mu \mathrm{M})$ and aminocaproic acid (50 mM). Reactions carried out at $\mathrm{pH} 7.4$ and $22^{\circ} \mathrm{C}$. 
We have previously observed that thiol-depleted bovine serum albumin reacts readily with OND 1. In contrast, no appreciable reaction was observed with the 720 solvent-exposed lysines on wild-type $Q b$ virus like particles in an independent experiment performed by Fiedler and collegues. ${ }^{30}$ It is clear that the rate of reaction of ONDs with protein amines is context dependent. OND reactivity with rat and bovine serum albumins was investigated as a representative comparison. A panel of previously described fluorogenic OND derivatives S3-S5 was selected to compare the reactivity of three main classes of OND electrophiles: diesters, trifluoromethylated linkers, and non-cleavable epoxyoxanorbornene (EONB) linkers (Figure S4).

Incubation of thiol-free samples of RSA and BSA with fluorogenic ONDs revealed a distinct trend: the reaction with RSA was faster than with BSA for all three ONDs. Additionally, trifluoromethylated linker S4 reacted much faster than either linker S3 or S5 (Figure S5). This is consistent with the lower kinetic selectivity toward thiols exhibited by the trifluoromethylated OND in reactions with RSA.

To determine whether the higher reactivity of linker $\mathbf{S 4}$ toward amine nucleophiles is specific for serum albumins, S3-S5 were incubated with small-molecule nucleophiles Nacetylcysteine (NAC) and 6-aminocaproic acid at $\mathrm{pH}$ 7.0. Comparable rate constants were observed for reaction with NAC for each of the linkers, but linker S4 again exhibited a faster rate of reaction with amines than OND S3 and EONB S5 (Figure S6, Table S1). This is consistent with the hypothesis that trifluromethylated ONDs are more reactive toward amines than OND diester derivatives.

Table S1. Rates of reaction of ONDs S3-S5 with N-acetyl cysteine and aminocaproic acid.

$\begin{array}{cccc}\text { OND } & \begin{array}{c}\boldsymbol{k}_{\text {obs thiol }} \\ \left(\mathbf{M}^{-1} \mathbf{s}^{-1}\right)\end{array} & \begin{array}{c}\boldsymbol{k}_{\text {obs amine }} \\ \left(\mathbf{M}^{-1} \mathbf{s}^{-1}, \mathbf{1 0}^{-4}\right)\end{array} & \boldsymbol{k}_{\text {Nu thiol }} / \boldsymbol{k}_{\text {Nu amine }}{ }^{a} \\ \text { S3 } & 29.4 \pm 0.2 & 6.7 \pm 0.1 & 2231 \\ \text { S4 } & 29.8 \pm 0.8 & 19 \pm 1 & 776 \\ \text { S5 } & 34.0 \pm 2.2 & 6.3 \pm 0.3 & 2597\end{array}$

${ }^{a}$ Observed rate constants scaled based on reported pKa of the nucleophilic group in question (9.52 for $\mathrm{N}$-acetylcysteine thiol, 10.8 for aminocaproate primary amine). ${ }^{3-4}$

3 Tournier, E. J. M.; Wallach, J.; Blond, P. Anal. Chim. Acta 1998, 361, 33.

${ }^{4}$ Luo, R.; Head, M. S.; Moult, J.; Gilson, M. K. J. Am. Chem. Soc. 1998, 120, 6138. 


\section{Degradation of model adducts}

\section{Calculation of half-lives of model adducts by ${ }^{1} \mathrm{H}-\mathrm{NMR}$}

To determine of the stability of thiol and amine adducts of representative ONDs in aqueous media at $37{ }^{\circ} \mathrm{C}$, beta-mercaptoethanol and ethanolamine adducts of trifluoromethylated and dimethyl ester ONDs were prepared. The appearance of furan peaks, and the disappearance of the alkene peak of the corresponding adduct were monitored, and $\ln \left(1 /\right.$ fraction adduct remaining) was plotted against time to produce $1^{\text {st }}$-order kinetic plots (Figure S7). These plots were linear over the entire course of degradation monitored. For amine adducts of the trifluoromethylated OND, only a small amount of fragmentation was observed over the course of the experiment ( 300 hours).
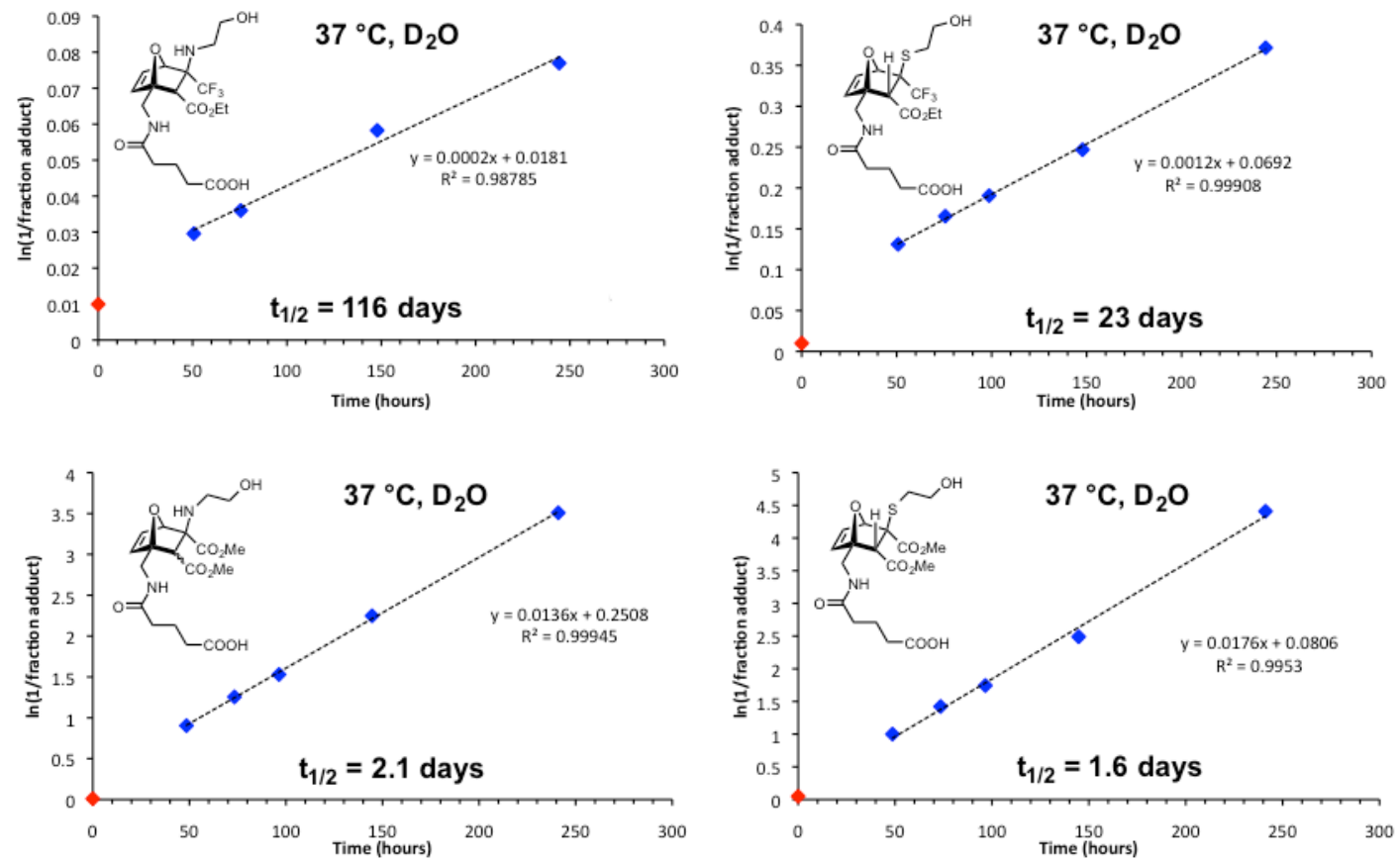

Figure S7. First-order kinetic plots for retro-Diels-Alder fragmentation of ethanolamine and beta-mercaptoethanol adducts in $\mathrm{D}_{2} \mathrm{O}$ at $37^{\circ} \mathrm{C}$ by NMR.

\section{Stability of OND derivatives in rat plasma}

\section{V.a. Additional Experiments}

In order to probe the contribution of esterases to the decline in linker concentration in fresh rat plasma, the experiment described in the main text (Figure 6) was repeated in heatinactivated ( $\mathrm{HI}$ ) serum (Figure S8). In this plasma sample, the activity of plasma hydrolases is 
significantly diminished by prolonged incubation of the sample at $57{ }^{\circ} \mathrm{C}$. For both linkers 5 and 7, a marked increase in stability was observed ( $t_{1 / 2}=19$ mins vs. 3.2 mins for 5 , and 13 mins vs. 1.2 mins for 7 (Figure S8, A-C and Table S3). There was very little change in stability of linker 6, with an observed $t_{1 / 2}$ of 3.7 mins vs. 4.5 mins in HI plasma and untreated plasma, respectively.

Further comparison of stability of 5-7 at limiting concentrations of electrophile reveal a similar trend (Figure S8, D-F). Compounds $\mathbf{5}$ and $\mathbf{7}$ are extremely short-lived in plasma preparations containing active esterases, and after pre-saturation of albumin thiols with iodoacetamide. Heat inactivation of hydrolases leads to an increase in the half-life of $\mathbf{5}$ and 7. In contrast, 6 was consumed quickly in heat inactivated plasma samples, and disappeared more slowly in plasma samples that had been pre-saturated with iodoacetamide. This observation is consistent with the rapid reaction of 6 with a combination of serum albumin thiol and amine nucleophiles, and parallels the observed reactivity of linker $\mathbf{1 b}$ with thiol-rich and thiol-depleted RSA (Figures 3c and 4c, main text). A slight increase in stability of 6 in samples that have been both over-saturated and heat-inactivated $(\mathrm{HI}+\mathrm{OS})$ compared to OS plasma indicates that there is a modest amount of linker consumption that may be due to the action of plasma hydrolases. The observed half-lives of linkers under the various conditions tested are summarized in Table S2.
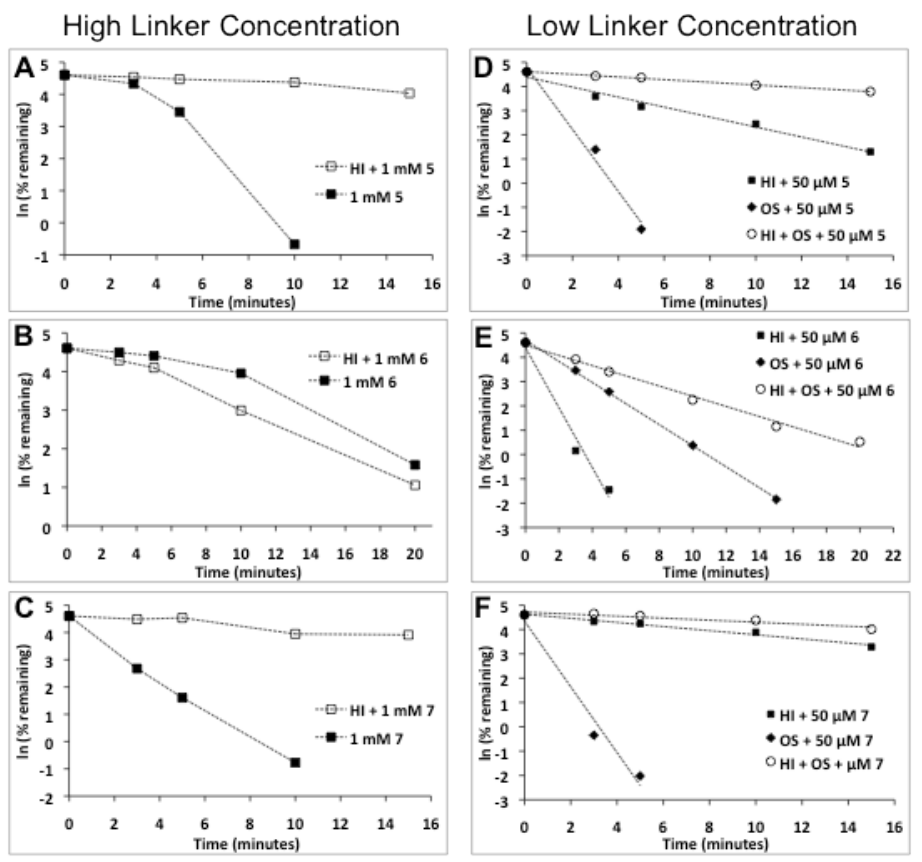

Figure S8. Stability of linkers 5-7 in plasma at $1 \mathrm{mM}$ and $50 \mu \mathrm{M}$ under various conditions at $37^{\circ} \mathrm{C}$. Plasma was heat inactivated $(\mathrm{HI})$ to reduce esterase activity, oversaturated (OS) with iodoacetamide to cap thiol electrophiles, or both (HI+OS) prior to addition of electrophiles 5-7 (A-C) Stability of linkers $\mathbf{5 - 7}$, respectively, at $1 \mathrm{mM}$. Dotted lines serve as a visual guide. (D-F) First-order plots for stability of linkers 5-7, respectively, at $50 \mu \mathrm{M}$. Dotted lines represent linear fits of data. 
Table S2. Half-lives of OND Derivatives in Rat Plasma.

\begin{tabular}{|c|c|c|c|c|c|}
\hline \multirow[b]{3}{*}{ Linker } & \multicolumn{5}{|c|}{ Half-life, $t_{1 / 2}$ (minutes) $^{a}$} \\
\hline & \multicolumn{2}{|c|}{ [Linker] = $1 \mathrm{mM}$} & \multicolumn{3}{|c|}{ [Linker] = $50 \mu \mathrm{M}$} \\
\hline & Untreated $^{b}$ & $\mathrm{HI}^{c}$ & $\mathrm{HI}^{c}$ & $\mathrm{OS}^{d}$ & $\mathrm{HI}+\mathrm{OS}^{e}$ \\
\hline 5 & 3.2 & 19 & 3.0 & 0.5 & 12.6 \\
\hline 6 & 4.5 & 3.7 & 0.4 & 1.6 & 3.3 \\
\hline 7 & 1.2 & 13 & 8.1 & 0.5 & 16.7 \\
\hline
\end{tabular}

${ }^{\mathrm{a}}$ Determined from $\mathrm{t} 1 / 2=-\ln (2)$ /slope of lines observed in 1st-order kinetic plots shown in Figure 6 (main text). ${ }^{\mathrm{b}}$ Freshly isolated rat plasma. ${ }^{\mathrm{C}}$ Rat plasma heated at $57^{\circ} \mathrm{C}$ for 1 hour to deactivate serum esterases. ${ }^{d}$ Rat plasma treated with a large excess of iodoacetamide to cap nucleophilic thiols. ${ }^{\mathrm{e}} \mathrm{Heat}$ inactivated rat plasma treated with an excess of iodoacetamide to cap nucleophilic thiol sites.

\section{V.b. Plasma Stability Methods}

The in vitro stability of the test compounds was studied in rat plasma. The reactions were initiated by the addition of the test compounds to $0.5 \mathrm{~mL}$ of preheated plasma solution (initial compound concentration of $1 \mathrm{mM}$, final DMSO concentration $=2.0 \%$ ). Samples $(50 \mu \mathrm{l}$ ) were taken at 0, 3, 5, 10, and 30 min for compounds 5, 6 and 7 and at 0, 5, 10, 20, and 30 min for compounds 8 and $\mathbf{9}$, and added to $200 \mu$ lacetonitrile containing internal standard $(0.1 \mu \mathrm{M}$ dextrophan). The samples were centrifuged $\left(4^{\circ} \mathrm{C}\right.$ for $3 \mathrm{~min}$ at $\left.3000 \mathrm{~g}\right)$ through a filter plate (MultiScreen ${ }^{\circledR}$ Solvinert, $0.45 \mu \mathrm{m}$ low-binding hydrophilic, EMD Millipore). The samples were analyzed by LC-MS/MS (AB SCIEX Triple Quad ${ }^{\text {TM }}$ 5500, Framingham, MA). A 5-minute chromatographic separation was performed at $40^{\circ} \mathrm{C}$, and an aliquot $(5 \mu \mathrm{l})$ of the sample was injected into a Phenomenex Kinetex ${ }^{\mathrm{TM}}$ XB-C18, $100 \AA$ (2.6 $\left.\mu \mathrm{m} \times 50 \times 2.1 \mathrm{~mm}\right)$ column with an aqueous mobile phase containing $0.1 \%$ formic acid (solvent- $A$ ) and $A C N$ with $0.1 \%$ formic acid (solvent-B) run at a flow rate of $0.4 \mathrm{~mL} / \mathrm{min}$. Linear gradients were used as follows: $0-1 \mathrm{~min}$ at $10 \% \mathrm{~B}, 1-2.0 \mathrm{~min}$ to $95 \% \mathrm{~B}, 2.0-2.5 \mathrm{~min}$ at $95 \% \mathrm{~B}, 2.5-3.5 \mathrm{~min}$ to $10 \% \mathrm{~B}$ and $3.5-5 \%$ at $10 \% \mathrm{~B}$. Mass transitions were used to detect the OND derivatives and were as follows, $\mathbf{5}(\mathrm{m} / \mathrm{z}$ 282.1 $\rightarrow 208$, dp $45 \mathrm{eV}$ and CE $12 \mathrm{eV}), \quad 6(\mathrm{~m} / \mathrm{z}$ 306.3 $\rightarrow 264$ dp $100 \mathrm{eV}$ and CE $18 \mathrm{eV}), 7$ (m/z 298.2 $\rightarrow 192$, dp $90 \mathrm{eV}$ and CE $26 \mathrm{eV}), 8$ (m/z 140.7 $\rightarrow 80.9$, dp $50 \mathrm{eV}$ and CE $12 \mathrm{eV}), 9$ (m/z 126.3 $\rightarrow 98.1$, dp $80 \mathrm{eV}$ and CE $13 \mathrm{eV}$ ). The optimized dp and CE were $58 \mathrm{eV}$ and $38 \mathrm{eV}$ for dextrophan, respectively. The in vitro plasma half-life $\left(t_{1 / 2}\right)$ was calculated using the expression 
$t_{1 / 2}=0.693 / b$, where $b$ is the slope found in the linear fit of the natural logarithm of the fraction remaining of the parent compound vs. incubation time.

V.c. Detection of hydrolysis products by LC-MS/MS

The masses of predicted hydrolysis products for compounds 5, 6, 7, and 8 were detected in rat plasma after incubation of $1 \mathrm{mM}$ (initial concentration) of these linkers at $37^{\circ} \mathrm{C}$ by LCMS/MS (Q Exactive hybrid quadrupole-Orbitrap mass spectrometer, Thermo Fisher Scientific, Waltham, MA, USA) equipped with a Phenomenex Kinetex ${ }^{\mathrm{TM}}$ EVO-C18, $100 \AA$ (5 $\mu \mathrm{m} \times 150 \times 2.1$ $\mathrm{mm}$ ) column. The flow rate and column temperature was set at $0.5 \mathrm{~mL} / \mathrm{min}$ and $40^{\circ} \mathrm{C}$ respectively. Buffer $A(0.1 \%$ FA in water) and buffer $B(0.1 \%$ FA in $A C N)$ were used as mobile phases for gradient separation which was as follows: 0-1 min at 5\% B, 1-12.0 min to $90 \%$ B, 12.0-14.5 $\mathrm{min}$ at $90 \% \mathrm{~B}, 14.5-14.6 \mathrm{~min}$ to $5 \% \mathrm{~B}$ and $14.6-19 \%$ at $5 \% \mathrm{~B}$. Time points and incubation conditions are the same as described in the stability of OND derivatives section.

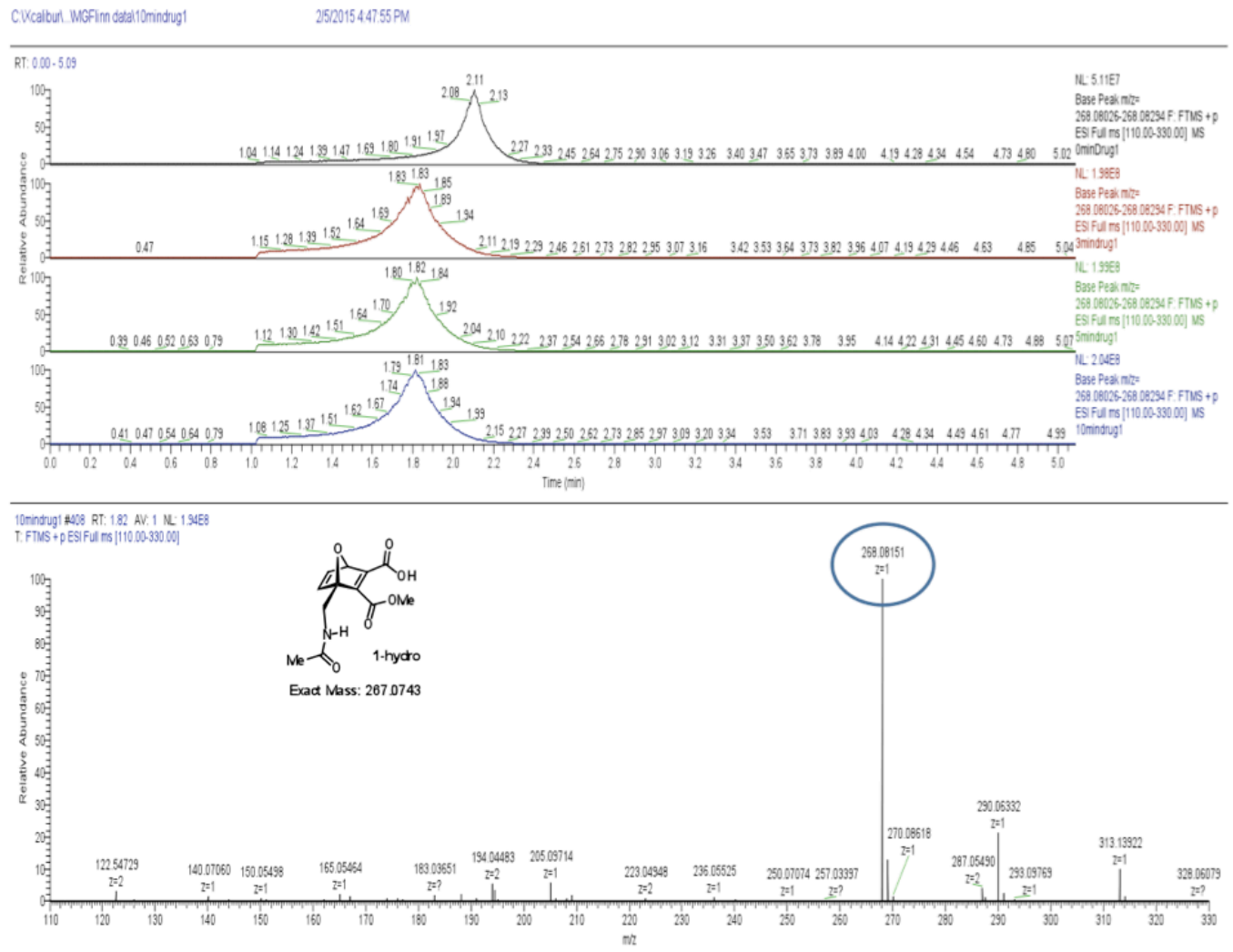

Figure S9. Detection of ester hydrolysis product of linker 5 by LC-MS/MS 


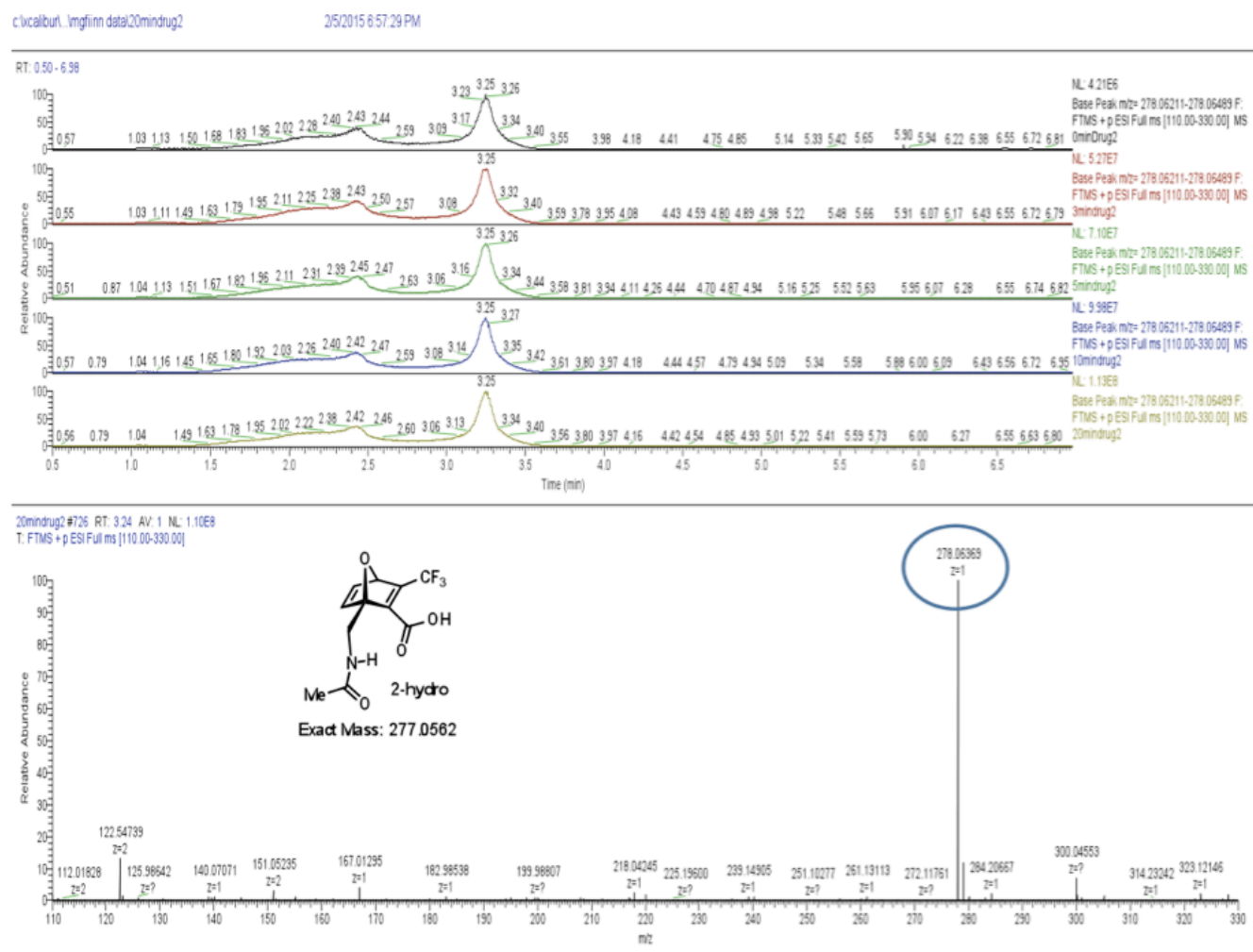

Figure S10. Detection of ester hydrolysis product of linker 6 by LC-MS/MS/
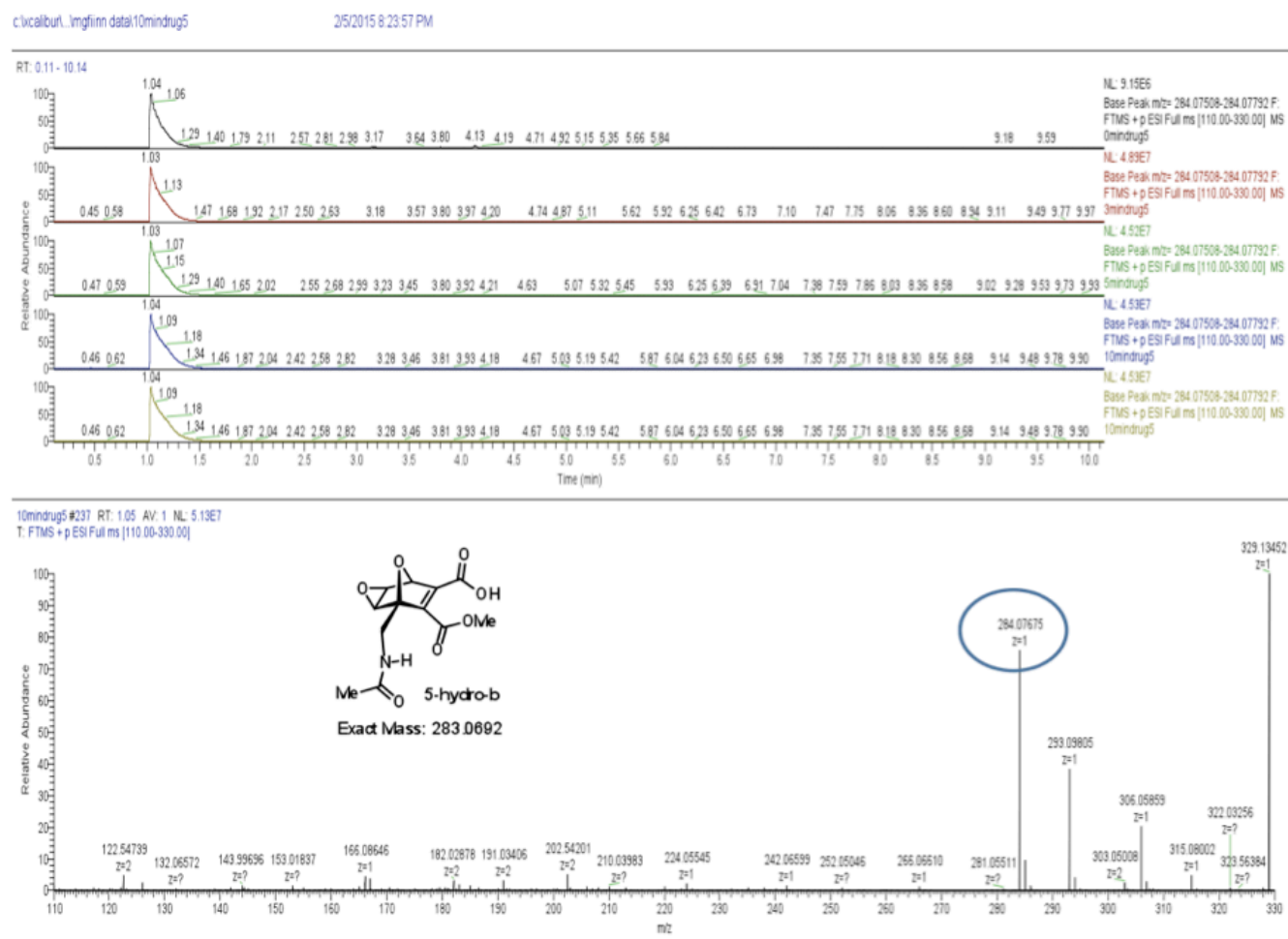

Figure S11. Detection of ester hydrolysis product of linker 7 by LC-MS/MS. 


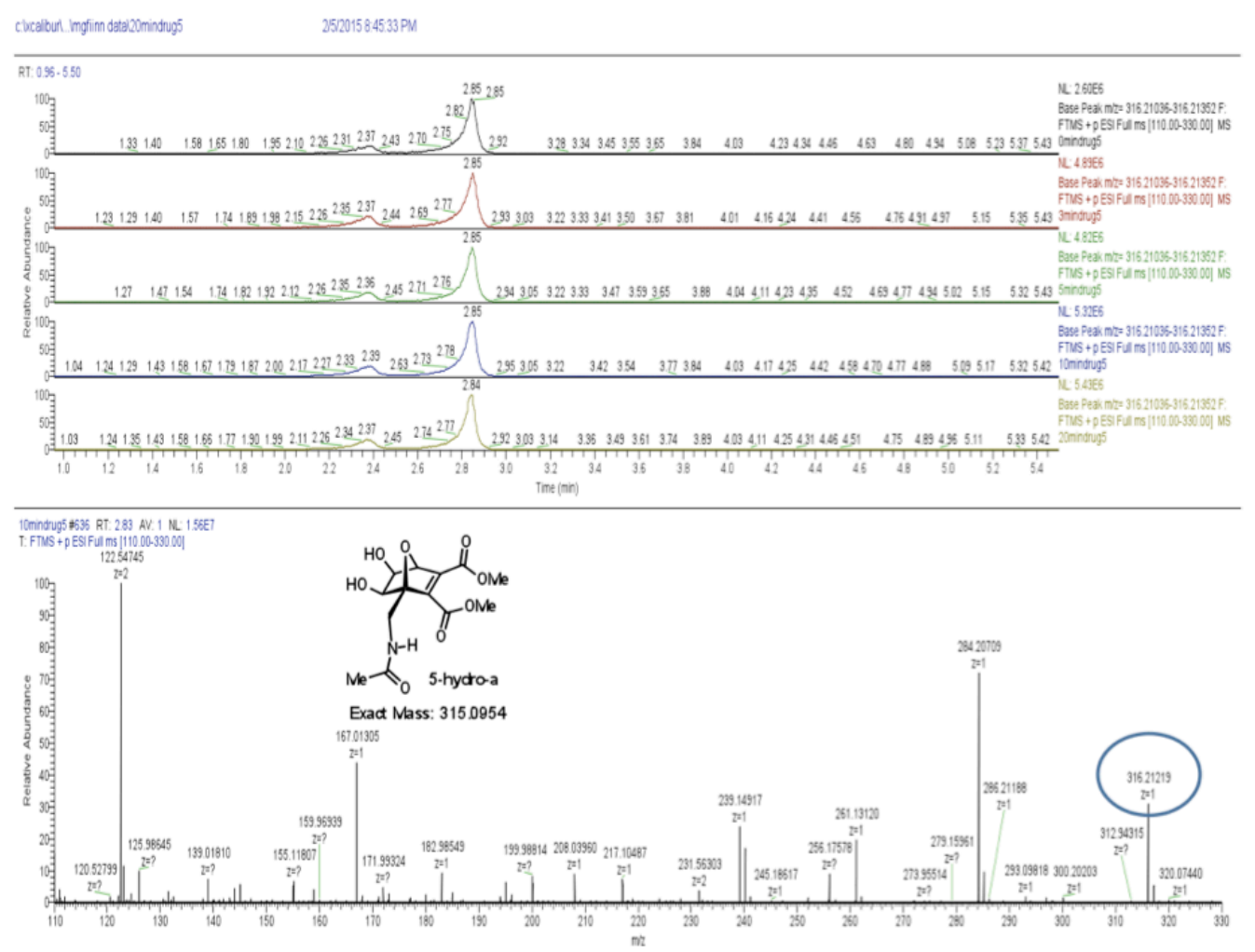

Figure S12. Potential epoxide hydrolysis product of linker 7 by LC-MS/MS. Mass of circled peak differs from predicted mass by $>0.1 \mathrm{~m} / \mathrm{z}$

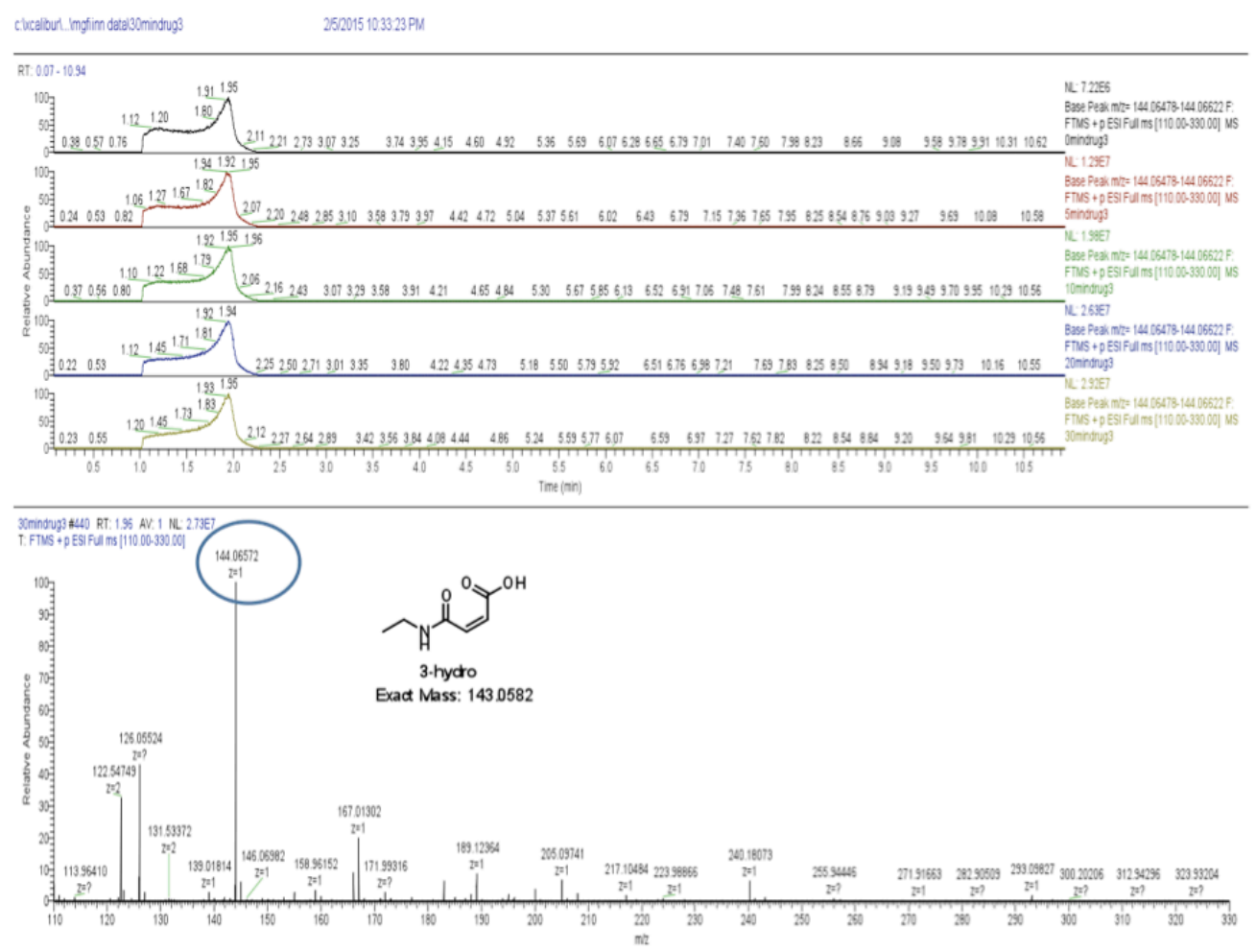

Figure S13. Detection of maleimide hydrolysis product of linker 9 by LC-MS/MS. 


\section{Pharmacokinetics of Gd-OND derivatives in rats}

\section{VI.a. Injection and sampling protocol}

Rat handling and blood collection were performed in the laboratory of Dr. Michael Cameron (Scripps Florida PK/PD Lab). Solutions of Gd-OND and derivatives 1-4 were dissolved in phosphate buffered saline. Juvenile Sprague-Dawley rats of known mass were anesthetized and a quantity of linker solution providing a dose of $10 \mu \mathrm{mol} / \mathrm{kg}$ was drawn into a heparintreated syringe. Approximately $1 \mathrm{~mL}$ of blood was withdrawn into the syringe containing the compounds and incubated at room temperature for 15 minutes prior to reinjection into the animals over 5 minutes. Blood samples ( 250 $\mu \mathrm{L})$ were collected post-injection via jugular vein at 5 minutes, 1, 2, 4, 8, 12, 24, 48, and 96 hours. Blood samples were flash frozen and stored at $-20{ }^{\circ} \mathrm{C}$ until digestion.

\section{VI.b. Digestion of blood samples for analysis by ICP-AES}

Blood samples were removed from $-20^{\circ} \mathrm{C}$ and thawed at $4{ }^{\circ} \mathrm{C}$ to minimize coagulation during handling. Samples were transferred to tared microwave reactor vials $(0.5-2 \mathrm{~mL}$ capacity conical), and the mass of blood was weighed. A stir bar was added, followed by $300 \mu \mathrm{L}$ of trace metals-free concentrated nitric acid. The sample coagulated immediately. The vessel was sealed and heated in a microwave reactor while stirring at $150{ }^{\circ} \mathrm{C}$ for 40 seconds (very high absorber setting). A fraction of the resulting clear yellow solution was diluted to $1 \mathrm{~mL}$ with milliQ water with 10 ppm yttrium internal standard added. The appearance of blood samples at various stage of digestion is shown for demonstration in Figure S14. Each sample was centrifuged at $10,000 \times \mathrm{g}$ for 10 minutes prior to analysis to avoid clogging of ICP-AES sample uptake tubing and nebulizer.
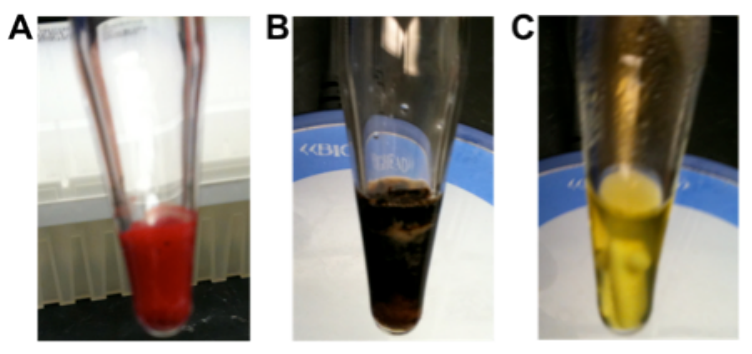

Figure S14. Appearance of blood samples at different stages of the digestion procedure. (A) Blood after thawing at $4{ }^{\circ} \mathrm{C}$; (B) Sample after addition of concentrated nitric acid; (C) Sample after microwave digestion, pre-dilution for ICP-AES analysis. Note stir bar is visible in the cleared digest. 
Samples were analyzed by ICP-AES by direct aspiration of samples, with sufficient sample rinse time to minimize sidewall contamination from sample to sample ( 2 minutes between samples). Rinsing was performed with milliQ water. Gadolinium concentration was determined by interpolation to a standard curve generated with samples prepared in diluted phosphate buffered saline (to simulate high ionic strength of tissue digests). Internal standard was included in samples to detect changes in flow and partial clogging of sample uptake lines, as well as to detect errors in sample preparation.
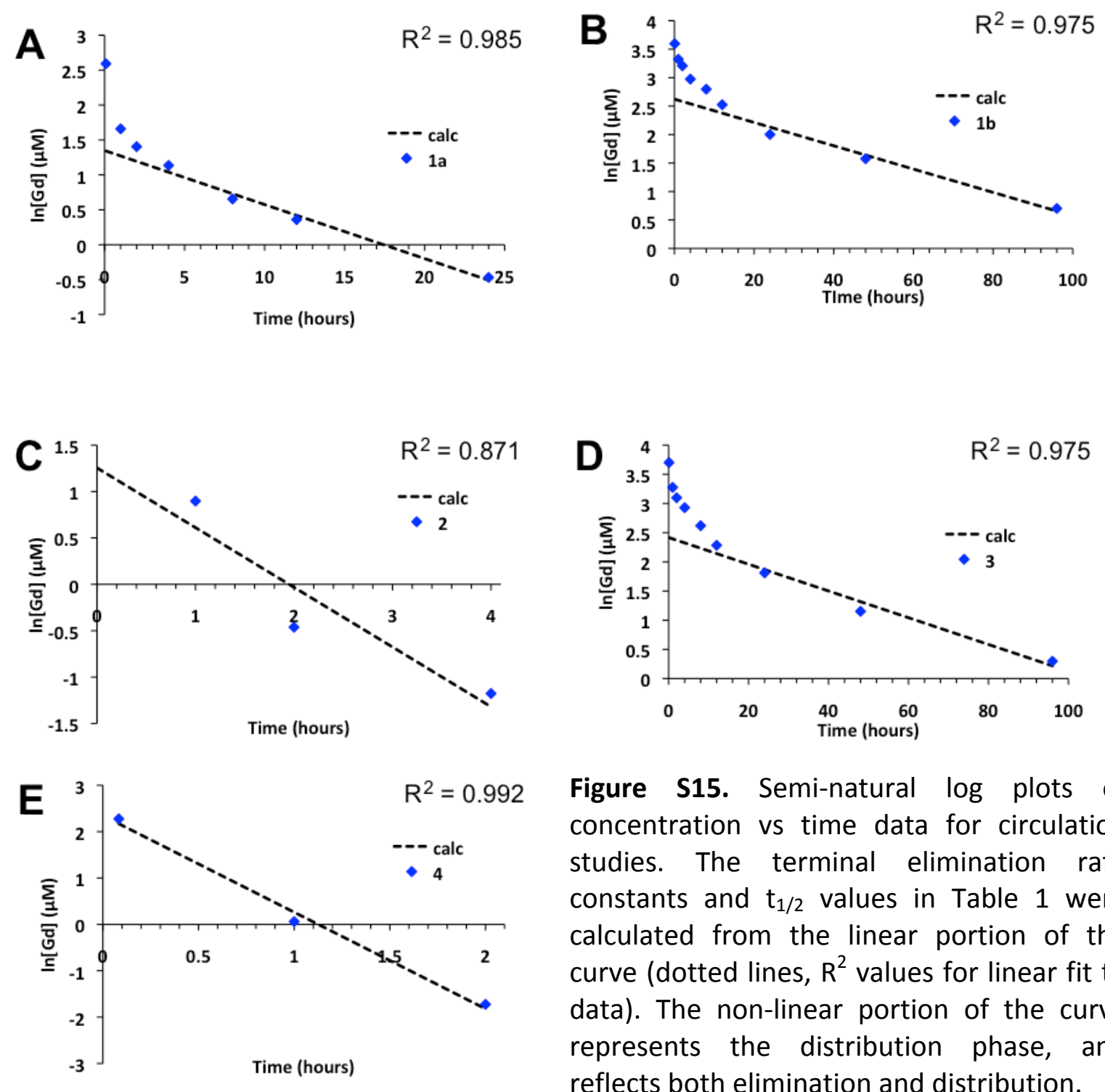

Figure S15. Semi-natural log plots of concentration vs time data for circulation studies. The terminal elimination rate constants and $t_{1 / 2}$ values in Table 1 were calculated from the linear portion of the curve (dotted lines, $R^{2}$ values for linear fit to data). The non-linear portion of the curve represents the distribution phase, and reflects both elimination and distribution. 


\section{VI.c. Calculation of terminal elimination rate constants and half-lives}

The natural log of the observed concentration of $\mathrm{Gd}$ in blood was plotted against time to produce the $1^{\text {st }}$ order plots below. The initial non-linear portion of the curve is assigned as the distribution phase, and the linear portion of the curve is the elimination phase (Figure S15 below). The slope of the line of best fit for the linear section was assigned as the elimination rate constant. The lines were plotted by fitting the observed data to $[G d]=[G d]_{0}-e^{-k t}$. Half-lives were calculated as $t_{1 / 2}=\ln (2) / k$.

\section{Analysis of labeled albumin by mass spectrometry}

VII.a. Model peptide incubation with linkers

Linkers 1a, 1b and $3(100 \mu \mathrm{M})$ were incubated with $20 \mu \mathrm{M}$ model peptide (CSYDEHAK, corresponding to AA 58-65) from mouse serum albumin in 50mM ammonium bicarbonate buffer for 1 hour at $37^{\circ} \mathrm{C}$. TCEP (1 mM) was added to prevent the formation of disulfide bonds between the peptide.

\section{VII.b. Rat plasma protein digestion}

For digestion of proteins from rat plasma, protein concentrations were determined using the bicinchoninic acid assay kit (Pierce, Rockford, IL). Rat plasma protein (200 $\mu \mathrm{g}$ ) was reduced with $4 \mathrm{mM}$ TCEP for $15 \mathrm{~min}$ at room temperature and alkylated with $10 \mathrm{mM}$ iodoacetamide for $20 \mathrm{~min}$ at room temperature in the dark. Proteins were digested with lysc/trypsin (Mass spectrometry grade; Promega, Madison, WI) at 1:100 (w/w) for 3 hours at $37^{\circ} \mathrm{C}$ followed by another addition of lys-c/trypsin 1:50 (w/w) for an overnight digest. Digestion was terminated by the addition of trifluoroacetic acid to a final concentration of $0.5 \%$, and samples were concentrated in a vacuum centrifuge.

\section{VII.c. LC-MS/MS Analyses and Identification of adducts.}

Digested samples from rat plasma were analyzed on a $Q$ Exactive hybrid quadrupoleOrbitrap mass spectrometer (Thermo Fisher Scientific, Waltham, MA, USA) equipped with an Aeris WIDEPORE $3.6 \mu \mathrm{m} \mathrm{C4,} 150 \times 2.1 \mathrm{~mm}$ (Phenomenex Inc., Torrance, CA). The flow rate and 
column temperature was set at $0.45 \mathrm{~mL} / \mathrm{min}$ and $40^{\circ} \mathrm{C}$ respectively. Buffer $\mathrm{A}(0.1 \% \mathrm{FA}$ in water) and buffer B (0.1\% FA in ACN) were used as mobile phases for gradient separation. Model peptide adducts were separated by an 18-min gradient which was 0-1 min at 2\% B, 1-10 min to $45 \% \mathrm{~B}, 10-12 \mathrm{~min}$ to $90 \% \mathrm{~B}, 12-14 \mathrm{~min}$ at $90 \% \mathrm{~B}, 14-14.1 \mathrm{~min}$ to $2 \% \mathrm{~B}$ and $14.1-18 \%$ at $2 \% \mathrm{~B}$. The 120-min gradient for separation of peptides from digested rat plasma samples was 0-2.0 min at $2 \% \mathrm{~B}, 2.0-95 \mathrm{~min}$ to $50 \% \mathrm{~B}, 95-105 \mathrm{~min}$ to $95 \% \mathrm{~B}, 105-106 \mathrm{~min}$ to $2 \% \mathrm{~B}$ and $106-120$ at $2 \% \mathrm{~B}$.

A top 5 method was used for the model peptides and a top 10 method was used for rat plasma digested samples. Full MS scans were acquired in the Orbitrap mass analyzer over the range $\mathrm{m} / \mathrm{z}$ 350-1600 for model peptides and m/z 420-1850 for rat plasma samples with a mass resolution of 70000 (at $\mathrm{m} / \mathrm{z}$ 200). The target value was $1.00 \mathrm{E}+06$. The five (model peptides) or ten most intense peaks (rat plasma) with charge state $\geq 2$ were fragmented in the HCD collision cell with a normalized collision energy of $28 \%$, and tandem mass spectra were acquired in the Orbitrap mass analyzer with a mass resolution of 17,500 at $\mathrm{m} / \mathrm{z} 200$. The target value was $5.0 \mathrm{E}+04$ for model peptides and plasma samples. The ion selection threshold was $1.00 \mathrm{E}+05$ counts, and the maximum allowed ion accumulation times were $100 \mathrm{~ms}$ for full MS scans and 120 ms for tandem mass spectra for plasma digested samples. For model peptides, an ion selection threshold of $1.00 \mathrm{E}+04$ counts and a maximum allowed ion accumulation time $100 \mathrm{~ms}$ for full MS scans and 100 ms for tandem mass spectra were also applied. For both of the experiments, the dynamic exclusion time was set to $6 \mathrm{~s}$.

\section{VII.d. Protein identification}

The MS-MS spectra were matched to rat database sequences against a merged UniProtKB/SwissProt database (downloaded on 2/19/14 from www.uniprot.org/downloads) and searched with PEAKS (version 7.5, Bioinformatics Solutions Inc., Waterloo, ON). SCarboxamidomethylation of Cys (+57.02146 Da), deamidation (NQ), oxidation of Met (+15.99492), adduction of linkers 1a (+780.1601 Da), 1b (+814.1577 Da), 3 (+681.1394 Da),

hydrolyzed 3 (+699.1499 Da) at C,K,R,E were specified as variable modifications to identify spectra of adducts at $1 \%$ FDR with the following parameters: maximum of 3 missed cleavages 
lys-c/trypsin, mass tolerance $10 \mathrm{ppm}$ (precursor), 0.02 Da (fragment ions). PEAKS automatically generated a decoy-fusion, which appended a decoy sequence to each protein for calculation of FDR. Repeated search results had scores (-10log P) of 20 or higher, with an estimated FDR value of $<1 \%$ (at the protein level) as calculated by PEAKS. Adducts identified in this manner are shown in Table S2.

Table S3. Observed Adducts of 1a, $\mathbf{1 b}$, and $\mathbf{3}$ with RSA and Model Peptide CSYDEHAK.

\begin{tabular}{|c|c|c|c|}
\hline \multirow{2}{*}{ Compound } & \multirow{2}{*}{$\begin{array}{l}\text { Model Peptide } \\
\text { (CSYDEHAK) }\end{array}$} & \multicolumn{2}{|c|}{ Rat Plasma } \\
\hline & & Cysteine-34 ${ }^{a}$ & Other Amino Acids ${ }^{a}$ \\
\hline $1 a$ & Yes & No & \\
\hline $\begin{array}{c}\text { Thiomaleate } \\
\text { Fragment from 1a }\end{array}$ & - & Yes & K-460, K-490 \\
\hline 1b & Yes & Yes & $\begin{array}{l}\text { R-169, K-236, R-361, K-421, } \\
\text { K-499, E-529, K-549, K-588 }\end{array}$ \\
\hline 3 & Yes & No & Multiple unidentified \\
\hline Hydrolyzed 3 & - & Yes & peptides modified \\
\hline
\end{tabular}

${ }^{a}$ Modifications identified using PEAKS software, version 7.5.

\section{Graphical ${ }^{1} \mathrm{H}$ and ${ }^{13} \mathrm{C}$ NMR Spectra}




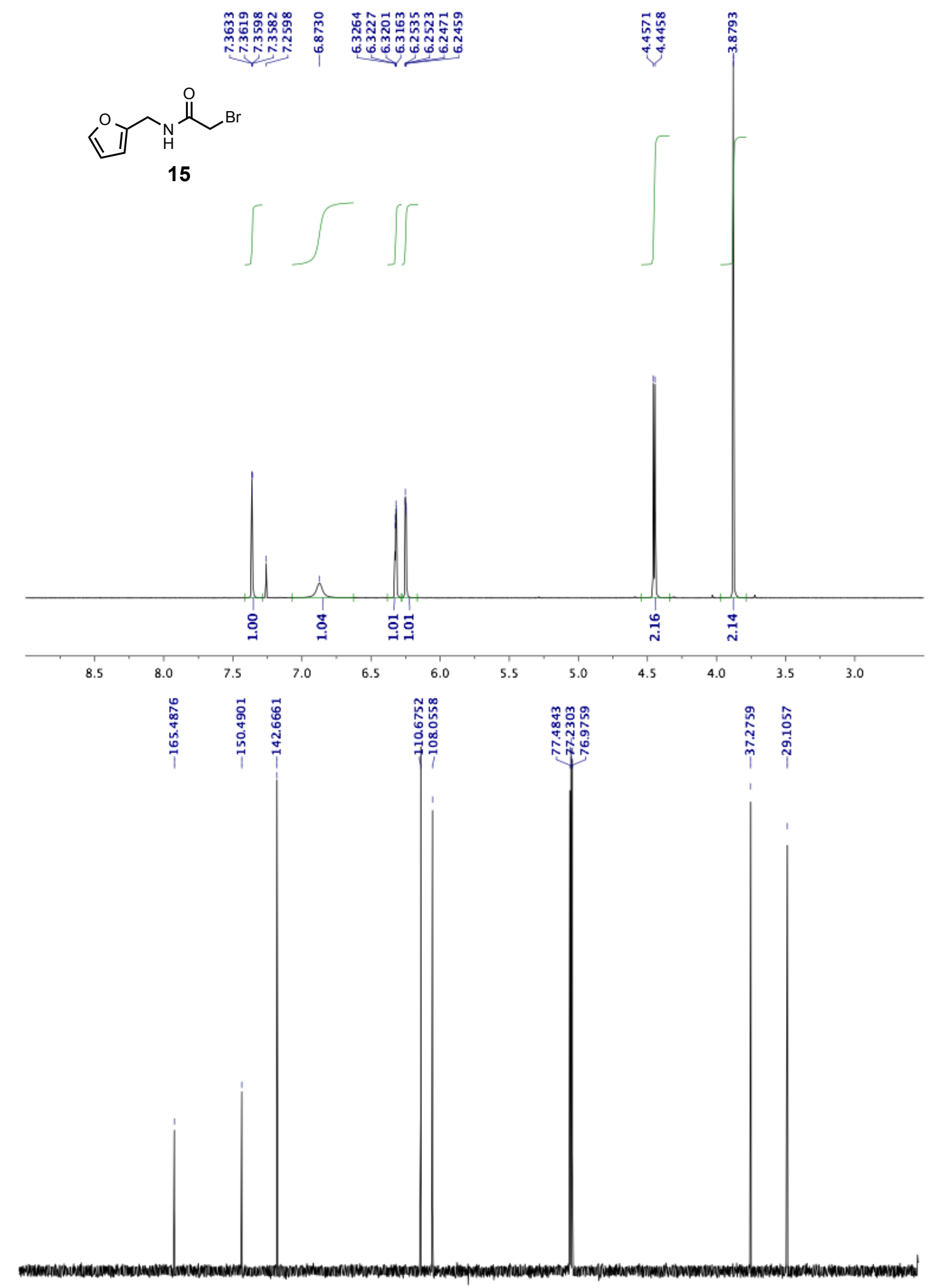

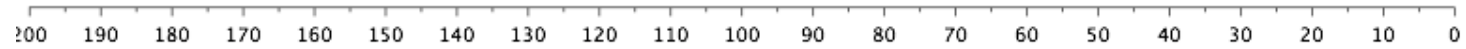



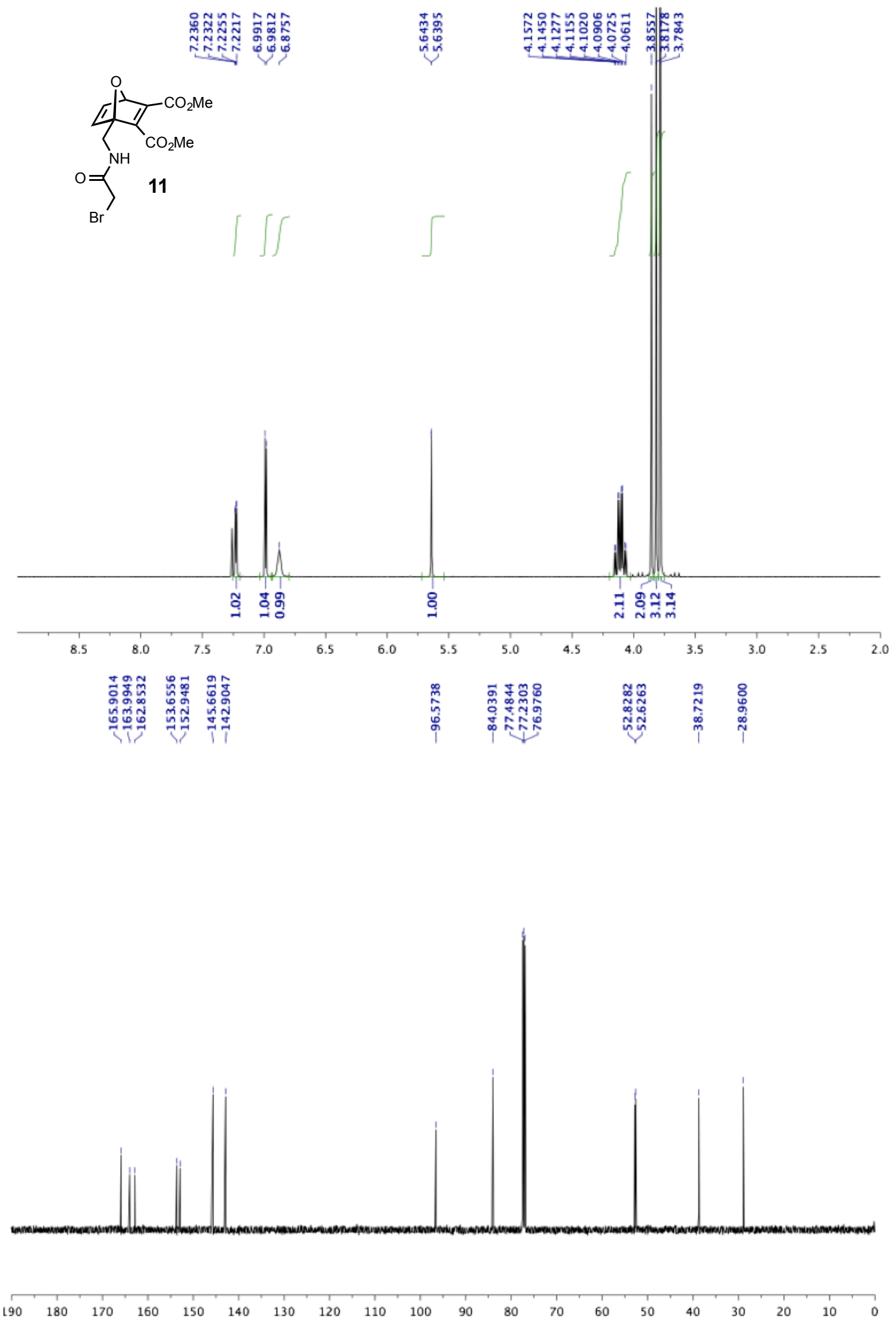


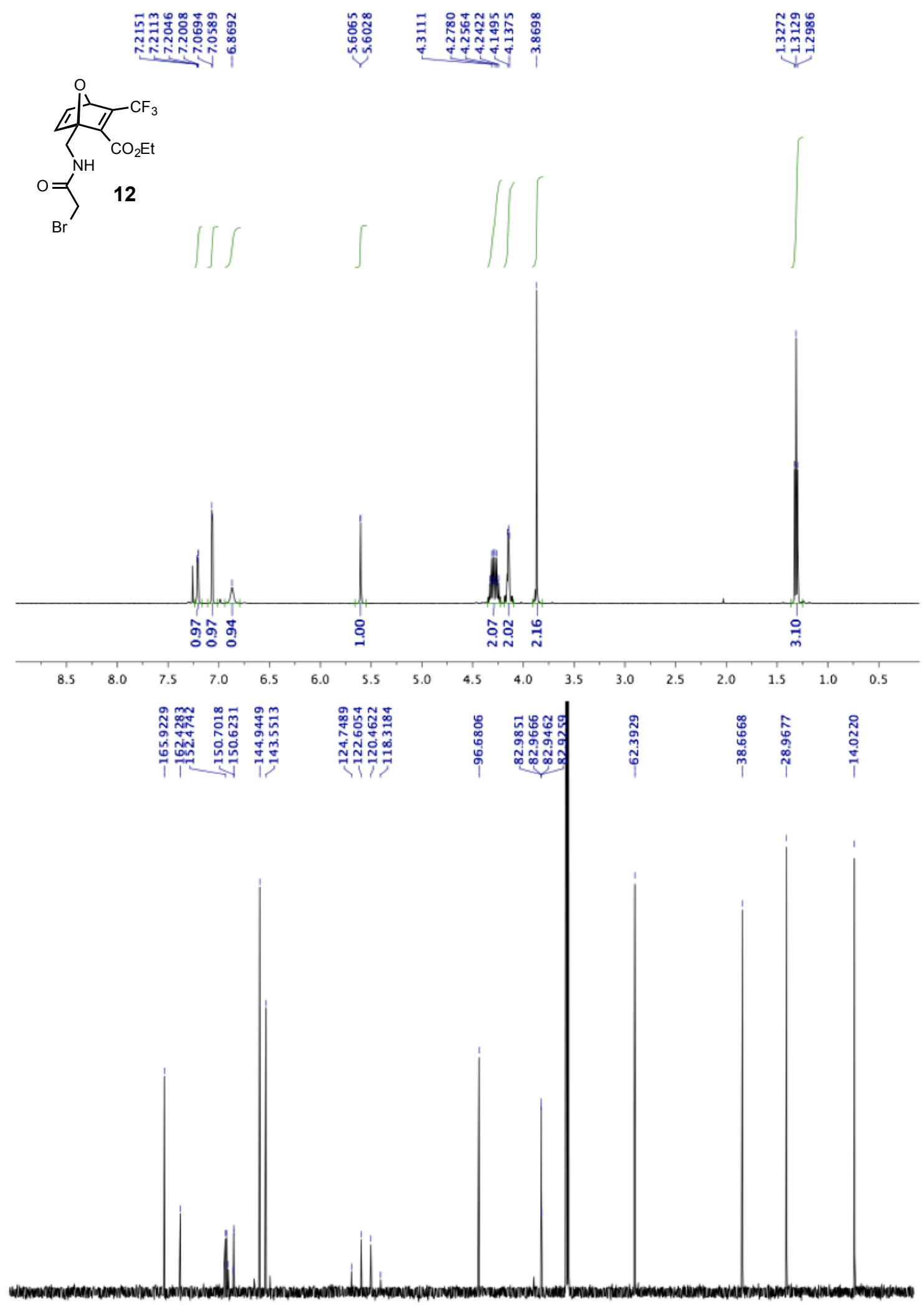

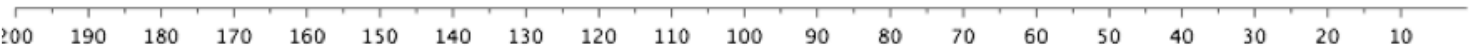



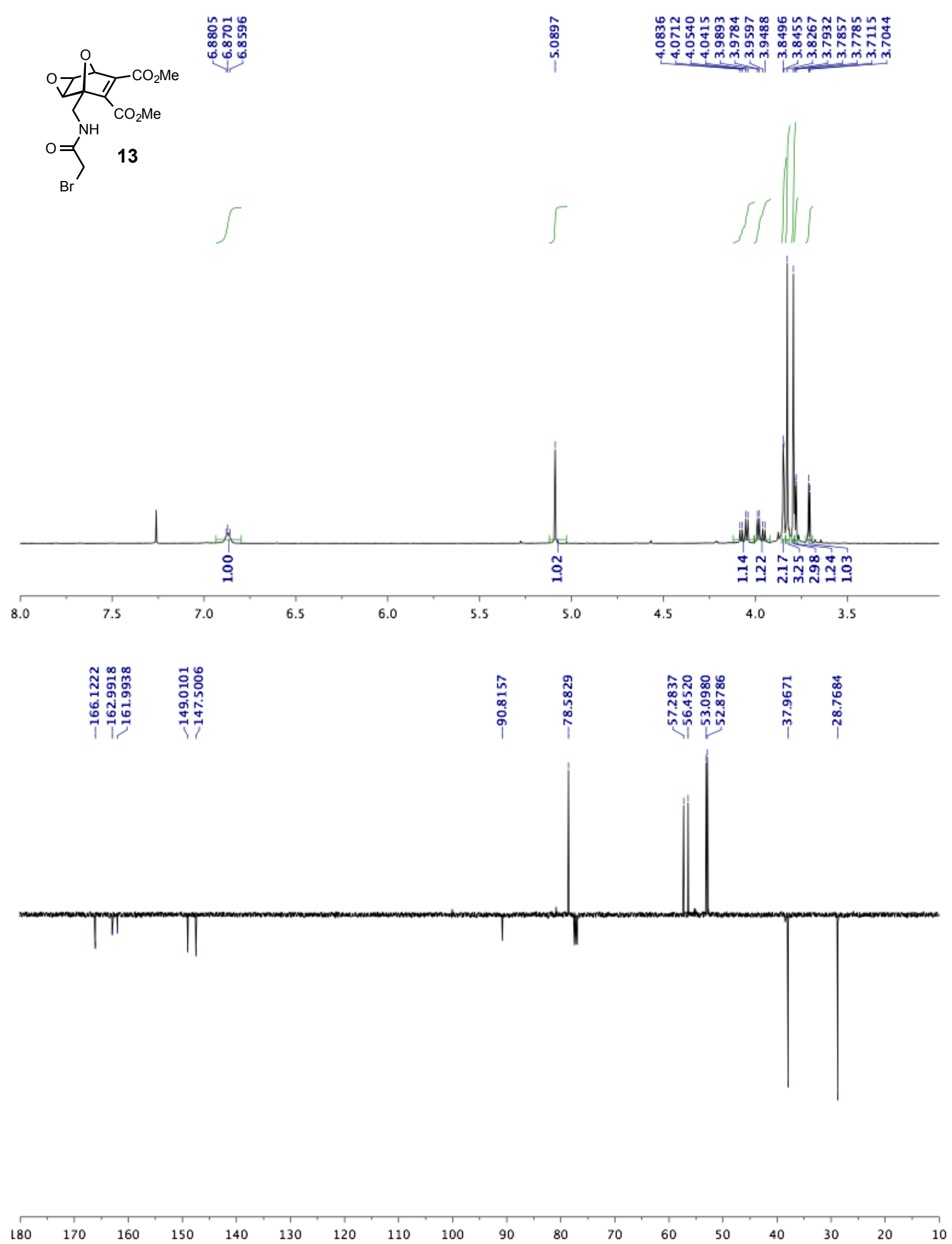


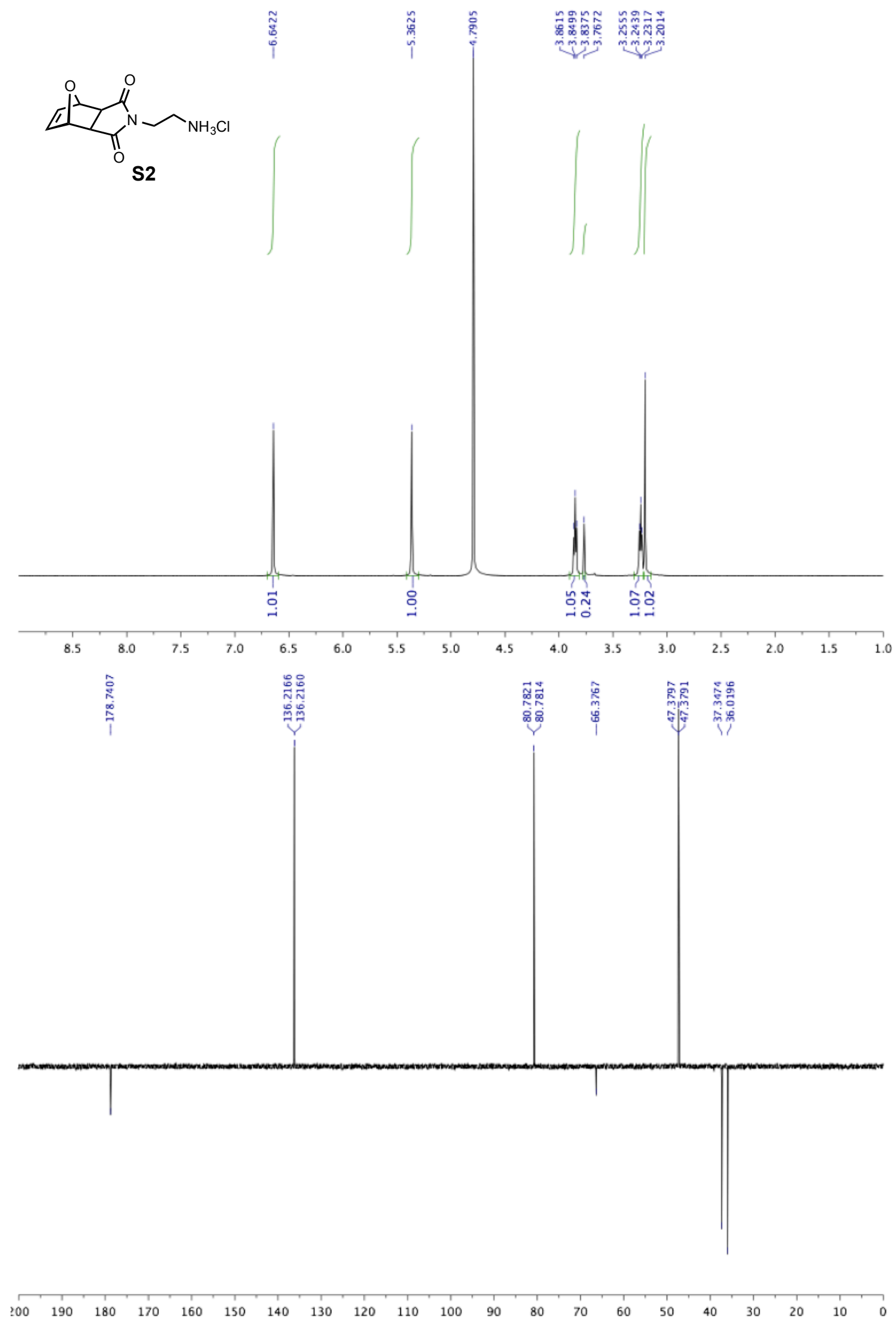



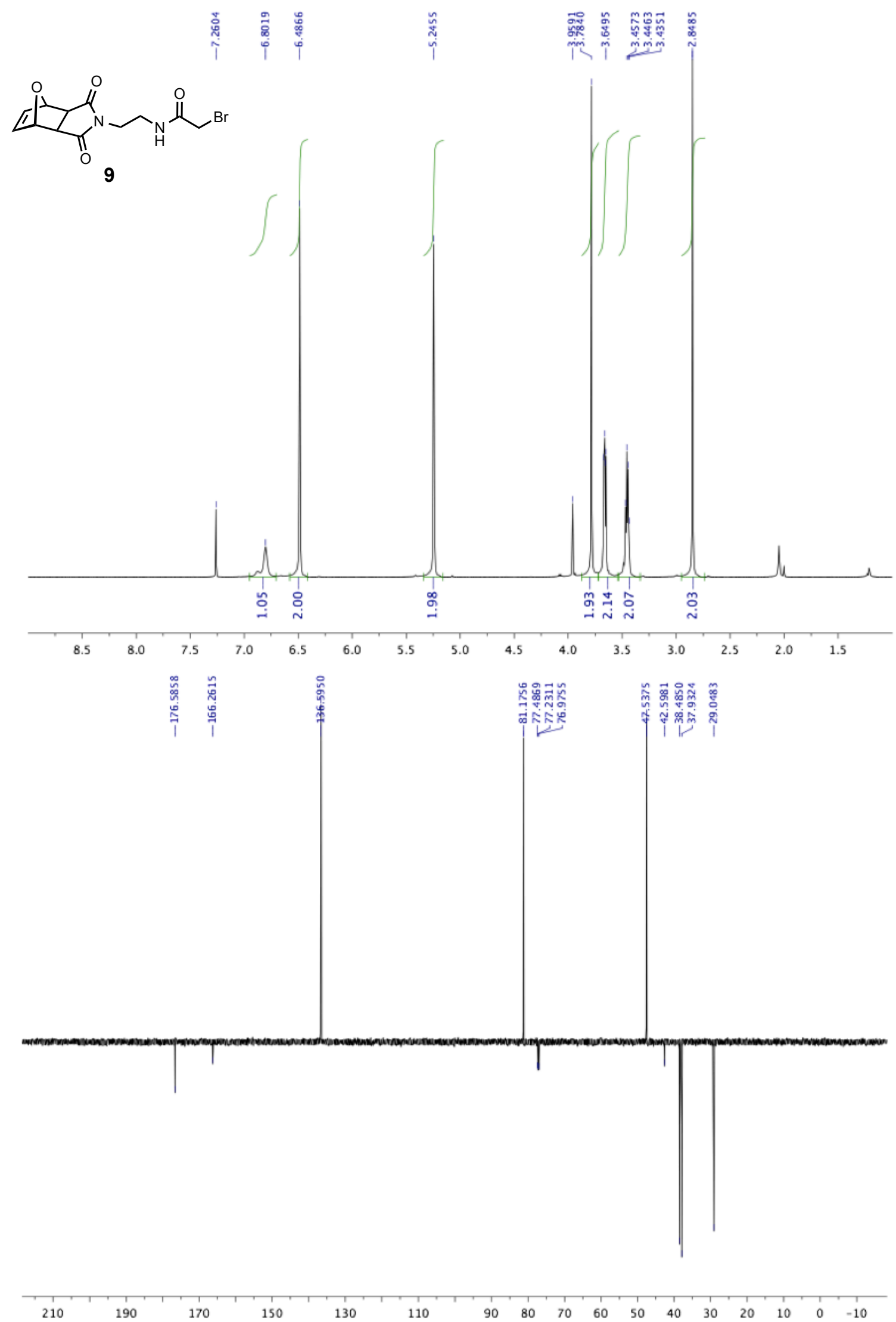

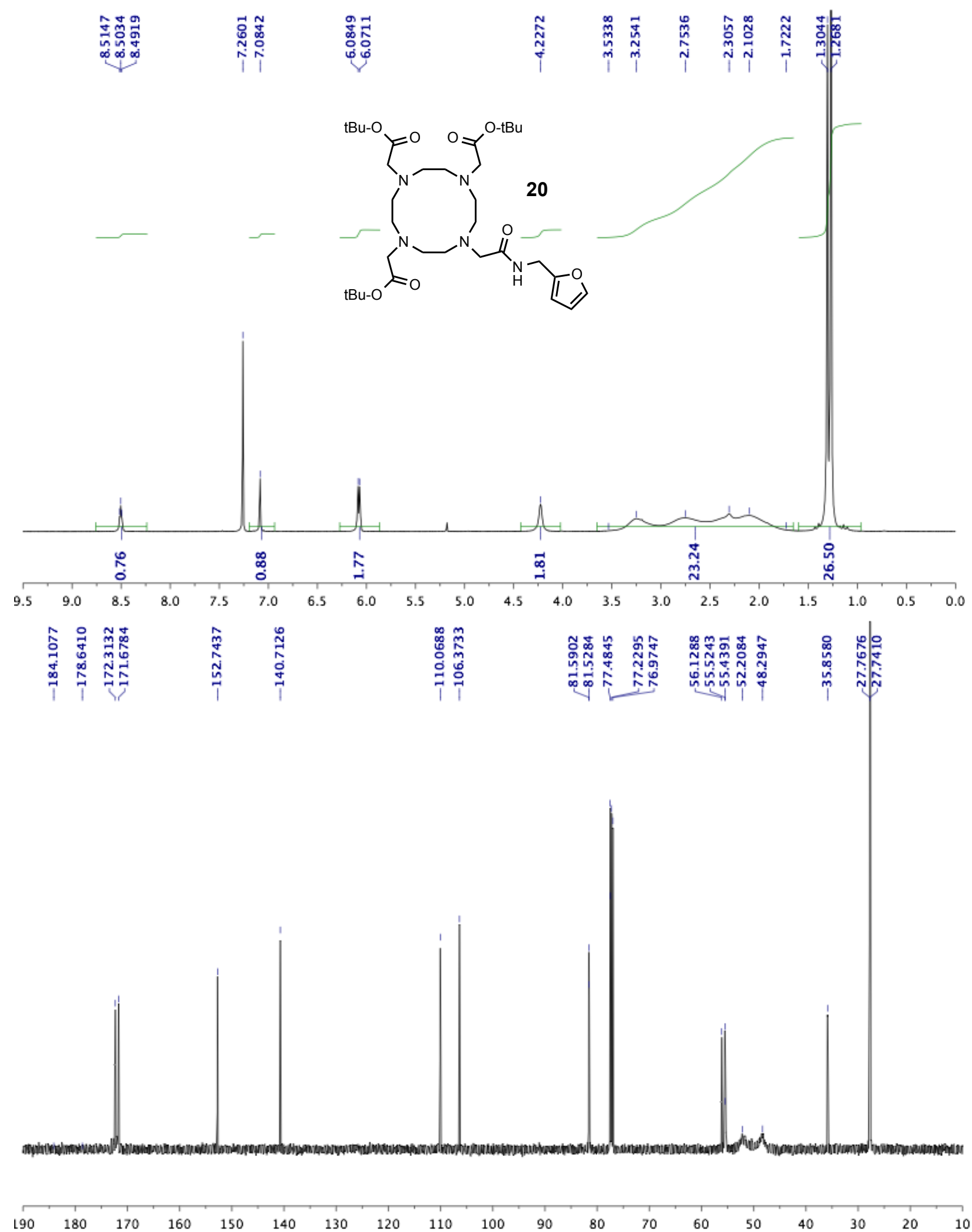

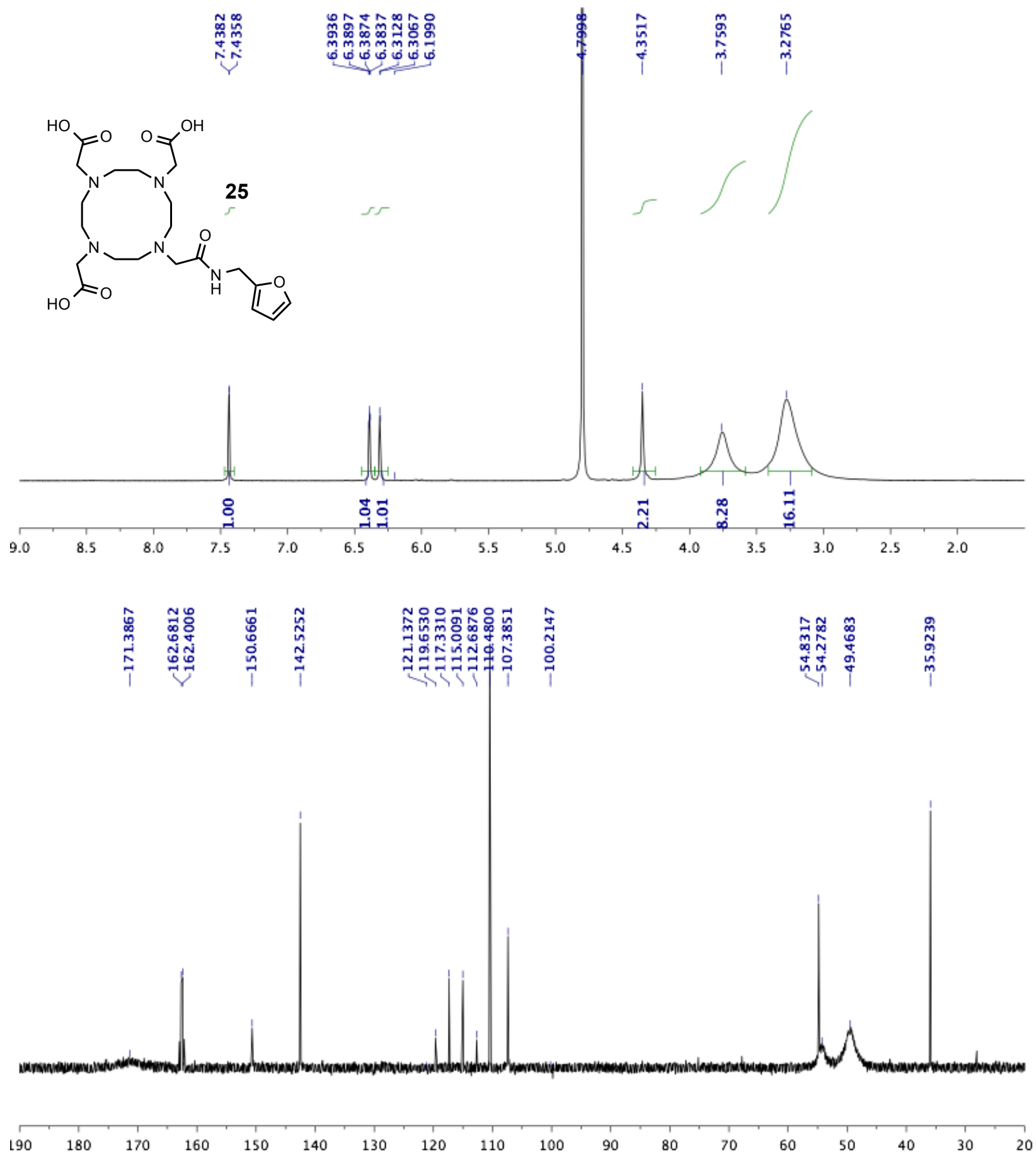


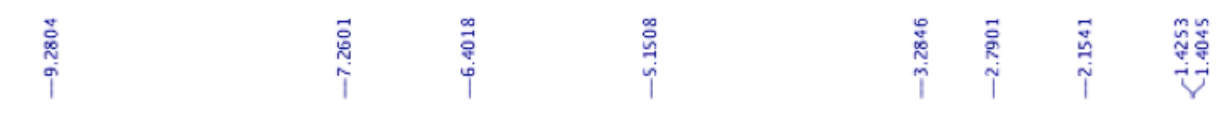<smiles>CCCCOC(=O)CN1CCN(CC(=O)NCCN2C(=O)C3C4C=CC(O4)C3C2=O)CCN(CC(=O)OCCC)CC1</smiles>
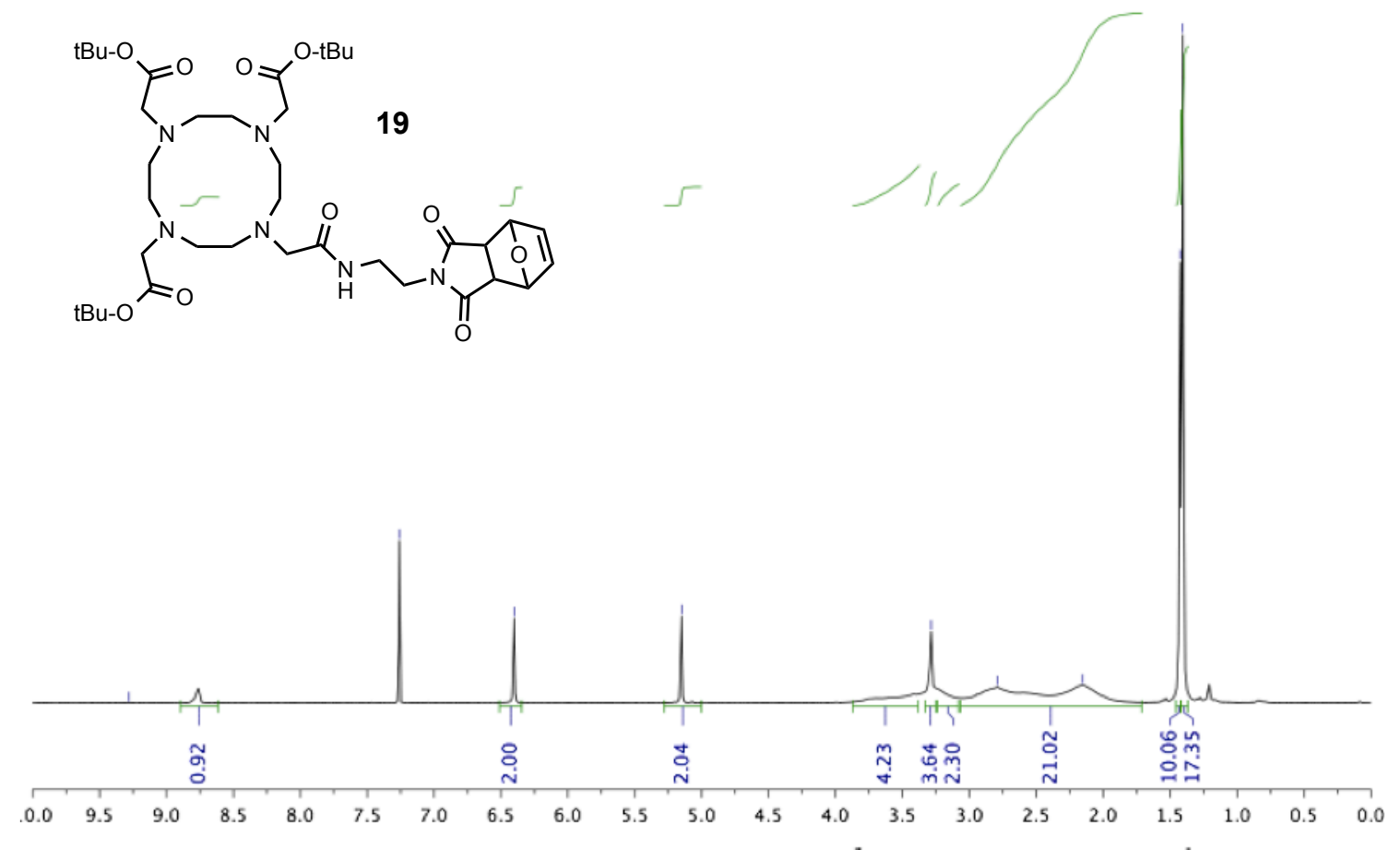

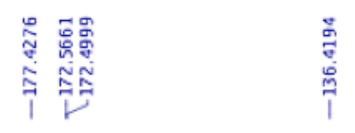
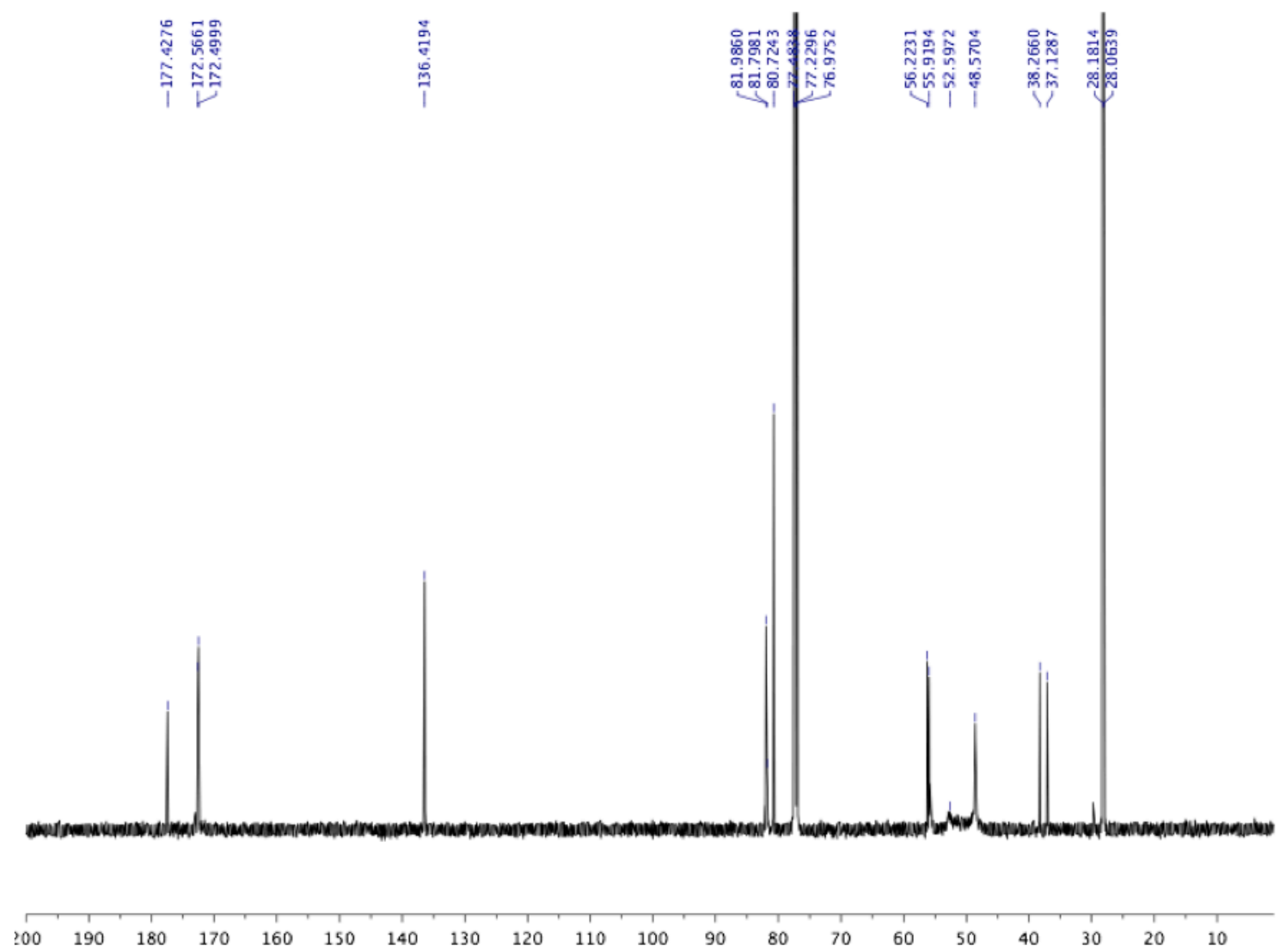

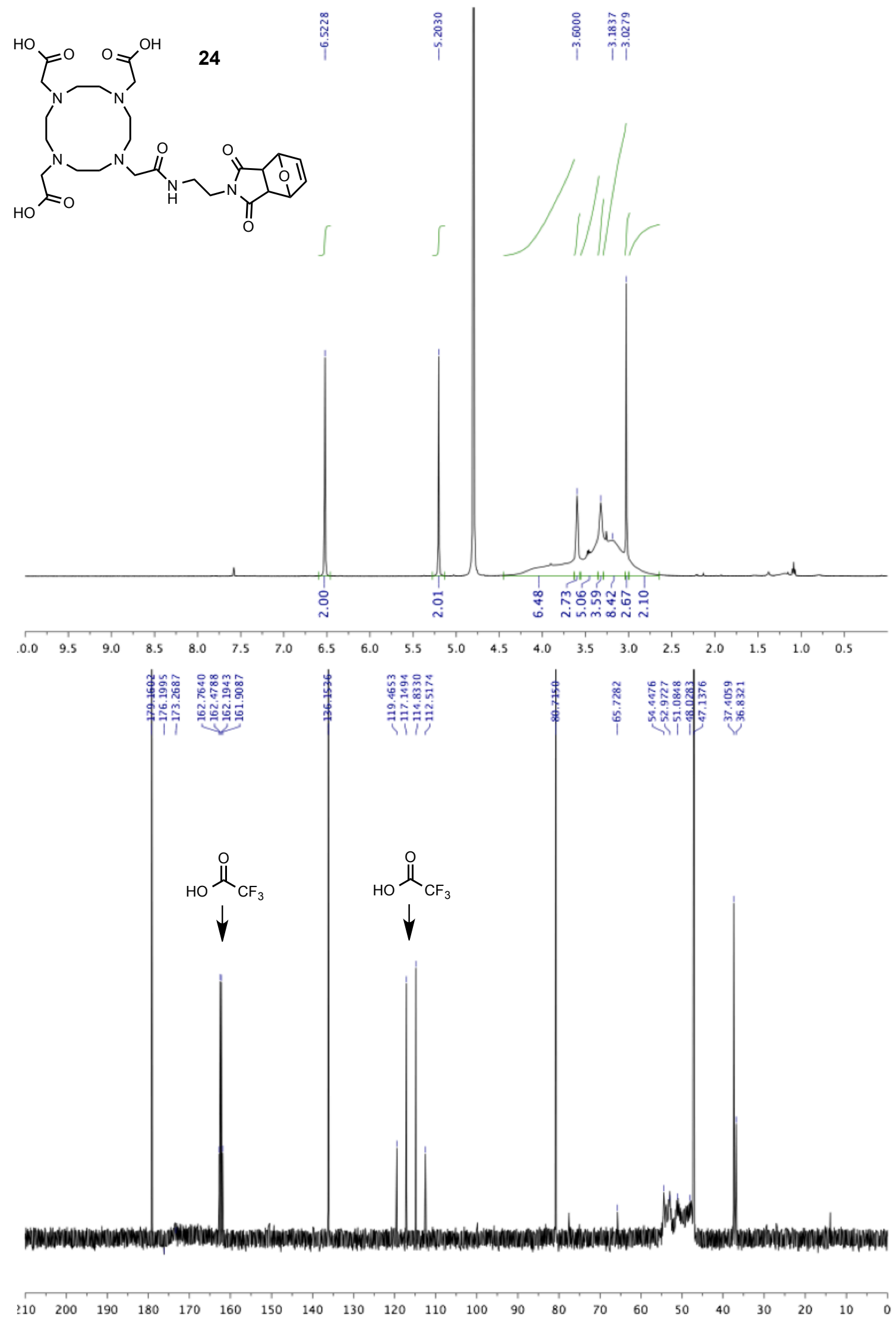

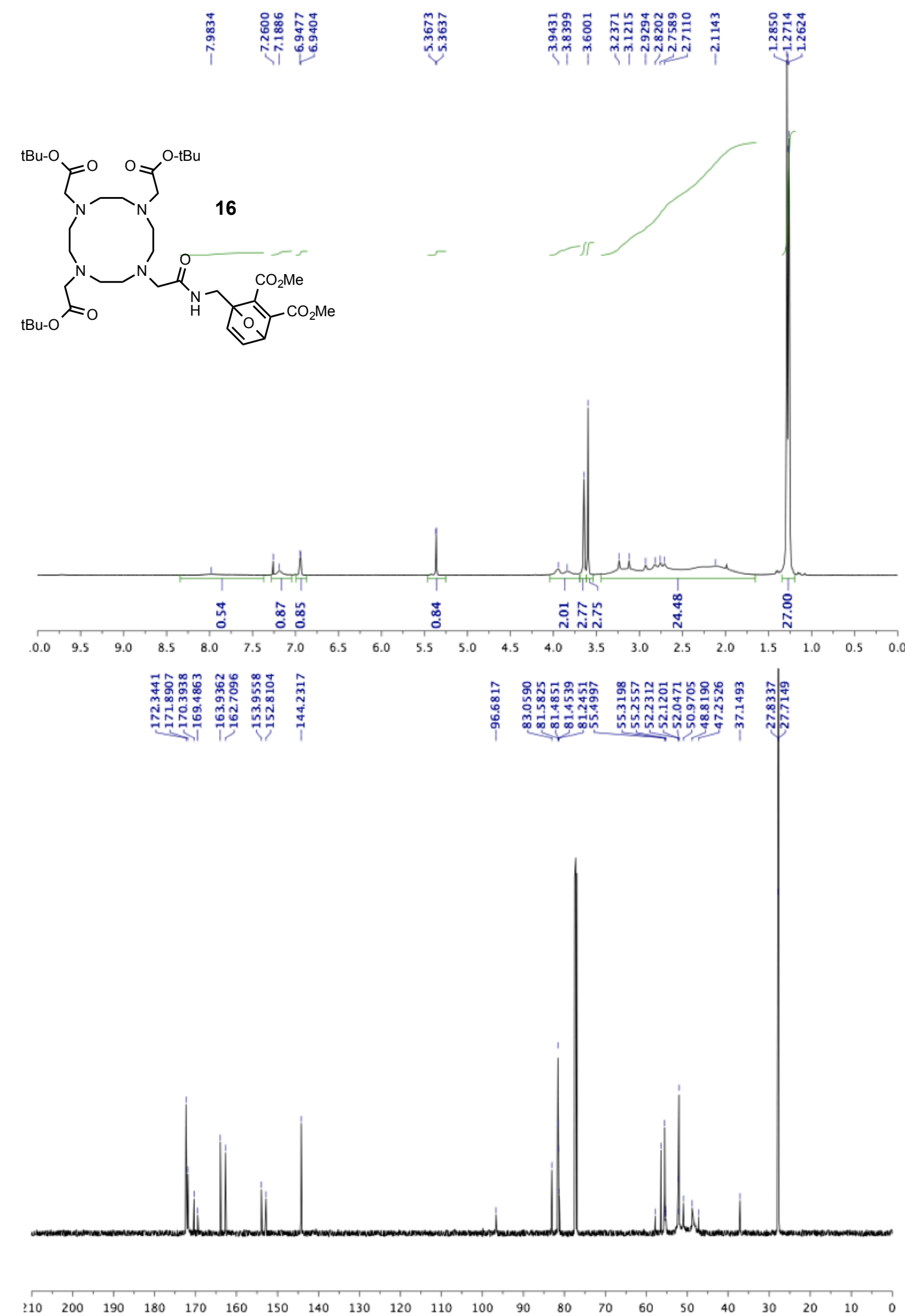

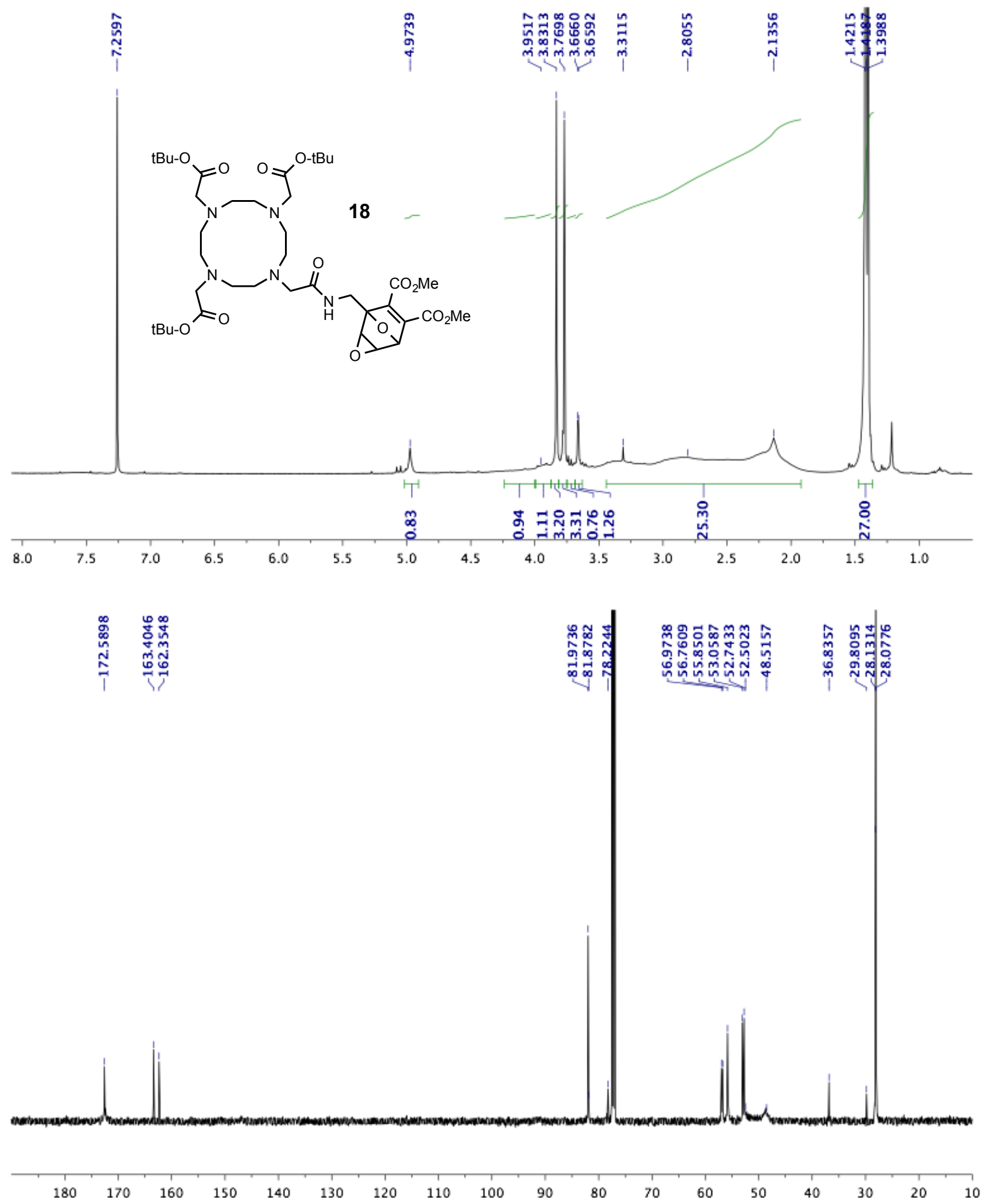

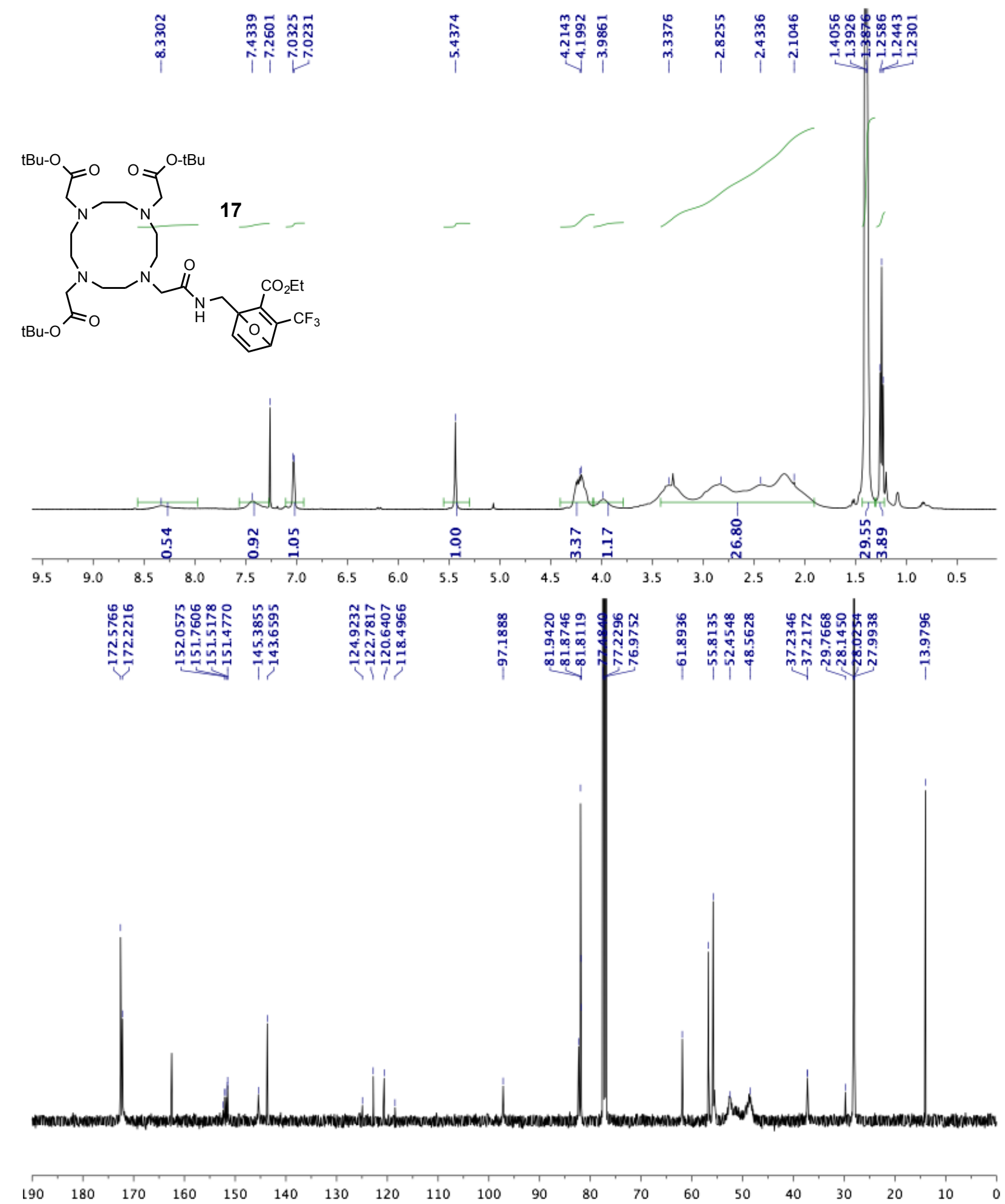

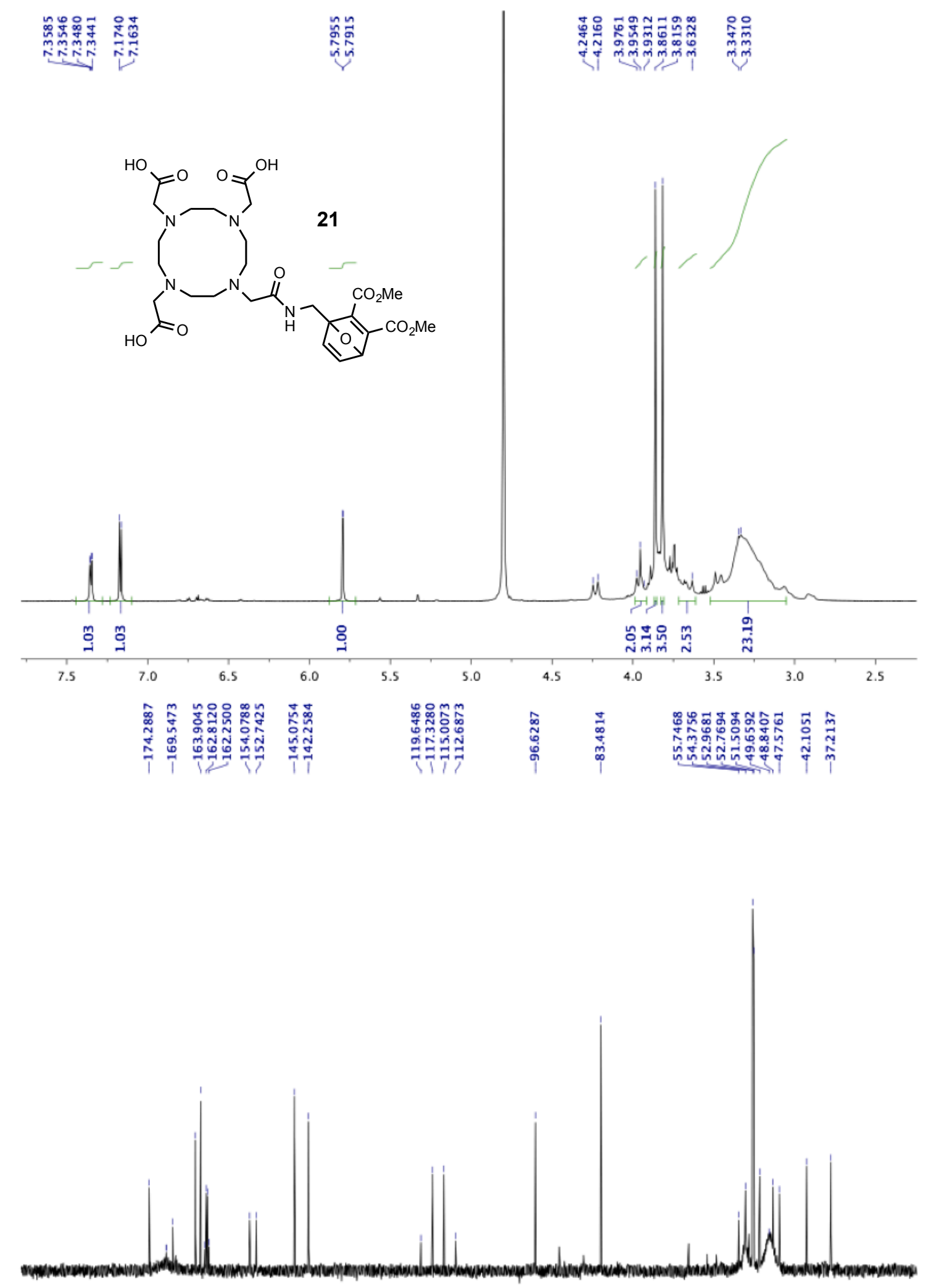

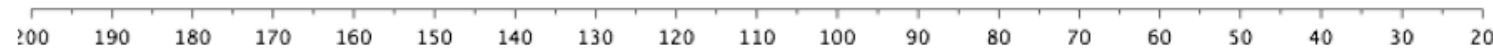



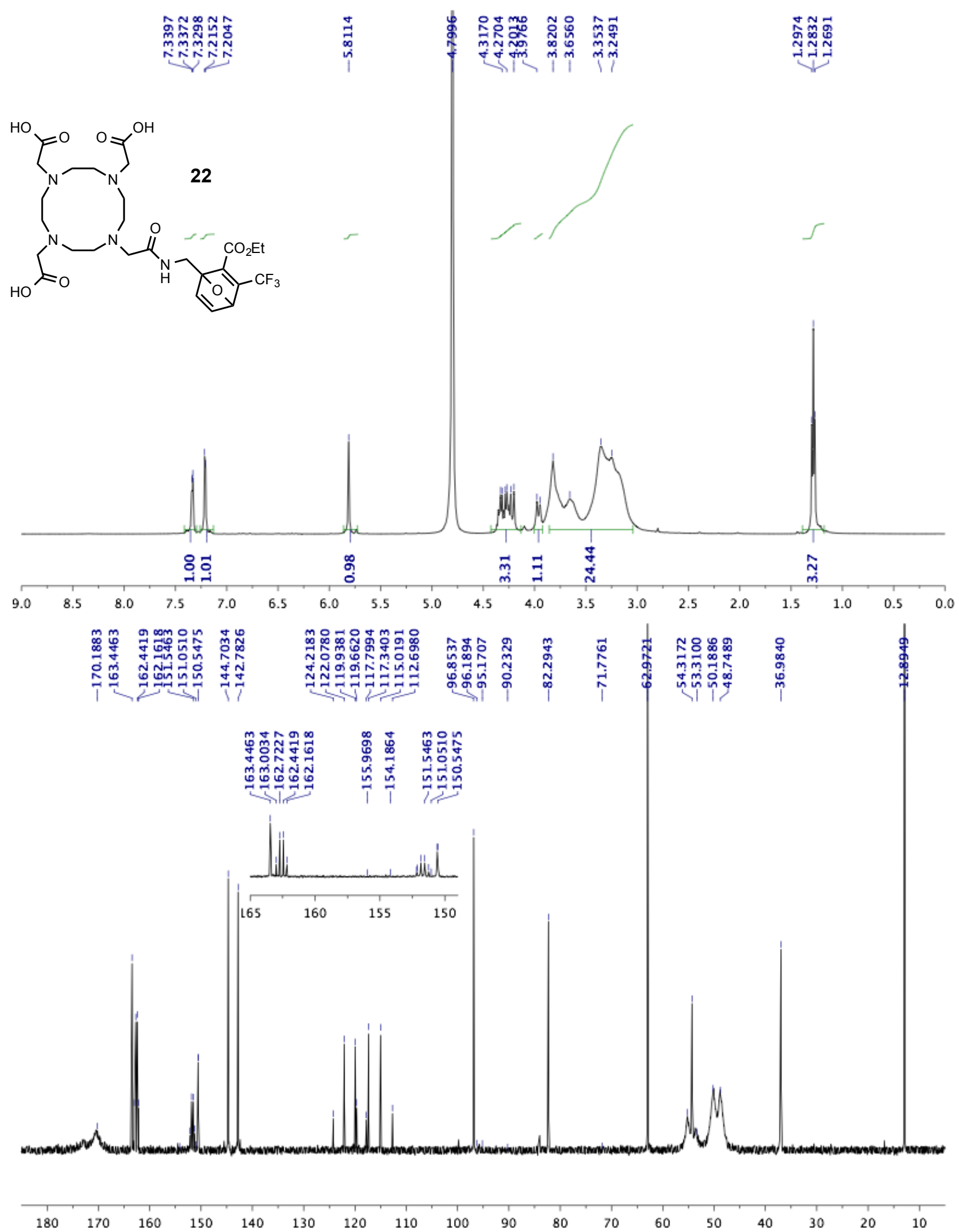
<smiles>COC(=O)C1=C(C(=O)OC)C2OC1C2CNC(=O)CN1CCN(CC(=O)O)CCN(CC(=O)O)CCN(CC(=O)O)C1</smiles>

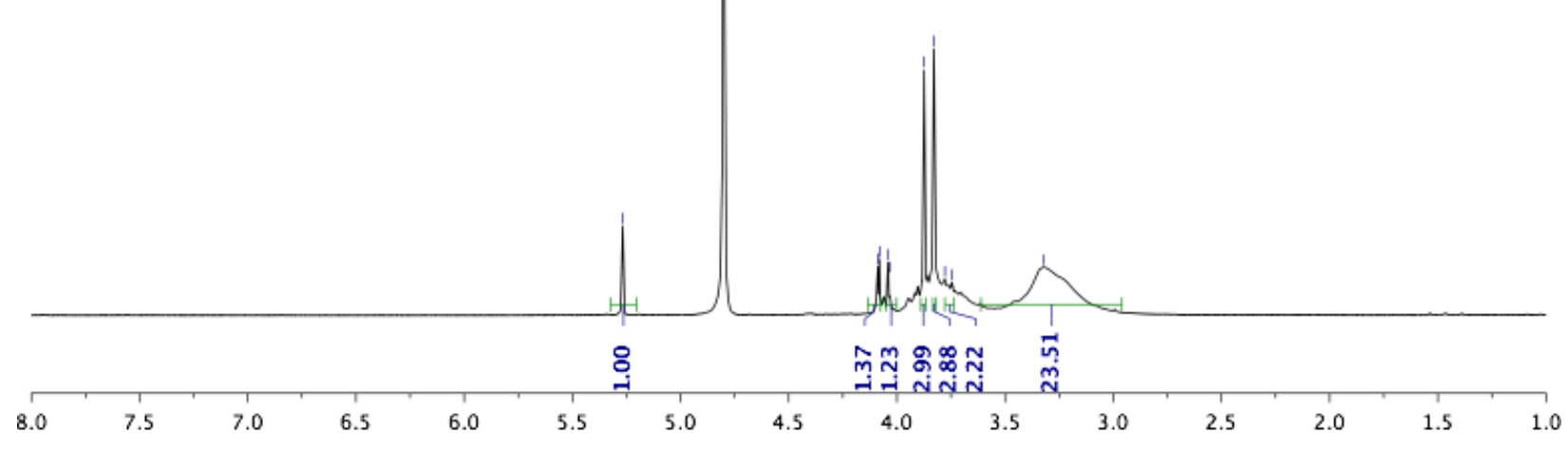

\begin{tabular}{|c|c|c|c|c|c|}
\hline 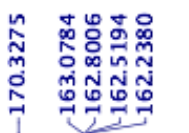 & 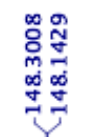 & 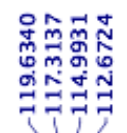 & $\begin{array}{l}\text { N } \\
\text { ஸे } \\
\stackrel{\circ}{0}\end{array}$ & 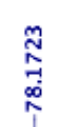 & 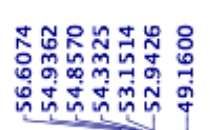 \\
\hline
\end{tabular}

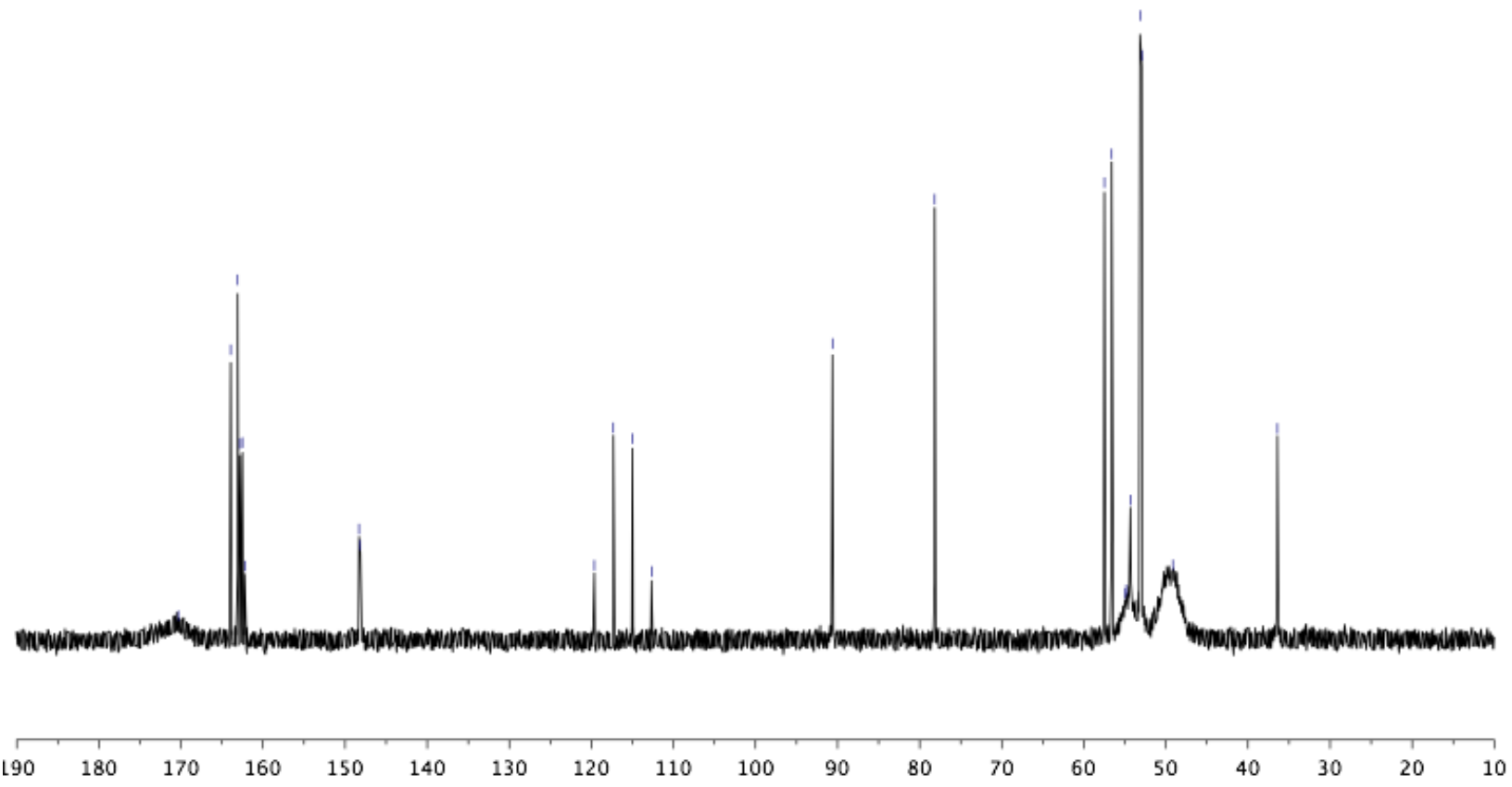




\section{Representative Mass Spectra from Adduct Determination Experiments}

Model Peptide Reactions:

\begin{tabular}{|l|l|l|l|l|}
\hline \multicolumn{5}{|c|}{ Model Peptide CSYDEHAK Reaction Predicted lons } \\
\hline & CSYDEHAK & CSYDEHAK+1a & CSYDEHAK+1b & CSYDEHAK+3 \\
\hline$(\mathrm{M}+\mathrm{H})^{+}$ & 952.38350 & 1732.54360 & 1756.54120 & 1633.52290 \\
\hline$(\mathrm{M}+2 \mathrm{H})^{2+}$ & 476.69568 & 866.77573 & 878.77453 & 817.26538 \\
\hline$(\mathrm{M}+3 \mathrm{H})^{3+}$ & 318.13308 & 578.18645 & 586.18565 & 545.17955 \\
\hline$(\mathrm{M}+4 \mathrm{H})^{4+}$ & 238.85178 & 433.89180 & 439.89120 & 409.13663 \\
\hline
\end{tabular}

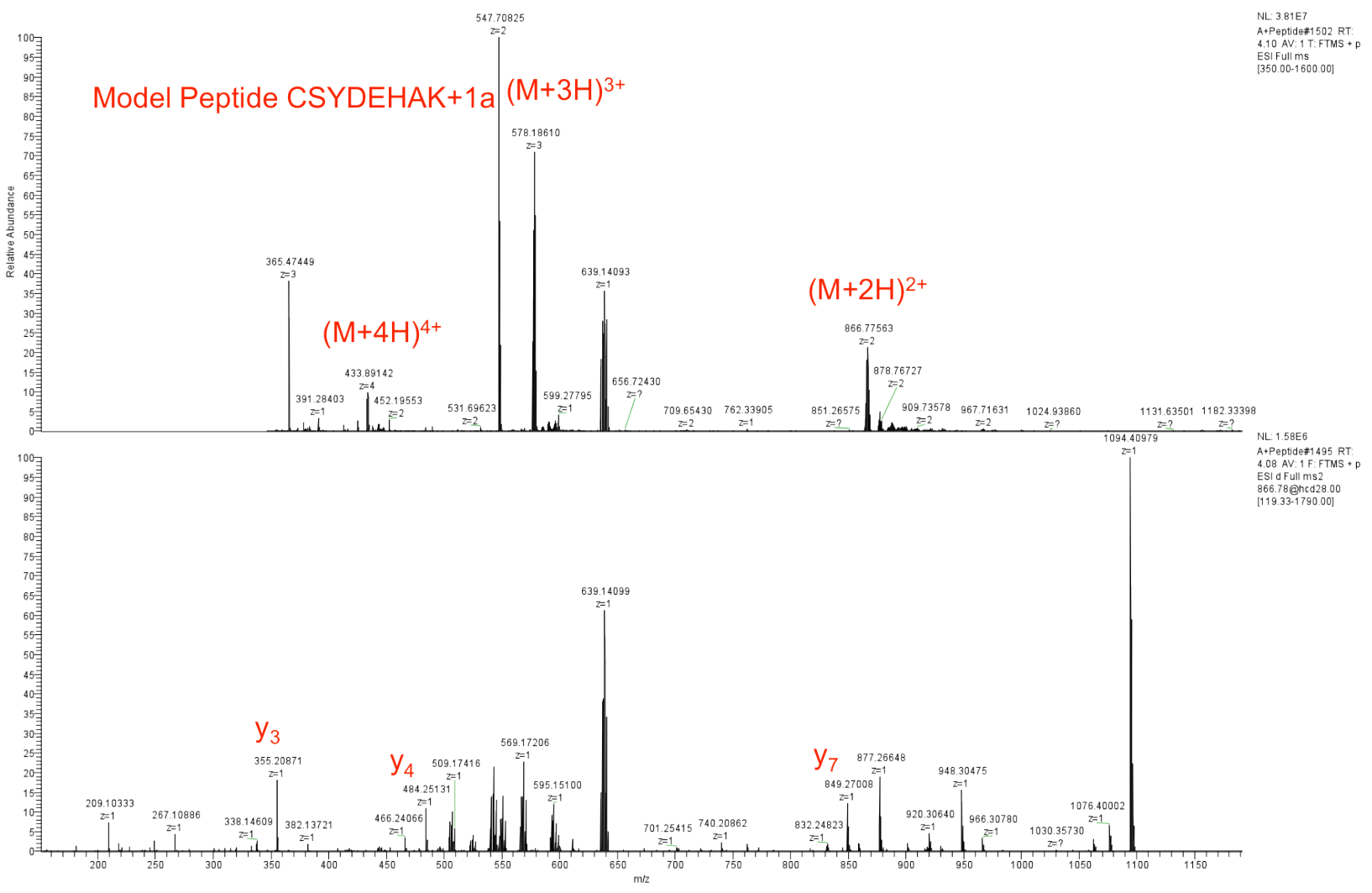




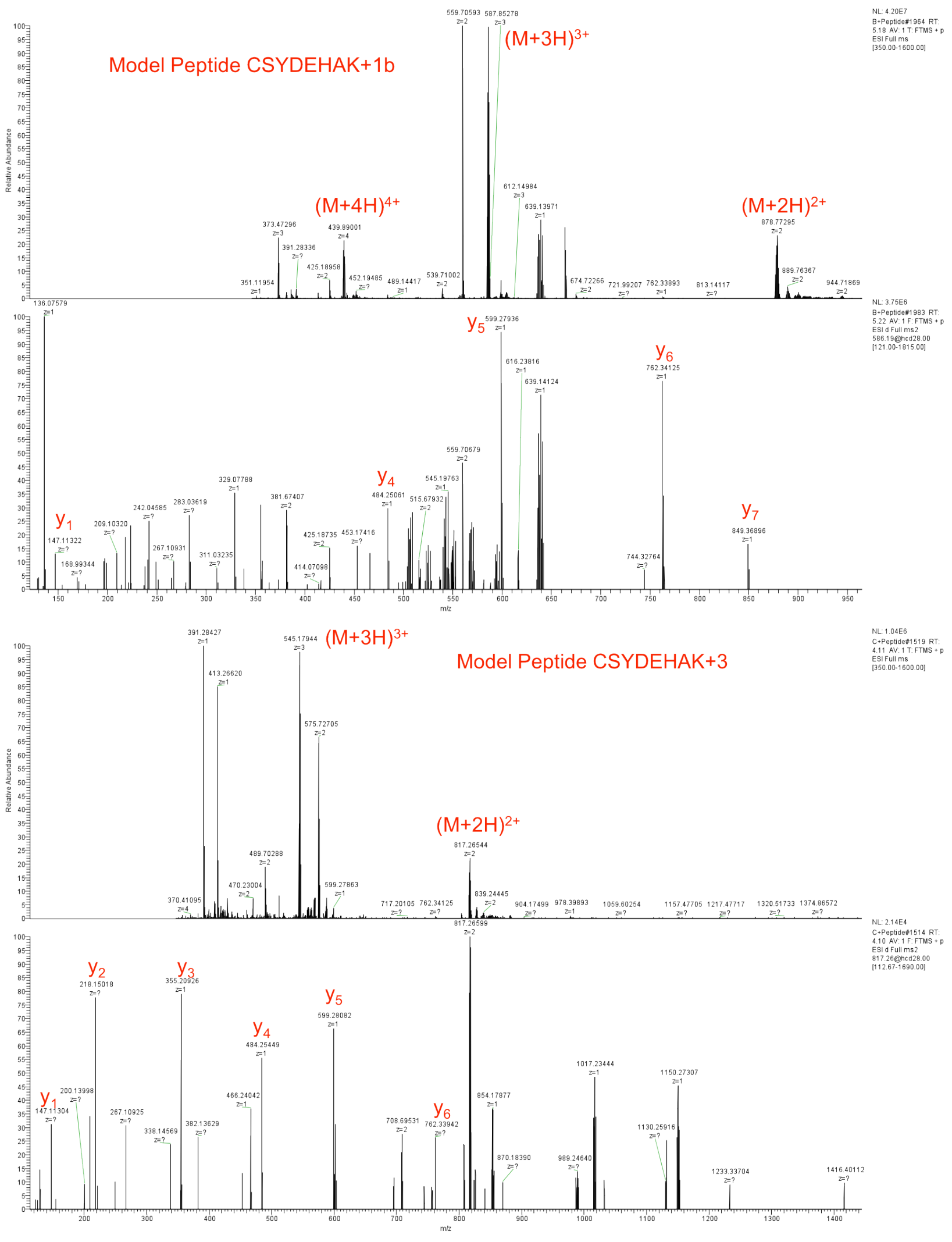




\section{Adduct Identification on RSA Isolated from Blood:}

\section{MS2 of Thiolmaleate Fragment of linker 1a adducted to C34}
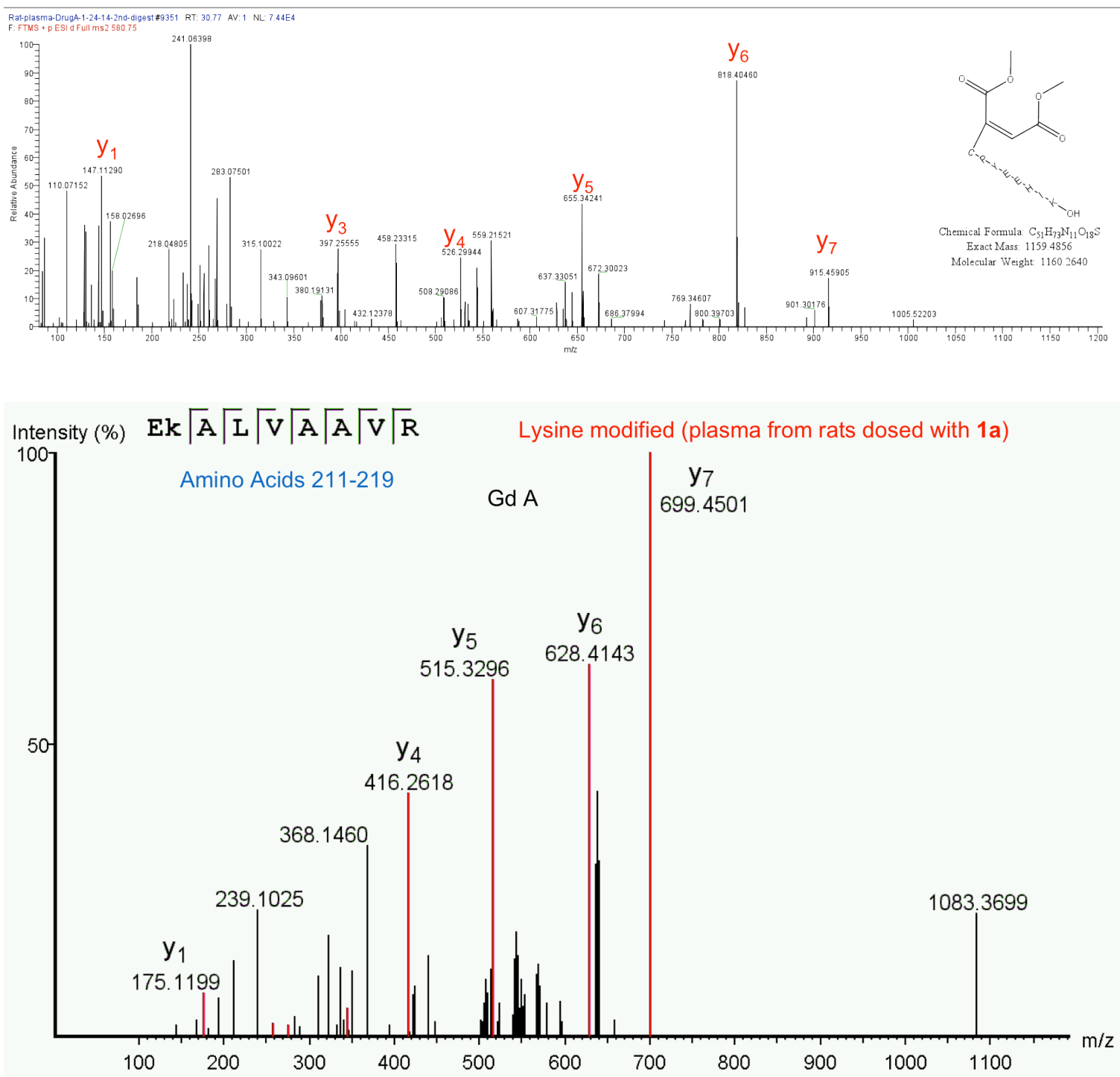

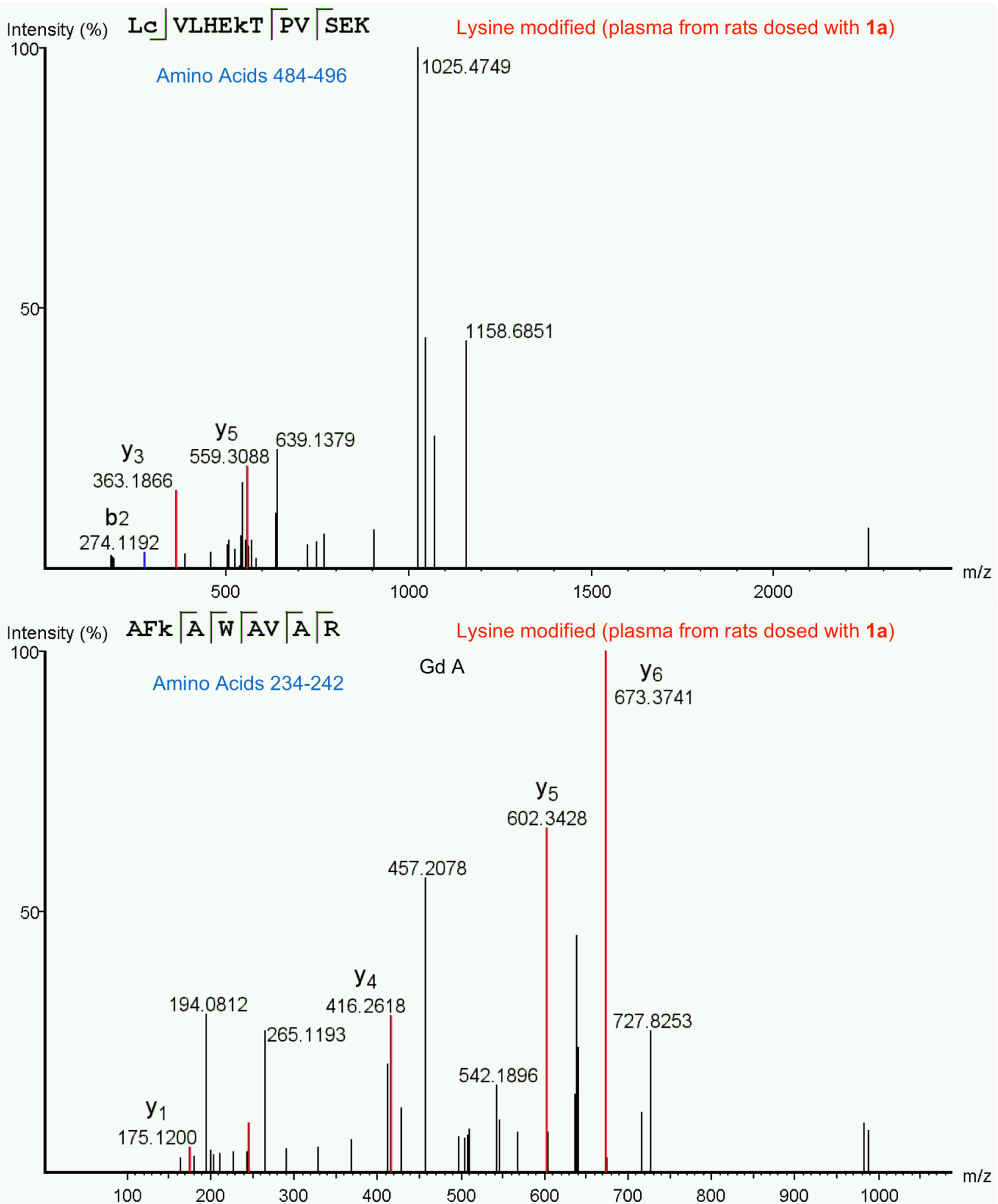


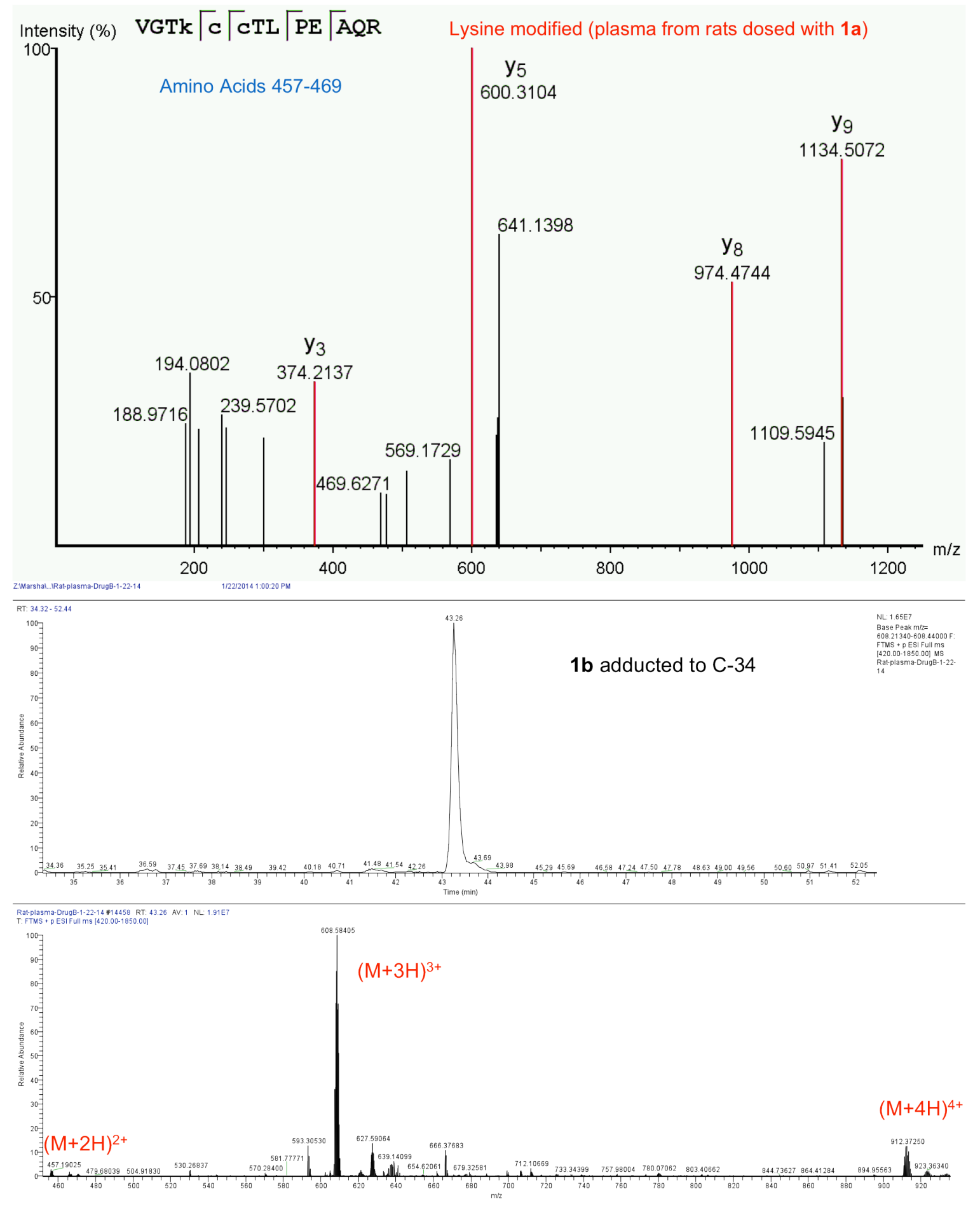




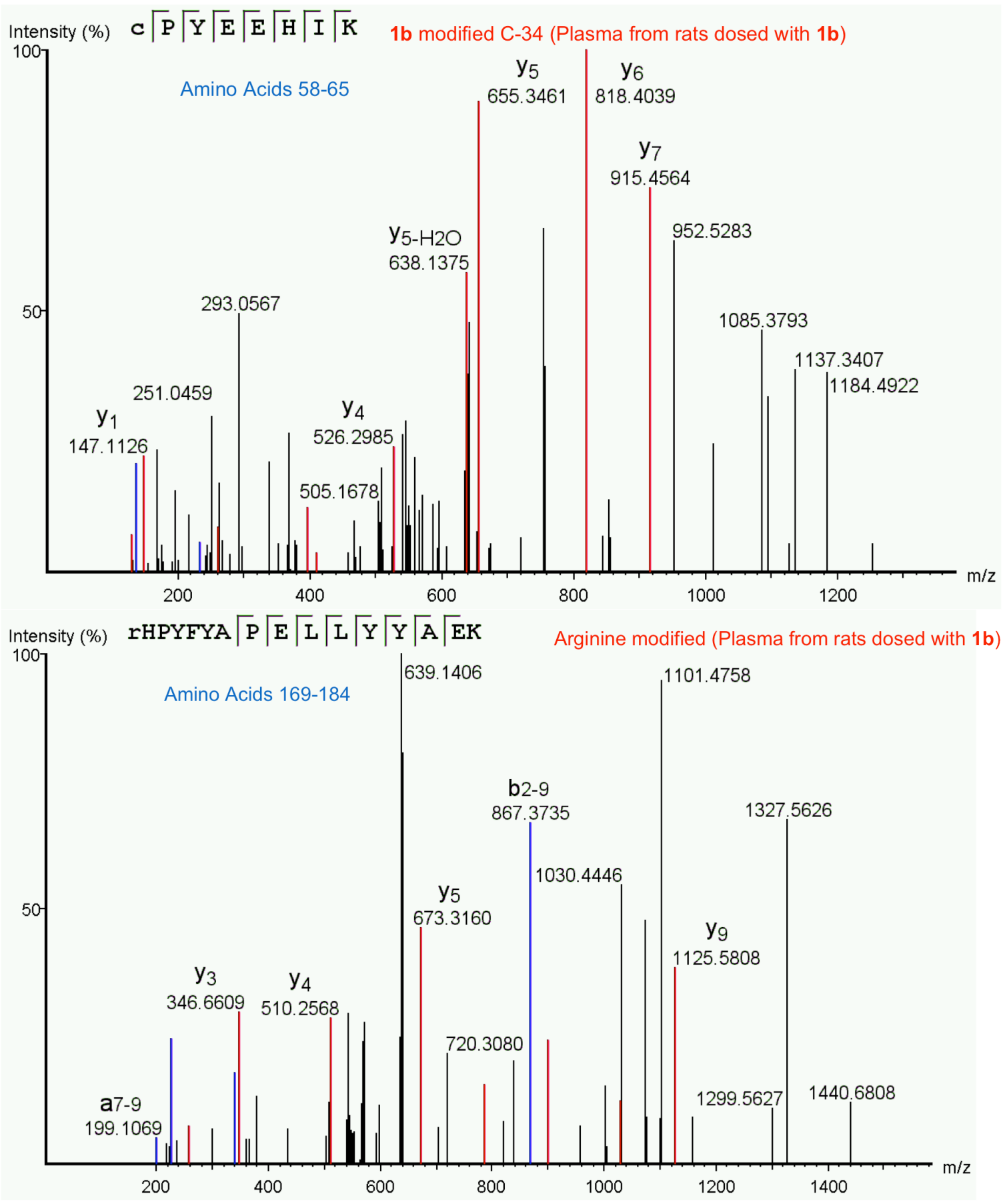




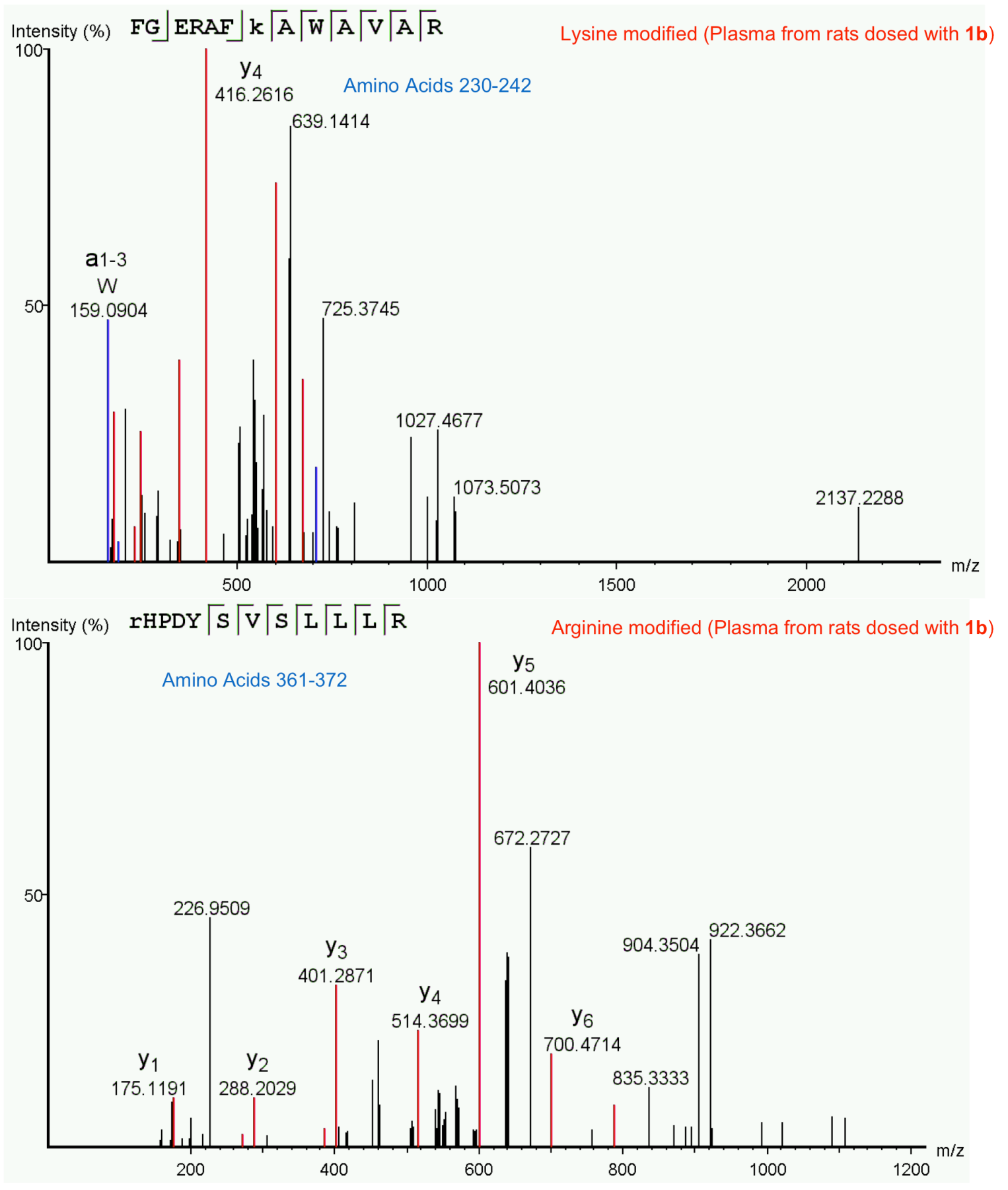




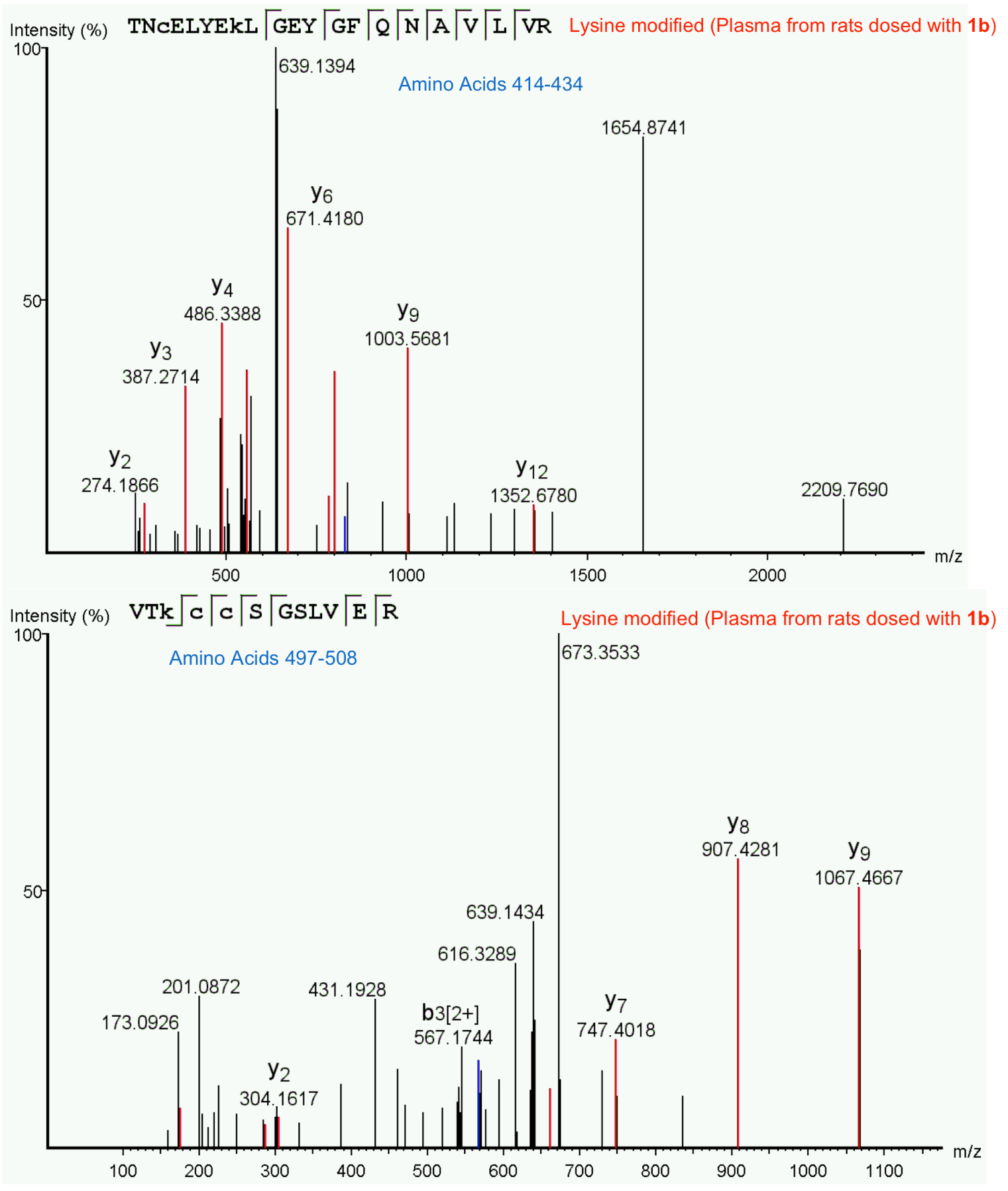




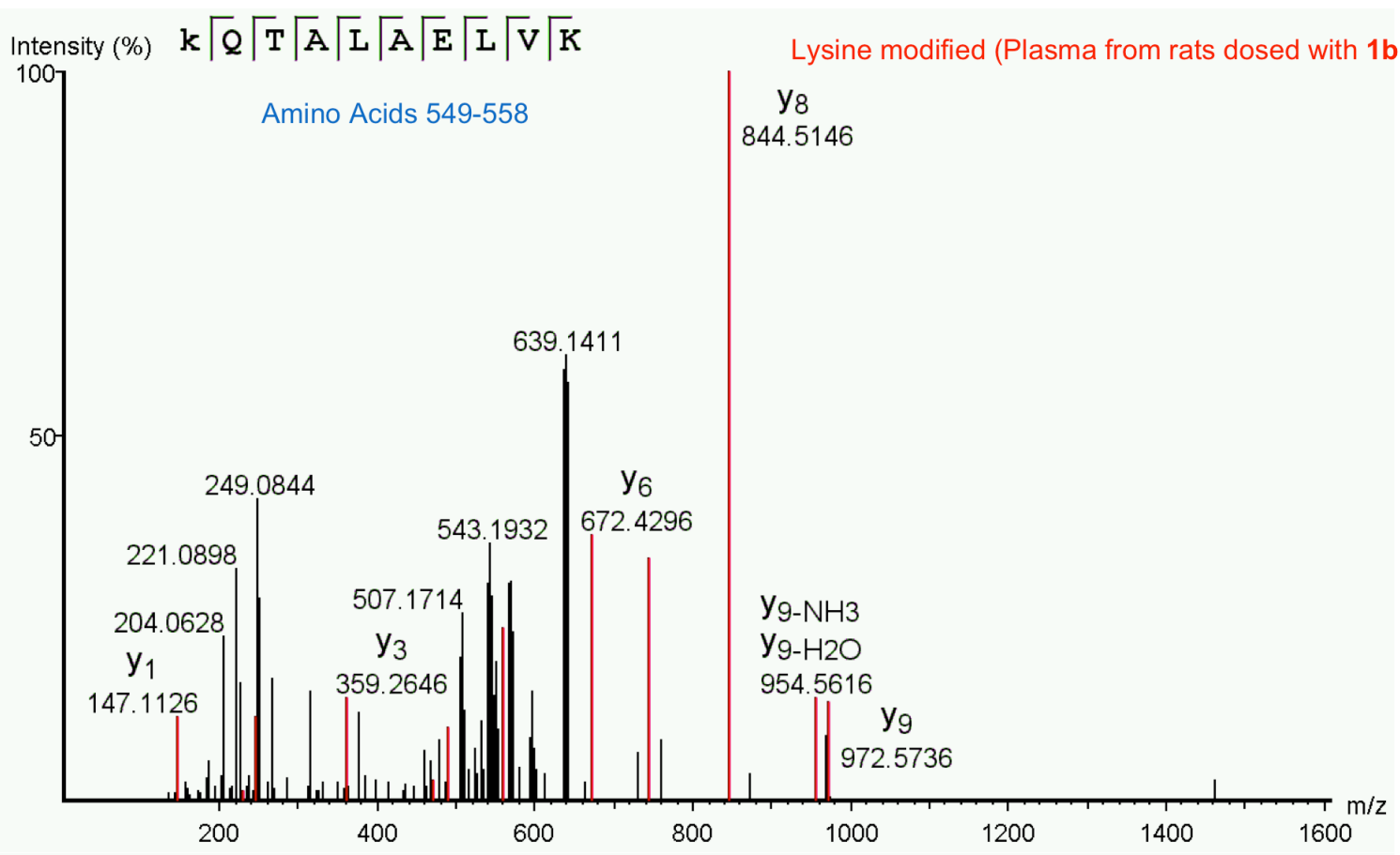

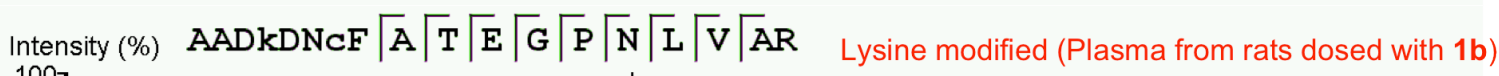

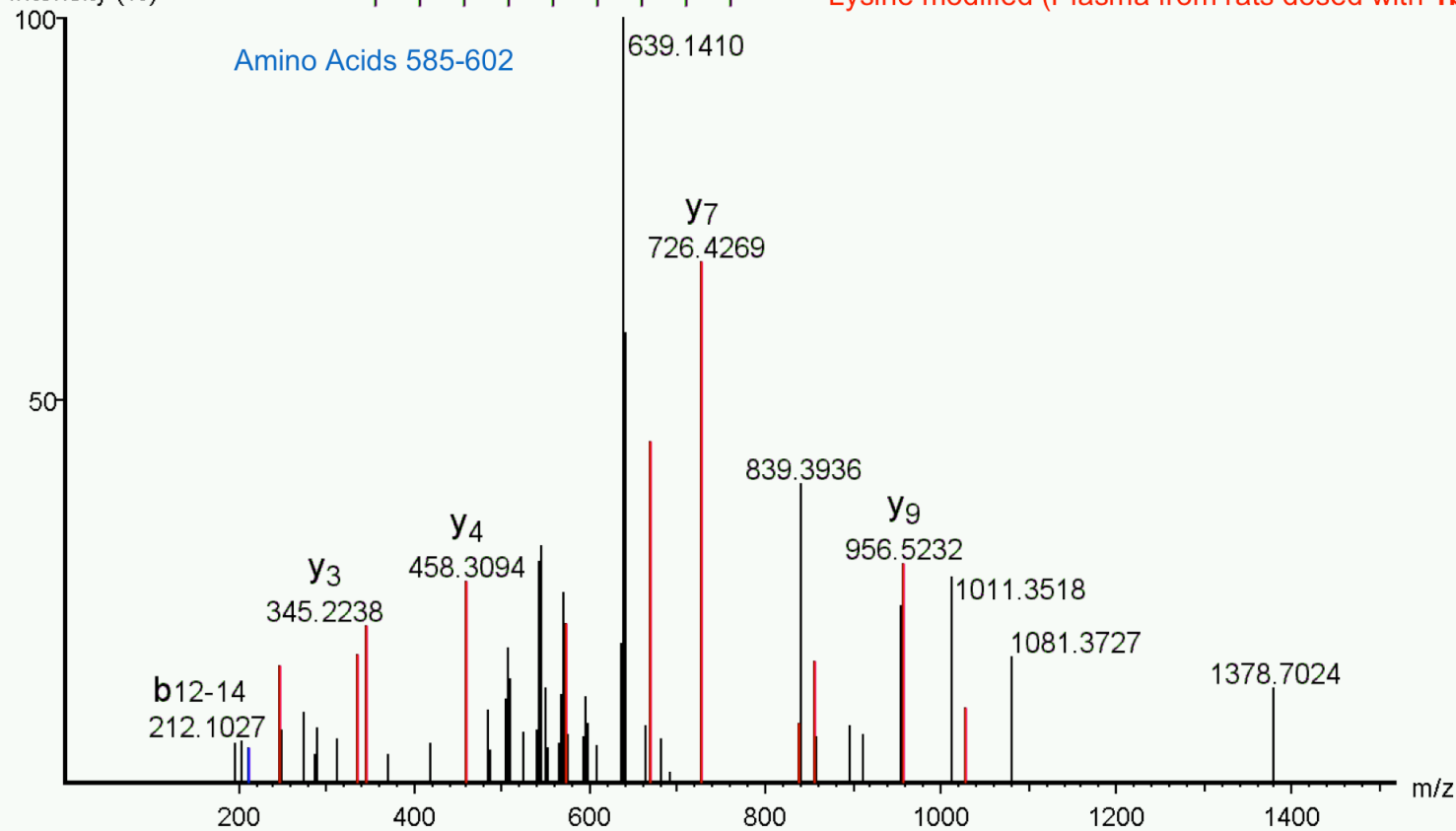




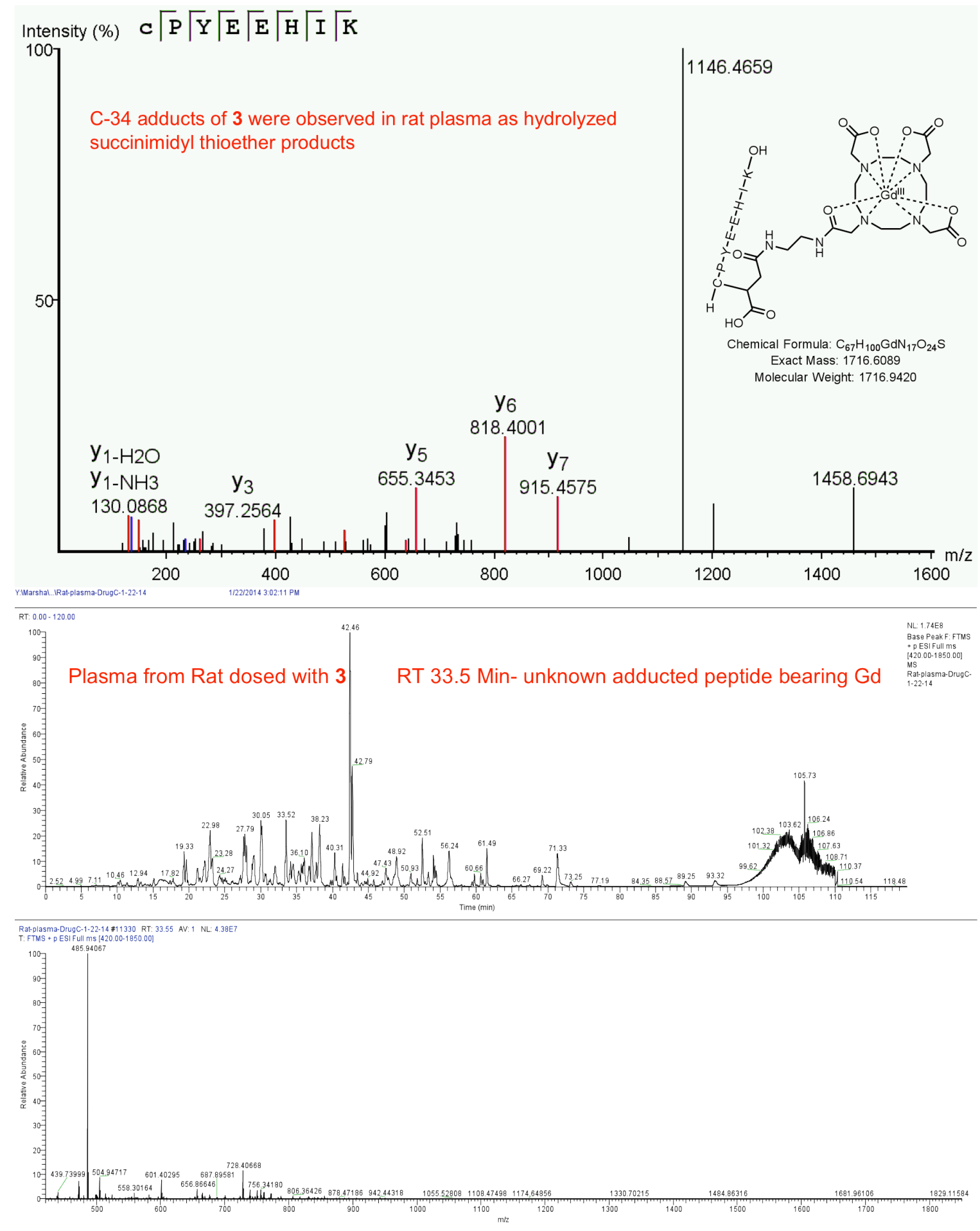




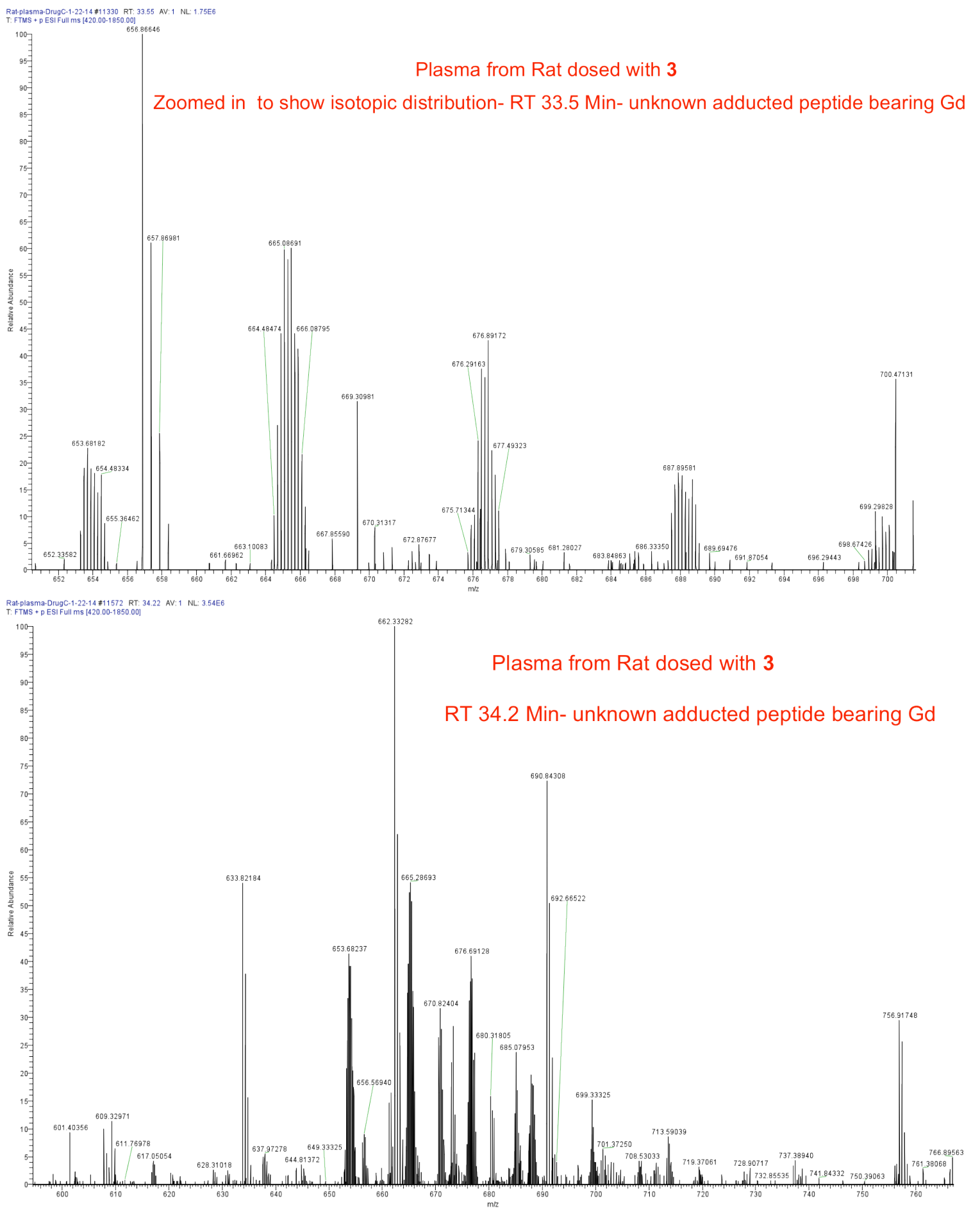



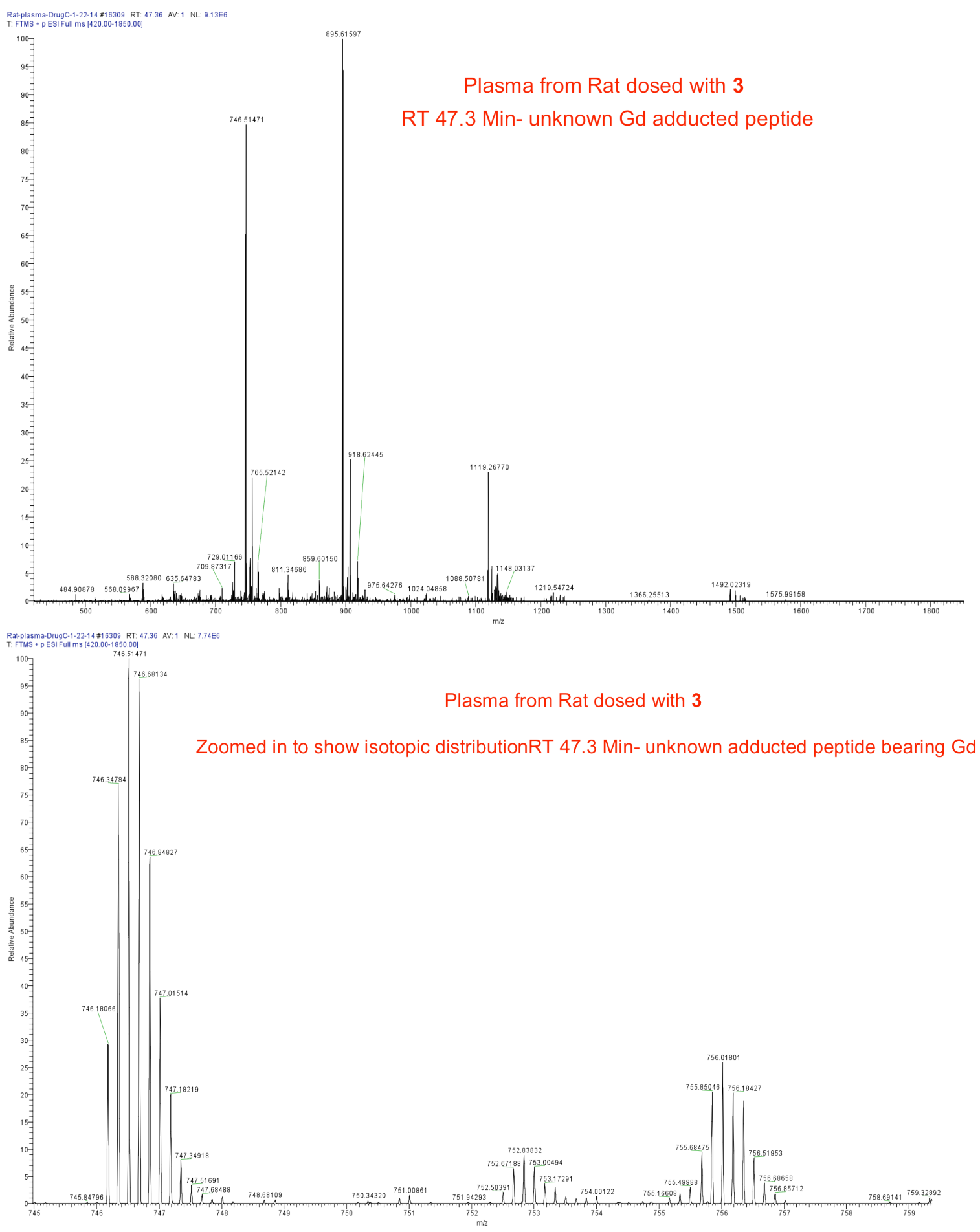

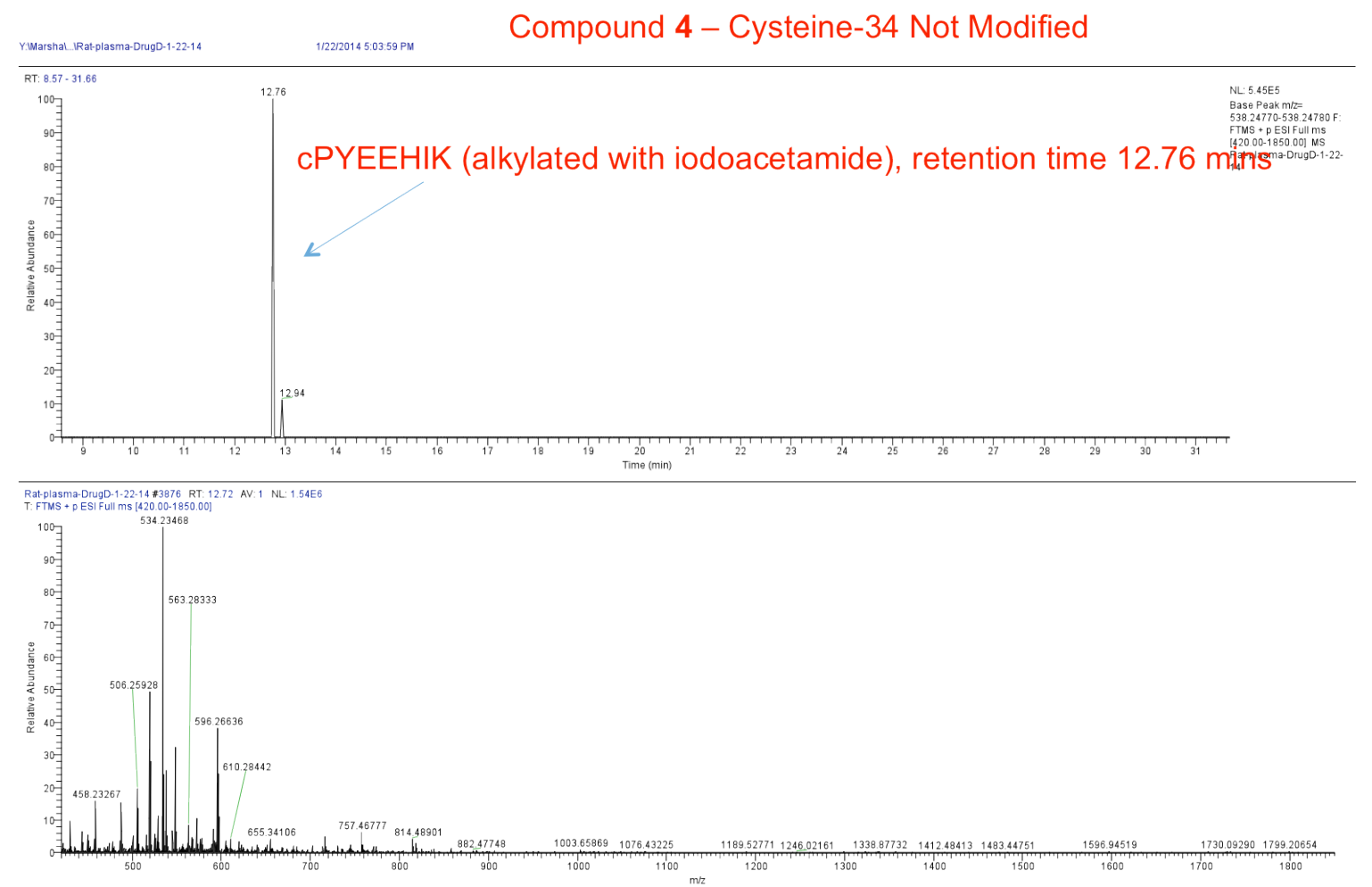